\title{
HSV Recombinant Vectors for Gene Therapy
}

\author{
Roberto Manservigi*, Rafaela Argnani and Peggy Marconi \\ Department of Experimental and Diagnostic Medicine - Section of Microbiology, University of Ferrara, Via Luigi \\ Borsari 46, 44100 Ferrara, Italy
}

\begin{abstract}
The very deep knowledge acquired on the genetics and molecular biology of herpes simplex virus (HSV), has allowed the development of potential replication-competent and replication-defective vectors for several applications in human healthcare. These include delivery and expression of human genes to cells of the nervous systems, selective destruction of cancer cells, prophylaxis against infection with HSV or other infectious diseases, and targeted infection to specific tissues or organs. Replication-defective recombinant vectors are non-toxic gene transfer tools that preserve most of the neurotropic features of wild type HSV-1, particularly the ability to express genes after having established latent infections, and are thus proficient candidates for therapeutic gene transfer settings in neurons. A replication-defective HSV vector for the treatment of pain has recently entered in phase 1 clinical trial. Replication-competent (oncolytic) vectors are becoming a suitable and powerful tool to eradicate brain tumours due to their ability to replicate and spread only within the tumour mass, and have reached phase II/III clinical trials in some cases. The progress in understanding the host immune response induced by the vector is also improving the use of HSV as a vaccine vector against both HSV infection and other pathogens. This review briefly summarizes the obstacle encountered in the delivery of HSV vectors and examines the various strategies developed or proposed to overcome such challenges.
\end{abstract}

Keywords: HSV, viral vectors, oncolytic vectors, gene therapy, neurodegenerative disorders, cancer, targeting, vaccines.

\section{THE HERPES SIMPLEX VIRUS LIFE CYCLE}

Herpes simplex virus (HSV) is an enveloped, doublestranded (ds) DNA virus [1]. The mature virion consists of different components: an external envelope containing about 13 glycoproteins involved in different functions, among which the first steps of binding and entry into the host cell; an amorphous layer known as the tegument, containing some 20 different proteins with structural and regulatory roles; and an icosadeltahedral capsid containing a toroidal dsDNA. The HSV-1 genome consists of $152 \mathrm{~kb}$ of linear, dsDNA arranged as long and short unique segments (UL and Us) flanked by inverted repeated sequences (TRL/IRL and IRs/TRS, respectively) (Fig. 1). The repeated regions of the viral genome contain two immediate-early (IE) genes [infected cell protein (ICP) 4 and ICP0], a late (L) gene (ICP34.5) and the latency associated transcripts (LAT) that are each present in two copies. Thus, the repeated region located between the long and short segments of the genome (the joint repeat region) contains a single copy of each gene. HSV genome encodes approximately 90 genes that can be classified as essential or nonessential based on their requirement for virus replication in tissue culture. Essential genes are required for virus growth such that viral mutants lacking these genes can only establish a lytic infection if the missing genes are supplied in trans by an engineered cell line. Nonessential genes are often required for virus-host cell interactions, such as evasion of the host immune response and host cell shut-off which are important for growth during

*Address correspondence to this author at the Department of Experimental and Diagnostic Medicine - Section of Microbiology, University of Ferrara, Via Luigi Borsari 46, 44100 Ferrara, Italy; Tel: +39 0532 455401; Fax: +39 0532 247618; E-mail: mns@unife.it infection in vivo, but are not needed for growth in tissue culture.

The virus life cycle begins with virus attachment to the host cell mediated by viral glycoproteins (Fig. 2). One mode of HSV-1 entry is by endocytosis [2] that appears to be unique because it is likely not mediated by formation of clathrin-coated pits or caveolae. The other mode of HSV entry is virion fusion at the plasma membrane, which is $\mathrm{pH}$ independent and requires participation from multiple viral glycoproteins $(\mathrm{gB}, \mathrm{gC}, \mathrm{gD}, \mathrm{gH}$, and $\mathrm{gL})$ and cellular receptors. Entry via this mode is initiated by interaction of viral $\mathrm{gC}$ and/or $\mathrm{gB}$ with heparan sulfate (HS), followed by interaction of $\mathrm{gD}$ with one of its three receptors. These receptors include HVEM, a member of tumour necrosis factor receptor family; nectin-1 (CD111), a member of the IgG superfamily; nectin 2, and 3-O-sulfated heparin sulphate or 3-OS HS. Binding of $\mathrm{gD}$ to its receptor is essential for viral penetration, which ultimately results in deposition of viral DNA for replication in the nucleus. It has been recently shown that paired immunoglobulin (Ig) like type 2 receptor $\alpha(\operatorname{PILR} \alpha)$ binds to $\mathrm{gB}$ and functions as an entry receptor during HSV-1 infection in concert with an interaction between $\mathrm{gD}$ and $\mathrm{gD}$ receptors [3]. Entry of HSV into cells involves interactions between the viral receptor-binding protein $\mathrm{gD}$ and the $\mathrm{gD}$ receptors. When $\mathrm{gD}$ binds to its receptors, there are conformational changes in $\mathrm{gD}$ which apparently activate $\mathrm{gB}$ and $\mathrm{gH} / \mathrm{gL}$, so that these glycoproteins promote fusion involving the virion envelope and cellular membranes [4-6]. Other factors that may affect viral entry and/or intracellular signalling include: (1) the capability of $\mathrm{gB}$ to rapidly mobilize lipid rafts $[7,8]$, and (2) the release of plasma membrane $\mathrm{Ca}^{2+}$ stores and the increase in intracellular $\mathrm{Ca}^{2+}$ triggered by the engagement of nectin by $\mathrm{gD}$ and of integrin $\alpha \mathrm{v}$ subunits by $\mathrm{gH}$, respectively. 


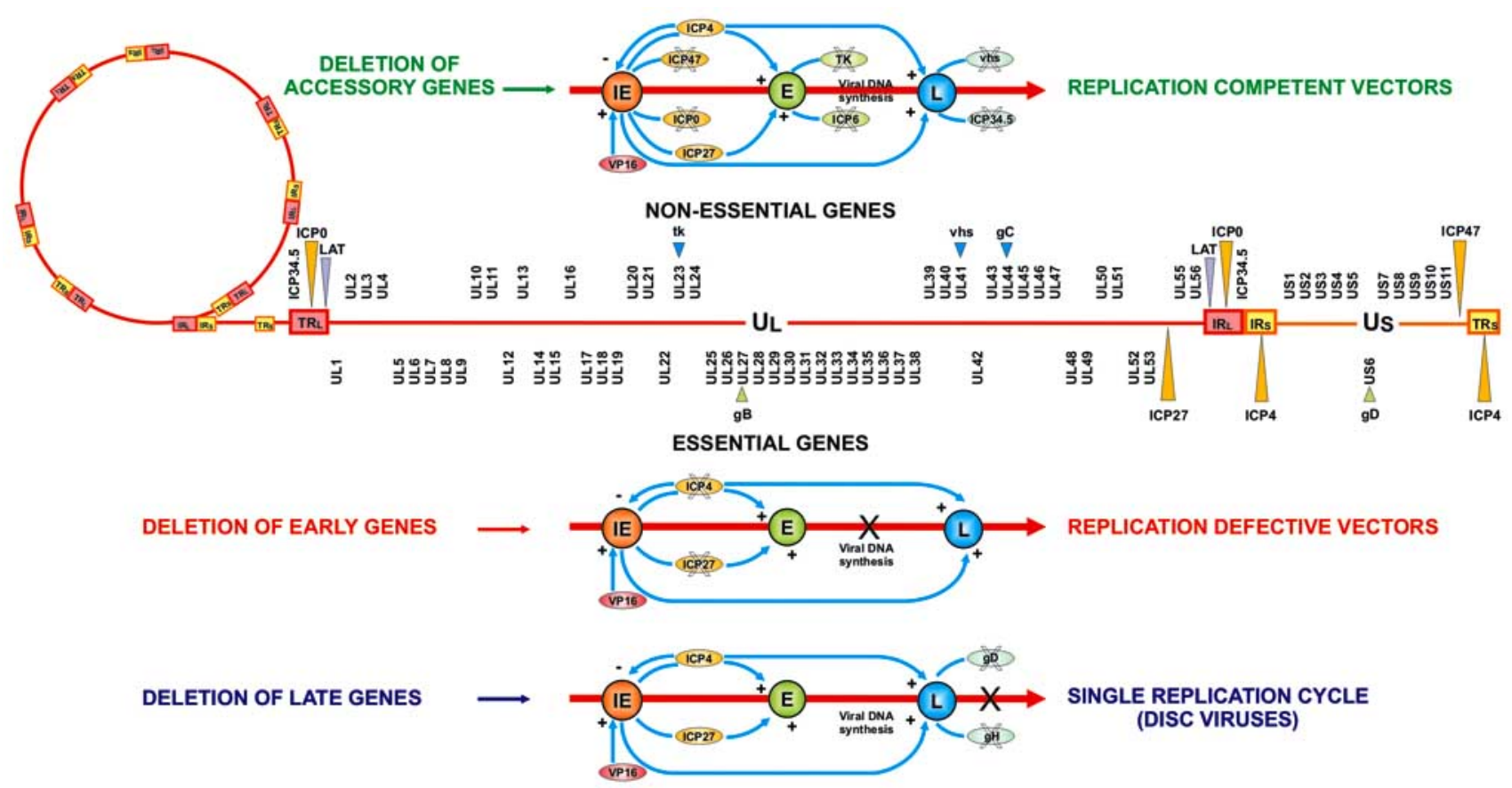

Fig. (1). Map of HSV-1 genome and schematic representation of replication-competent and defective vectors. A schematic representation of the position of the genes encoding proteins involved in virus replication, regulation, in virus formation and assembly, and in virion structural proteins is depicted. Genes that are modified or deleted to achieve viral attenuation are indicated.

After internalization, de-enveloped HSV particles travel to nucleus where the viral genes are expressed in a tightly regulated temporal sequence and consist of immediate early (IE), early (E), and late (L) gene functions. The IE gene products (ICP0, ICP4, ICP22, ICP27, and ICP47) induce expression of $\mathrm{E}$ genes that encode enzymes necessary for viral DNA replication, and $\mathrm{L}$ genes that express structural proteins that are assembled into new viral particles into the nucleus. The envelope is acquired by budding through the nuclear membrane with further processing in the Golgi apparatus. The virus replication cycle leads to rapid cell death and release of new viral particles during cell lysis. HSV-1 is a neurotropic virus. After initial lytic replication in epithelial cells of the primary lesion, the viral progenies enter sensory neurons whose axon terminals innervate the affected area. The nucleocapsid and tegument are transported retrogradely along axons from the site of entry to the neuronal soma, where viral DNA and VP16 enter the nucleus. At this point, the virus may either enter the latent state or initiate lytic replication. During latent infection, the viral genome persists as a stable episomal element, without detectable expression of IE, E or L gene products. Only a set of non-translated RNA species, known as the latencyassociated transcripts (LATs), are synthesized during latency. In a fraction of neurons harbouring latent HSV-1, the virus is periodically reactivated. Cascade expression of the viral IE, E, and $\mathrm{L}$ genes resumes, resulting in the production of mature virions. Infectious virus particles are transported to the peripheral nerve terminals by anterograde axonal transport pathway, released, and infect cells at or near the site of initial infection.

The anterograde and retrograde transport occur via interaction of capsid and/or tegument components and viral glycoproteins with microtubule-dependent molecular motor dynein/dynactin complex and kinesin [9]. The latent state is a characteristic of the equilibrium that is established between HSV infection and peripheral nervous system (PNS), whereas spread to the central nervous system (CNS), either from the PNS following reactivation from latency or as a new infection via the olfactory route [10], can end either in latency or productive replication. This last is one of the causes of rare episodes of devastating encephalitis. To infect the CNS, HSV must deal not only with the unique aspects of neuroanatomy and cell biology, but it also has to evade the compartmentalized immune response within the CNS to achieve viral persistence. This life style led to the evolution of elaborate control mechanisms that coordinately regulate HSV-1 gene expression during latent and productive infection [1].

\section{DESIGN OF HSV VECTORS}

Different aspects of HSV biology render this virus attractive for designing of gene therapy vectors:

- HSV displays a broad host cell range and its cellular receptors, HS, PILR $\alpha$ [3, 11-13], HVEM, and nectin1 and 2, are widely expressed on the cell surface of numerous cell types.

- $\quad \mathrm{HSV}$ is highly infectious.

- Non-dividing cells may be efficiently infected and transduced by HSV.

- Almost half of the about 90 known viral genes are nonessential for growth in tissue culture and then may be deleted to create genomic space for exogenous transgenes and to delete functions essential for viral virulence and toxicity in vivo. Deletion of some 


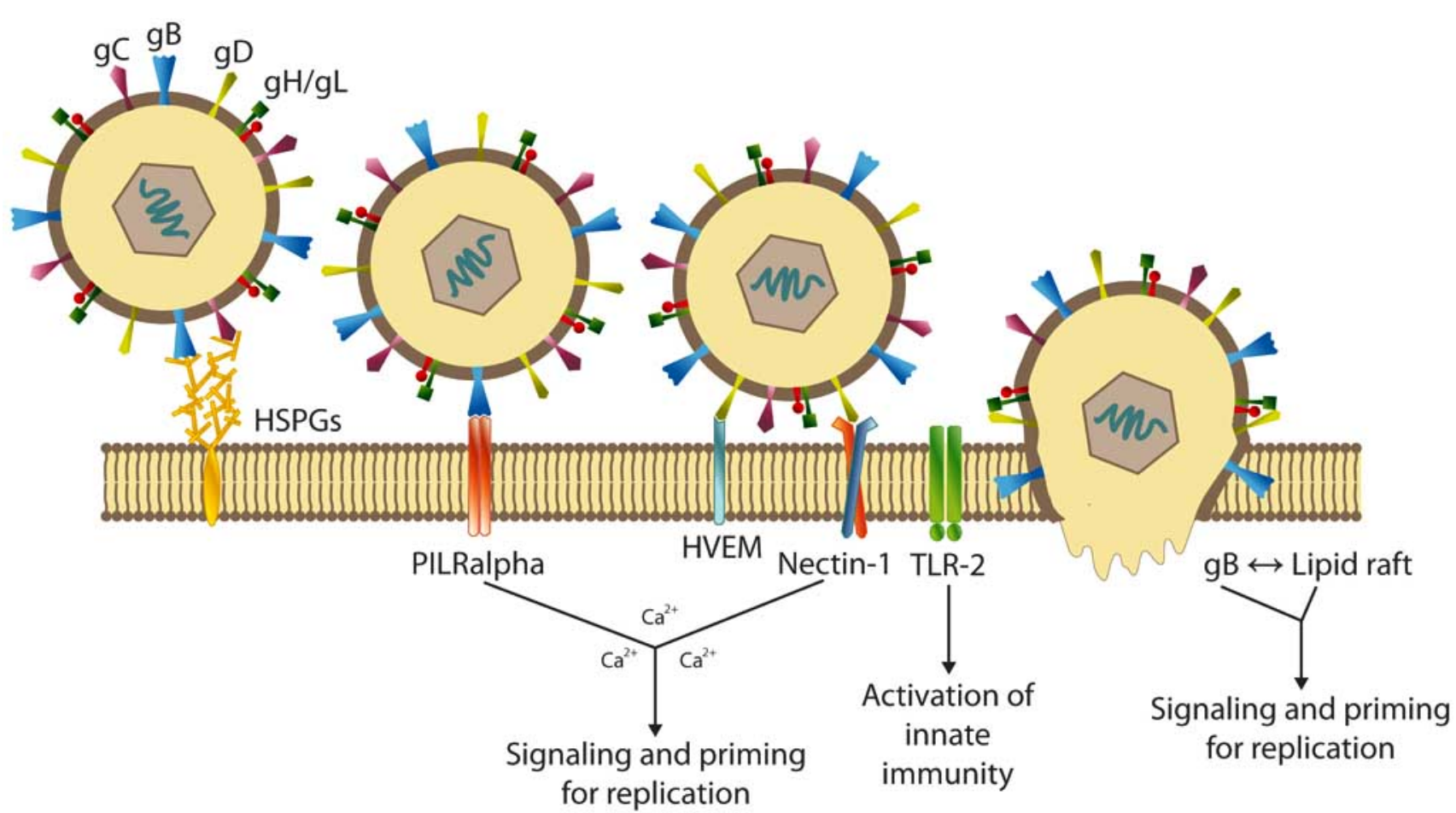

Fig. (2). Mechanism of HSV-1 entry into the host cell. The initial contact of the virus with the cell is the binding to the heparan sulfate (HS) proteoglycans on the cell surface, mediated by $\mathrm{gC}$ and $\mathrm{gB}$, with consequent binding of $\mathrm{gB}$ to the PILRalpha receptor. Subsequently, gD binds to one of its cellular receptors, including HVEM, a member of the TNF-receptor family; nectin-1 or 2, two related members of the immunoglobulin superfamily; or sites generated in HS by the action of specific 3-O sulfotransferases. This last binding triggers the fusion between the cell membrane and the viral envelope, which requires the action of $\mathrm{gB}, \mathrm{gD}$ and $\mathrm{gH}$-gL, with subsequent release of the viral nucleocapsid and tegument into the cytoplasm. Gene therapy strategies aimed to target viral infection to particular cells can be obtained by modifying the first steps of the virus life cycle, that is, adsorption and penetration. The three main glycoproteins involved in these two phases are $\mathrm{gB}, \mathrm{gC}$ and $\mathrm{gD}$ and their ORF backbone has been engineered to redirect infection to the target cell by deleting regions that affect binding to the main HSV receptors and/or inserting ligands that favour interaction with the new receptors. Envelope-HSV glycoproteins may also interact with TLRs on the cell surface, triggering signals that stimulate innate immunity.

nonessential genes (Fig. 1) results in viruses that retain the ability to replicate in vitro, but are compromised in vivo, in a context dependent manner $[14,15]$.

- $\quad$ Recombinant HSV vectors can be easily produced to high titer and purity without wild type (wt) contaminants.

- $\quad$ The latent behaviour of the virus may be exploited for stable long-term expression of therapeutic transgenes in neurons.

- HSV possesses the interesting features to be transported retrogradely in neurons and transferred across synapses and it is possible to take advantage of this virus characteristic to trace neuronal pathways [16].

Three types of HSV-1 vectors are currently in use: amplicons, replication-defective and replication-competent vectors. The amplicons are plasmid-derived vectors engineered to contain both the origin of HSV DNA replication (ori) and HSV cleavage-packaging recognition sequences ( $p a c)$. When amplicons are transfected into mammalian cells with HSV helper functions, they are replicated, form head-to-tail linked concatamers and are then packaged into viral particles. There are two major methods currently used for producing amplicon particles, one based on infection with defective helper HSVs and the other based on transfection of HSV-1 genes, such as a set of pac-deleted overlapping cosmids or a pac-deleted and ICP27-deleted BAC-HSV-1 [17]. The main advantages of these vectors are that they can accommodate large fragments of foreign DNA (theoretically up to $152 \mathrm{~kb}$ ), including multiple copies of the transgene (up to 15), and are non-toxic.

Replication-defective vectors are made of mutant viruses with deletions in one or more genes essential for the lytic cycle, whereas replication-competent vectors are composed of attenuated viruses where genes that are not essential for replication in cultured cells in vitro are either mutated or deleted (Fig. 1) [14, 15].

This review focuses on replication-defective and replication-competent $\mathrm{HSV}$-based vectors.

Several genes involved in HSV replication, virulence and immune evasion, non-essential for viral life cycle in vivo, have been identified. These genes are usually involved in multiple interactions with cellular proteins, which optimize the ability of the virus to grow within cells. Understanding such interactions has permitted the deletion/modification of these genes, alone or in combination, to create HSV mutants 
with a reduced ability to replicate in normal quiescent cells, but that can replicate in tumour or dividing cells. These attenuated viruses harbour further modifications so they also serve as therapeutic gene delivery vehicles $[14,18]$.

Which gene should be deleted in a live attenuated HSV vector? Many HSV-1 genes that are non-essential in culture alter virulence in animal models. Fewer HSV-2 genes have been studied, and there are almost certainly type-specific effects. Among these genes, the ones encoding thymidine kinase (TK), ribonucleotide reductase (RR), the virion-host shut off (vhs) and the ICP34.5 proteins have been extensively studied [1]. TK is involved in optimizing nucleic acid metabolism for virus growth and is necessary for efficient replication in neurons. RR is necessary for the conversion of rNTPs to dNTPs in neurons, which are otherwise lacking but necessary for the synthesis of new viral DNA during virus replication. The vhs function of HSV causes rapid destabilization of host RNAs and translational arrest. Vhs also destabilizes viral messages, resulting in regulation of immediate-early and early genes during lytic infection. The ICP34.5 neurovirulence factor has been found to be essential for HSV pathogenicity. It appears to provide multiple functions to the virus life cycle, one of which is to block the arrest in translation, which usually occurs in virusinfected cells as an antiviral response preventing virus replication. This effect is mediated through the cellular PKR kinase, which phosphorylates the translation initiation factor eIF2 $\alpha$, thereby stopping translation. ICP34.5 recruits protein phosphatase $1 \alpha$, to dephosphorylate eIF $2 \alpha$, allowing protein translation and continued virus replication. Tumour cells often display an impaired PKR pathway and/or elevated levels of eIF2 $\alpha$, that allow replication of ICP34.5-deleted viruses. Secondly, ICP34.5 takes part in blocking the stress response of endoplasmic reticulum (ER) via phosphorilation of ER resident kinase PERK [19]. In addition, ICP34.5 seems to be involved in the egress of the virus hence influencing the replication efficiency [20]. Moreover, it has been recently demonstrated that ICP 34.5 is involved in the inhibition of autophagy, another defence mechanism of infected cells, through the inhibition of Beclin 1, a critical factor involved in this pathway [21].

When constructing a recombinant virus for use as an attenuated vaccine or vector, it is possible to over-attenuate the virus, which could possibly negate its value. To minimize this possibility, a gradation of additional deletions has to be introduced and evaluated for eventual overattenuation.

HSV vectors have been tested as gene therapy vectors to deliver transgenes to the nervous system, as live viral vaccines, and as oncolytic viruses.

\section{HSV-BASED VECTORS FOR GENE THERAPY OF THE NERVOUS SYSTEM}

HSV-1 is a neurotropic virus that displays several important adaptations to the nervous system, and each of them can be rationally exploited in the design of gene therapy vectors with regard to neurological applications [22, 23]. HSV-1 contains genes that control neuroinvasiveness and neurovirulence; this virus can move both in the retrograde and anterograde directions and disseminates transynaptically from neuron to neuron [9]. The ability to be retrogradely transported can be useful in studying the physiopathology of motor and sensory neurons, because vectors can be introduced into muscle or into the skin, and produce expression of transgenes in the cell bodies of ventral-horn or sensory-ganglion neurons [24]. The virus envelope contains several glycoproteins that mediate entry to neurons due to the recognition of specific receptors (nectins) [25]. In many sensory neurons, HSV-1 can establish a latent infection, a situation in which the viral genome persists as a stable chromatinized episomal element and in which all lytic genes are silenced [26, 27].

Many studies indicate that most of these neurotropic features are retained in defective and attenuated HSV-1 vectors, including the abilities to be efficiently transported along axons in both directions, and to establish latent infections with prolonged gene expression, both in sensitive and in motor neurons.

The main replication-defective vectors used so far for experimental gene therapy of neurological disorders in central and peripheral nervous system are reported in Table 1.

\section{Replication-Defective Vectors}

Different types of defective recombinant vectors have been developed. The problems related to HSV-1 vector design fall into the following general categories: (1) elimination of the lytic viral gene expression and of the innate and immune responses (toxicity); (2) engineering of promoter systems to achieve appropriate, lasting transgene expression; (3) identification of strategies to target heterologous gene expression to specific neurons; and (4) simultaneous expression of multiple genes. In recent years, novel technologies have allowed researchers to get deeper into these problems. To date, several replication-defective vectors have been constructed in which the IE genes, expressing ICP $0,4,22,27$, and 47 , have been deleted in various combinations [28-30]. Non-replicative HSV vectors have been tested in many different gene therapy animal models of various neuropathies [31-33], such as epilepsy and multiple sclerosis (MS) [34, 35], Alzheimer's disease (AD) [36], Parkinson's disease [37], chronic pain [38-40] or lysosomal storage disorders with neurological involvement $[41,42]$.

\section{Epilepsy}

The concept is if it is possible to repair damage by providing appropriate cues to the endogenous neural staminal cells (NSCs) and progenitors; cues that are not available or insufficient in the injured tissue. The therapeutic applicability of this system was proved in a model of neuronal loss, the hippocampal sclerosis induced by prolonged generalized seizures. In this model, an epileptogenic insult (the episode of prolonged seizures) causes a damage pattern in the hippocampus that closely mimics the one observed in many patients affected by the most common adult epileptic syndrome [43]. In time, animals begin to display spontaneously recurrent seizures, i.e. they become truly epileptic, again reproducing the situation observed in patients $[44,45]$. Paradiso and coworkers demonstrated that recombinant HSV-1-based vectors expressing a combination of two NTFs, fibroblast 
growth factor-2 (FGF-2) and brain-derived neurotrophic factor (BDNF), increased survival and proliferation of freshly isolated neural progenitors and favoured their differentiation into neurons in vitro. These vectors were tested in vivo, in the pilocarpine model of status epilepticusinduced neurodegeneration and epileptogenesis. When injected in the hippocampus 3 days after status epilepticus, FGF-2/BDNF expressing vectors partially repaired neuronal damage and prevented the occurrence of spontaneous seizures. Thus, viral vector-mediated supplementation of FGF-2 and BDNF promotes neurogenesis and repair of an existing neuronal damage and these effects are diseasemodifying in epilepsies associated with hippocampal sclerosis, demonstrating the feasibility of use of HSV vectors expressing NTFs to provide recovery from damage and to prevent the development of epilepsy [35].

\section{Multiple Sclerosis}

One of the most important human demyelinating diseases of unknown aetiology is multiple sclerosis (MS), an autoimmune-mediated inflammatory disease of the CNS with inflammatory infiltrates containing auto-reactive $\mathrm{T}$ cells and a multitude of pathogenic nonspecific lymphocytes that might benefit from anti-inflammatory therapies [46, 47]. Furlan and colleagues have used viral vectors expressing immune-modulators to treat experimental autoimmune encephalomyelitis (EAE), which is a mouse model for MS, showing the therapeutic efficacy of non-replicating HSV-1derived vectors expressing anti-inflammatory genes, such as cytokine interleukin-4 (IL-4) [48] or cytokine interleukin-1 receptor antagonist (IL-1ra) [34, 49]. They have demonstrated that, after disease onset, CNS administration of HSV-1 defective recombinant vectors expressing IL-4 or IL1ra genes into Biozzi $\mathrm{AB} / \mathrm{H}$ mice stopped the progression of relapsing-remitting form of EAE. The treated mice showed a shorter duration of the first EAE attack, a longer interrelapse period, and a reduction in the severity and duration of the relapse. The results obtained by this group have revealed an in situ modulation of the cytokine/chemokine circuits, demonstrating that the local administration of antiinflammatory cytokines by viral vectors can be effective in the preventive treatment of chronic EAE [34].

\section{Alzheimer Disease}

Accumulation of insoluble aggregates of amyloid- $\beta$ peptide $(A \beta)$, a cleavage product of amyloid precursor protein (APP), is thought to be central to the pathogenesis of Alzheimer's disease (AD). Consequently, down-regulation of APP, or enhanced clearance of $\mathrm{A} \beta$, represent possible therapeutic strategies for AD. Hong CS and colleagues [36] have generated replication-defective HSV vectors that inhibit $\mathrm{A} \beta$ accumulation, both in vitro and in vivo. In cell culture, HSV vectors expressing either (i) short hairpin RNA (siRNA) directed to the APP transcript (HSV-APP/shRNA), or (ii) neprilysin, an endopeptidase that degrades A $\beta$ (HSVneprilysin), substantially inhibited accumulation of $A \beta$. To determine whether these vectors showed similar activity in vivo, it was developed a novel mouse model, in which overexpression of a mutant form of APP in the hippocampus, using a lentiviral vector (LV-APPSw), resulted in rapid $A \beta$ accumulation. Co-inoculation of LV-APPSw with each of the HSV vectors showed that either HSV-APP/shRNA or
HSV-neprilysin inhibited $A \beta$ accumulation in this model, whereas an HSV control vector did not. These studies demonstrate the utility of HSV vectors for reducing A $\beta$ accumulation in the brain, thus providing useful tools to clarify the role of $\mathrm{A} \beta$ in $\mathrm{AD}$ that may facilitate the development of novel therapies for this important disease.

\section{Focal Diseases}

Some brain diseases that are amenable to gene therapy are localized to particular region of the brain; example of these type of disorders include Parkinson's disease. Using a replication-defective HSV vector expressing either glial cell derived neurotrophic factor (GDNF) or the antiapoptotic peptide bcl-2, it has been shown that direct inoculation of the HSV vector into the substantia nigra can be used to protect rodents from 6-hydroxidopamine-induced degeneration of dopaminergic neurons [50, 51]. Using latency associated promoter (LAP2) to drive GDNF expression in the replication-defective vector prolonged biologically active transgene expression, over the course of many months, has been obtained [52]. In another study, it has been investigated the neuroprotective effect of erythropoietin (EPO) in a rodent model of Parkinson disease [37]. The effects of vector-produced EPO were similar in magnitude to the effects of vector-mediated GDNF in the same model. These results demonstrate that vector-mediated EPO production may be used to reverse dopaminergic neurodegeneration in the face of continued toxic insult.

\section{Diabetes}

Neuropathy is a common, untreatable complication of both type 1 and type 2 diabetes. In animal models peptide neurotrophic factors can be used to protect against the development of neuropathy, but the combination of short half-life and off-target effects of these potent pleiotropic peptides has limited translation to human therapy. Nerve growth factor (NGF) is probably the most extensively studied trophic factor in diabetic neuropathy. NGF levels are reduced in diabetic nerve, and though NGF receptor expression is normal in streptozotocin (STZ)-induced diabetic nerve there is a marked decrease in receptor saturation and concomitant reduced retrograde axonal transport of NGF. Other trophic factors that have been shown to have a protective effect in diabetic neuropathy models in rodent include: brain derived neurotrophic factor (BDNF), neurotrophin 3 (NT-3); ciliary neurotrophic factor (CNF), vascular endothelial growth factor (VEGF), IL-6, glial cell derived neurotrophic factor (GDNF), fibroblast growth factor (FGF) and erythropoietin. A detailed review on the therapeutic effects of the above receptor factors has been published [53]. Results suggesting a protective effect of NGF in patients with diabetic neuropathy were obtained in a phase 2 human trial but the following phase 3 prospective randomized control trial of efficacy NGF was found to be ineffective in preventing the progression of neuropathy [54]. Number of potential pitfalls can be identified that may have contributed to the failure of NGF treatment in this trial. The most obvious is the dose-related effect and that the treatment needs to be effective for a prolonged period of time.

Gene transfer is a promising strategy that might circumvent these limitations [55]. Replication-defective HSV vectors have been tested in several different models of 
neuropathy leading up to studies in diabetes [56-61]. In an experimental model of type 1 diabetes in STZ mice, subcutaneous inoculation of replication-defective HSV expressing VEGF was able to prevent the reduction in foot sensory nerve amplitude characteristic of diabetes [58]. Moreover, in a model of diabetic cystopathy, HSV vectormediated NGF gene therapy has been proved useful to restore decreased NGF expression in the bladder and bladder afferent pathways, thereby improving hypoactive bladder function in diabetes [62]. In a further study aimed to determine whether an HSV latency promoter can prolong expression of neurotrophin 3 (NT-3), it has been shown that the continuous production of NT-3 by Lap2-driven longterm expression of the transgene from an HSV vector protects against progression of diabetic neuropathy in mice [31].

\section{Chronic Pain}

Over the past several years, studies of the mechanisms that are involved in the development of chronic pain have created novel information that can lead to identify multiple points of intervention to treat this pathological condition. On the basis of this knowledge, HSV-based gene therapy approaches have been developed to locally express products that block pain transmission or reverse the chronic pain state [40, 63-66]. Preclinical studies on pain animal models have demonstrated in vivo the capacity of these vectors to effectively transfer genes into the dorsal root ganglia (DRG) neurons following direct pancreatic inoculation or subcutaneous inoculation to efficiently express and release inhibitory neurotransmitters or anti-inflammatory peptides that can be used to modulate pain-related behaviours and provide a therapeutic effect in models of poly-neuropathy and chronic regional pain $[40,67,68]$. Opioid receptors are found presynaptically on the terminals of primary nociceptive afferents in the spinal cord, and post synaptically on second-order neurons in the dorsal horn. Activation of receptors, naturally by endogenous ligands enkephalin or endomorphin, or therapeutically by opiate drugs such as morphine, inhibits pain-related neurotransmission at the spinal level. The first vectors to be used in models of pain were deleted for accessory viral functions (e.g. thymidine kinase, $t k$ ). Recombinant HSV defective in $t k$ can be propagated in culture and will replicate in skin, but are unable to replicate in the DRG and are thus forced into a pseudo-latent state. The efficacy of HSV-mediated gene transfer of enkephalin has been tested in several different models of pain in rodents [69, 70]. Expression of enkephalin from TK-negative vectors did not only reduce pain-related behaviours, but also prevented cartilagine and bone distruction in the inflamed joint. Similar effect were subsequentely demonstrated using a nonreplicating HSV vector deleted for both copies of the essential HSV IE gene ICP4 [71]. The observations regarding reinoculation of the vector, which have been repeated in several different model of pain and with different transgene products, indicate the absence of any significant immune response to vector inoculation in rodent. Studies of the enkephalin-expressing HSV vectors have been extended to primates [72] and provide proof-of-principle evidence that HSV vectormediated delivery of enkephalin can provide an analgesic effect and set the stage for a human trial to treat chronic pain using HSV vector-expressing enkephalin. The clinical-grade replication-defective ICP4 and ICP27 deleted vector engineered to express preproenkephalin was termed NP2. This vector entered in phase 1 clinical trial, enrolling patients with cancer-associated pain, and based on the predefined parameters of the toxicology study was well tolerated with no significant toxicity [39].

Animal pancreatitis models have been used to test innovative preclinical, site-specific gene therapeutic interventions $[65,66]$. The efficacy of pre- and posttreatment with a replication-defective HSV-1 vector construct encoding human preproenkephalin gene (HSVEnk) to bring overexpressed opioids directly to pancreatic tissue was tested. Reduced pain-related behaviours, inflammatory and cellular activation responses in rats with acute and chronic pancreatitis were demonstrated after direct injection of the viral vector into the pancreas by laparatomy. As an important safety issue, in this experimental model there was no evidence of spread of HSV-1 centrally or peripherally other than into the appropriate level DRG. HSV-1 vectors that express glutamic acid decarboxylase (GAD) have been shown to be more effective than the opioid peptide in neuropathic pain $[67,68]$. Defective HSV-1derived vectors expressing anti-inflammatory cytokines, such as IL-4 or IL-10 $[39,73]$, have been deeply studied to examine the involvement of cytokines in the development of inflammatory pain. Mata and colleagues have demonstrated, in a rat model of inflammatory pain, that expression of IL-10 by a HSV-1 vector in DRG prevents activation of p38 mitogen-activated protein kynase (p38 MAPK) and expression of full-length membrane-spanning tumour necrosis factor- $\alpha(\mathrm{mTNF} \alpha)$ in dorsal horn and spinal cord, suggesting the involvement of TNF $\alpha$ in the development of inflammatory and neuropathic pain $[55,74]$. Plans for an efficacy trial with an opioid producing vector in inflammatory pain and with a GAD producing vector in diabetic neurophatic pain are outlined.

Recently, it has been shown silencing in DRG neurons in vivo by vector-mediated delivery of small interfering RNA (shRNA). This study support the utility of HSV vectors for gene silencing in peripheral neurons and the potential application of this technology to the study of nociceptive processes and in pain gene target validation studies [64].

\section{Lysosomal Storage Diseases}

The lysosomal storage diseases (LSDs) are caused by genetic defects in lysosomal enzymes that result in the accumulation of substrates in the lysosomes. Over 50 LSDs exist and the group of disease has a collective occurrence of about one in 7,000 [75]. Therapy of lysosomal storage disorders with neurological involvement, such as Tay-Sachs (TS) disease, requires active hexosaminidase (Hex) A production in the CNS and an efficient therapeutic approach that can act faster than human disease progression. Several therapeutic approaches have been developed that allow to restore the enzymatic activity in many key tissues (kidney, liver, spleen, etc.). However, the reduction of the GM2 ganglioside deposits in the CNS is difficult to achieve since CNS represents a privileged environment, separated from the blood system by the blood-brain barrier (BBB) that is an obstacle to therapy. Martino S. and colleagues [42] combined the efficacy of a non-replicating HSV-1 vector 
encoding for the Hex A alpha-subunit (HSV-T0alphaHex) and the anatomic structure of the brain internal capsule to distribute the missing enzyme optimally. With this gene transfer strategy, for the first time, it was possible to reestablish the Hex A activity and totally remove the GM2 ganglioside storage in both injected and controlateral hemispheres, in the cerebellum and spinal cord of TS animal model in the span of one month's treatment. In this study, no adverse effects were observed due to the viral vector, injection site or gene expression and it has been hypothesized that the same approach could be applied to similar diseases involving an enzyme defect [42].

\section{Replication-Competent or -Attenuated Vectors}

Replication-competent HSV vectors have been used mainly as oncolytic therapeutic agents. However, some studies have been conducted on CNS disorders, such as lysosomal disorder, multiple sclerosis or acute injury.

\section{Lysosomal Disorder}

Berges B.K. and colleagues [41] have used HSV1716 attenuated vector, an ICP34.5 null mutant, to treat Mucopolysaccharidosis (MPS) VII. MPS VII is caused by a gene deficiency in the lysosomal enzyme $\beta$-glucoronidase (GUSB) with consequent accumulation of glycosaminoglycans (GAGs) affecting a number of organ systems. The investigators have demonstrated the capacity of HSV1716 virus expressing GUSB driven by the latency-associated transcript promoter (HSV-1716-LAT-GUSB virus) to correct the lysosomal storage in the adult MPS VII mouse model following intracranial injection. The authors have shown that this neuroattenuated vector was able to establish latency and to express GUSB at a distance from the site of injection and the correction of the lysosomal storage was demonstrated in several brain regions. This result was the consequence of the ability of neuroattenuated vectors to traverse at least one neuronal synapse and achieve gene expression in a secondary neuron followed by the secretory properties of GUSB that can cross-correct a larger brain area.

\section{Multiple Sclerosis}

Two neuroattenuated, ICP4-negative HSV vectors expressing IL-4 or IL-10 have been used as gene therapy approach in the EAE animal model for human MS [76]. The results of this study demonstrate that local expression of IL-4 from a replication-competent HSV vector precludes sign of EAE, whereas local expression of IL-10 did not have the disease-abolishing effect as did the expression of IL-4, although IL-10 has been shown to be connected to the recovery phase of disease development of EAE. These results confirm the different roles of different Th2-type cytokines expressed during the recovery phase of EAE.

\section{Ischemic Brain Injury}

The development of therapeutic strategies to attenuate the neurological symptoms of acute injury is the subject of major research interest. However, effective treatments remain elusive, due at least in part, to the complex cell-tocell interactions that regulate neuron cell life/death decisions. Therefore, multiple-target strategies to rescue neurons, including those that surround the treated ones, are particularly desirable. At this regard, it has been recently reported that neurons surviving apoptosis through expression of HSV-2 ICP10PK gene (containing a deletion in the protein kinase -PK- domain of the ICP10 gene), delivered by the replication attenuated vector $\Delta R R$, release increased levels of VEGF and FKN that protect uninfected neurons from apoptosis both through neuron-neuron and bidirectional neuron-microglia communications [77]. The latter involves increased release of IL-10 and decreased release of TNF- $\alpha$ by the FKN-treated microglia. Further to these considerations, it has been suggested that $\Delta \mathrm{RR}$ delivered ICP10PK is a multiple-targeted strategy to rescue neurons. It has the distinct advantage that in addition to protecting the infected neurons, it modulates them to release neuroprotective soluble factors in a balanced proportion such as to create a self-propagating cycle of neuronal inputs and release of chemical mediators that inhibit the progression of acute and chronic neurodegeneration through protection of uninfected neurons.

\section{Concluding Remarks}

As described above, a number of different HSV-1 vectors for specific gene therapy applications in CNS and PNS have been developed so far and have been studied using different routes of inoculation to efficiently deliver genes into the CNS and PNS in both small (mice) and large (non-human primates) animals, specially for neurodegenerative diseases that involve large areas of the CNS [78, 79]. Recent advances and current applications of existing vectors are still focused in improving the properties of these vectors, in particular in modulating the intensity and time-course of transgene expression $[52,80]$. Long-term gene expression is still difficult to achieve, although some success has been obtained in the PNS with the HSV-1 latency-active promoter 2 (LAP2) [31, 52]. Other recent studies have focused in improving target expression to specific neuronal populations [81] and, since there is considerably neuronal heterogeneity in both the PNS and CNS, it would be naive to presume that the behaviour of viral vectors will be the same for all neuronal populations in different regions of the nervous system. Because of this intrinsic complexity, it is more feasible that neural targeting may be achieved through the use of specific promoters to drive expression of the therapeutic gene, such as promoters of genes encoding neuropeptides or enzymes involved in the synthesis of neurotransmitters, which are attractive candidates for cell targeting because many types of neurons are defined by their neurotransmitters $[82,83]$.

Neuron proliferation or regeneration would be important in the treatment of diseases associated to neurodegeneration (epilepsy, stroke, ischemic injury, spinal cord injury) [35, 84]. Alterations in NTF expression patterns in different physiopathological situations, as well as effects of NTF in the adult brain (e.g. axonal sprouting induction and neuroprotection), suggest their involvement in neuronal plasticity [85]. Previous observations demonstrate that synergies occur between NTFs and that it is possible to manipulate neural stem cells (NSC) and to obtain neural progenitor proliferation, differentiation, and migration, by using appropriate NTF combinations [86, 87]. The HSV-1 genome has the advantage of allowing the insertion of large amounts of exogenous DNA, such as multiple distinct transgene expression cassettes, therefore allowing to test 
Table 1. Experimental Gene Therapy of Neurological Disorders Using HSV Vectors

\begin{tabular}{|c|c|c|c|}
\hline Pathological Disturbances/Clinical Indications & Therapeutic Transgenes & Stage & Ref. \\
\hline \multicolumn{4}{|l|}{ Replication-Defective Vectors } \\
\hline Epilepsy & FGF-2, BDNF & Preclinical & [35] \\
\hline Multiple sclerosis & IL-4, IL-1 ra & Preclinical & {$[34,48,49]$} \\
\hline Alzheimer's disease & shRNA, neprilysin & Preclinical & [36] \\
\hline Parkinson's disease & $\begin{array}{c}\text { GDNF } \\
\text { bcl-2 } \\
\text { Erithropoietin }\end{array}$ & Preclinical & $\begin{array}{c}{[51,52]} \\
{[50,51]} \\
{[37]}\end{array}$ \\
\hline Diabetes & Neurotrophic factors & Preclinical & {$[56-60]$} \\
\hline Chronic pain & Preproenkephalin & Phase I & {$[38,39,88]$} \\
\hline Lysosomal storage diseases: Tay-Sachs & HexA $\alpha$ subunit & Preclinical & [42] \\
\hline \multicolumn{4}{|l|}{ Replication-Competent Vectors } \\
\hline Lysosomal disorders: MPS VII & $\beta$-glucoronidase & Preclinical & [41] \\
\hline Multiple sclerosis & IL-4, IL-10 & Preclinical & {$[76]$} \\
\hline Ischemic brain injury & HSV-2 ICP0PK & Preclinical & {$[77]$} \\
\hline Chronic pain & Preproenkephalin & Preclinical & {$[69,70]$} \\
\hline
\end{tabular}

whether treatment with multiple NTFs can significantly increase neuronal survival in comparison with the delivery of single factors.

\section{HSV-BASED VECTORS FOR VACCINATION}

Many of the HSV based vectors have been used in gene therapy studies and some of them as experimental vaccines against HSV-1 infection [89-91]. However, studies related to the evaluation of the potential of these vectors, as foreign gene or protein delivery systems for immunological studies are very limited. The use of HSV vectors requires the development of mutated viruses that are genetically stable, incapable of replicating in the CNS and of spreading in immunocompromised individuals, not transmissible from immunized individual by contacts and, at the same time, capable of inducing protective immunity against the disease. The main HSV vectors used for vaccination are summarized in Table 2.

Recent major breakthroughs in the field of HSV-1 technology authorize and support the use of HSV-1 as vaccine vectors for the delivery of foreign antigens [91-95]. In particular, HSV vectors show several advantages for prophylaxis against viral infections. They have been shown: i) to elicit strong and durable immune responses by various routes of inoculation [96,97]; ii) the viral DNA persists inside the host's cell nucleus as an episomal element, thus eliminating the safety concerns deriving from the random integration of the viral genome into the host's DNA; iii) they carry the $t k$ gene, encoding the viral thymidine kinase, that, in case of undesired effects, can be used, in combination with specific antiviral drugs, to kill the virus-harbouring cells.

The efficacy of all of these vectors might potentially be affected by the pre-existing immunity to viral antigens in host. The effect of pre-existing immunity on HSV-1 vectors remains controversial, with some studies showing strong immune response in the face of anti-HSV-1 immunity [97, 98] while another study showed a reduction in the immune response to a transgene, with the intensity of the reduction depending on the route of inoculation.

Moreover, HSV encodes multiple proteins that allow the virus to inhibit an effective host immune response. To this purpose, to obtain an effective immunity it would be required the manipulation of the vaccine candidate strain to remove its ability to suppress, in particular, dendritic cell (DC) activation.

\section{Replication-Defective Vectors}

Until recently, it was believed that, to be effective, viral vaccines must consist of a live, replication-competent virus or a large dose of inactivated virus. Replication of live virus was believed to be essential to provide sufficient immunogen to induce a strong immune response. However, several nonreplicating vaccines, including replication-incompetent HSV, have been shown to induce an immune response [95, 99]. These HSV mutants show a reduced cytotoxicity, due to their inability to replicate and to spread in the host, but maintain the capability to infect a wide range of tissues and host species.

HSV replication-defective viruses with mutations in essential genes that fail to form progeny virions and disabled infection single cycle (DISC) viruses with mutations in structural protein genes that form uninfectious, progeny virions have been used as vaccines against $\mathrm{HSV}$ infections and as vaccine vectors [100-102].

It has been shown that the HSV-2 double mutant d15-29, deleted in the essential UL5 and UL29 genes, and its derivative d15-29-41L, deleted also in UL41 gene, do not cause any disease in immunodeficient mice indicating that the virus would be safe even in immunocompromised individuals [103, 104]. Moreover, both the viruses are equally effective and immunogenic in the guinea pig model 
[99, 105]. In February 2008, Acambis, a leading vaccine company developing novel vaccines, has initiated preclinical testing with d15-29 recombinant HSV-2.

Based on the data obtained with a DISC-gH HSV-1 virus, deleted for the $\mathrm{gH}$ coding sequence, tested as a vaccine vector [101, 106], a DISC HSV-2 vaccine [107] has undergone clinical trial but was ineffective as therapeutic vaccine in previously infected persons. DISC-HSV-2 has been shown to be an efficient vector for cytokine gene delivery into tumour cells, and that the expression of mGMCSF or hIL-2 enhances the immunogenicity of whole-cell vaccines [108, 109].

It has been recently demonstrated that immunization with CJ9-gD, a novel HSV-1 recombinant virus that is replication-defective due to the deletion of the UL9 locus, and expresses high levels of $\mathrm{gD}$, elicits a strong and longlasting humoral and Th1-like cellular immune response against both HSV-1 and 2, and that mice immunized with CJ9-gD were completely protected from local or systemic herpetic disease after intravaginal challenge with wt HSV-1 or 2 [110-112].

The appealing properties of replication-incompetent HSV-1-based vectors inducing strong CTL response, both in murine and in simian model, against foreign genes delivered by viral particles have made them very promising candidates for potential anti-HIV-1 and also other viral or intracellular bacterial pathogens vaccine development [94, 113, 114].

It has been shown that a mutant HSV-1 virus deleted for the ICP4, ICP22, and ICP27 genes and expressing ovalbumin (OVA) as a model antigen elicited protection in mice against a lethal challenge with a recombinant Listeria monocytogenes expressing OVA [94].

A similar vector, named d106, expressing HIV-1 Tat protein, has been demonstrated to induce long-term Tatspecific immune responses in the Balb/c murine model [114]. Moreover, vaccination of Rhesus macaques with a HSV-1 mutant virus that contains a deletion in ICP27 and expresses SIV Env and Nef antigens showed partial protection against mucosal challenge with the highly pathogenic SIVmac239 [115]. In the same animal model, using a prime-boost strategy of vaccination, recombinant HSV-1 vectors deleted for ICP4, ICP22, ICP27 and ICP47, and expressing Gag, Env, and a Tat-Rev-Nef fusion protein of SIV, elicited robust anti-Gag and anti-Env cellular responses and induced partial protection against intravenous challenge with SIVmac239 [95, 116]. The safety profile of this vector has been improved with the construction of d106S vector with increased sensitivity to acyclovir [117].

Due to their ability to accept multiple heterologous genes, the IE replication-defective vectors could be used for innovative and synergistic strategies of immunization. For example, it is possible to engineer vectors to express specific chemokines and cytokines, together with antigens targeted to MHC-I or II molecules, in order to attract monocytes to the sites of infection, to induce their differentiation into DCs and to favor antigen presentation.

\section{Replication-Competent Vectors as "Live Viral Vaccines"}

Live attenuated viral vaccines have many clear advantages. They provide a vehicle for complete presentation of all viral antigens to the host's immune system, stimulating both humoral and cell-mediated immune responses. They can be efficiently propagated with ease and are therefore extremely cost-effective vaccines. Live attenuated viruses have also been successful at combating myriad human viral diseases. The concerns surrounding the development of a live viral vaccine for HSV are mainly safety issues revolving around the potential for reactivation from latency, recombination with wt virus, and the oncogenic potential of viral DNA [91, 118-120].

The first attenuated HSV virus to be constructed and analyzed as a viral vaccine in humans, was the previously mentioned NV1020 [121, 122]. This virus was very strongly attenuated in rodents and primates. In a dose escalation study, local reactions were noted in HSV-1-infected persons. A dose-dependent induction of antibodies occurred in HSVseronegative subjects, but the development of this mutant has been stopped since it resulted too overattenuated, and it was consequently poorly immunogenic.

The goal to construct a safe, less attenuated vaccine candidate, lead to the construction of RAV9395 mutant [118]. When used as a live viral vaccine in a guinea pig model of HSV infection, it was shown to be protective, and it was also demonstrated that the immunologic answer depended on the route of administration of the virus. RAV9395 is based on HSV-2, strain G, which carries deletions in the UL55 and UL56 genes, encoding proteins with unknown functions, the deletion of which causes attenuation, and deletion in both copies of the $\gamma-34.5$ gene. Concomitant with this deletion, both copies of the open reading frame (ORF) $\mathrm{P}$ have also been deleted. The $t k$ gene was left intact and functional, conferring acyclovir sensitivity to the recombinant virus.

Mutations in $t k$, especially for HSV-2, do not attenuate the virus sufficiently for human vaccines [123]. Other attenuated HSV-1 and HSV-2 viruses with single deletion in $v h s$ or in $R R$ respectively [124, 125], were shown to determine a protective immunity when tested in animal models, but still they are too neurovirulent to be used for human trials.

On the basis of RAV9395, the AD-472 attenuated virus was developed. This HSV-2 strain contains the same deletions of the previous mutant with addition of deletion of UL43.5 and US-10-12 region. This AD-472 virus proved effective in reducing clinical disease in the guinea pig model, but still did not prove effective in reduce infection rates or in eliminating latency or recurrent disease [126, 127].

It has been recently constructed a replication-competent, live attenuated HSV-1 vaccine, NS-gEnull, in which the US8 gene, encoding $\mathrm{gE}$, has been deleted. The NS-gEnull virus was shown to have a defect in anterograde and retrograde directional spread and cell-to-cell spread. When used as a live vaccine in the murine model, it did not reach the dorsal root ganglia (DRG) and, even if it did not provide sterilizing immunity against viral infection, the challenge virus replicated to low titers at the site of inoculation with less severe disease and vaccinated mice were totally protected from zosteriform disease and death. Moreover, after HSV-1 challenge, latent virus was recovered by DRG explants in less than $10 \%$ of vaccinated mice, compared to $100 \%$ of mock vaccinated once [128]. 
BioVex Inc, a biotechnology company developing clinical stage treatments for cancer and the prevention of infectious disease, has announced, in August 2008, that the UK Medicines and Healthcare products Regulatory Agency (MHRA) has accepted BioVex's Clinical Trial Application to conduct a phase I clinical study (http://www.biovex.com/ immunovex.html) testing the safety and immunogenicity of its lead infectious disease candidate for genital herpes, ImmunoVEX ${ }^{\mathrm{HSV} 2}$ (www.biovex.com).

ImmunoVEX $\mathrm{HSV}^{\mathrm{H} 2}$ is a novel live-attenuated vaccine, which has been rationally designed to remove the genes that allow herpes virus to avoid the immune system. This should allow the immune system to recognize and mount a powerful immune response against the causative agent of genital herpes. In preclinical studies, ImmunoVEX ${ }^{\mathrm{HSV} 2}$ completely prevented all symptoms of genital herpes and triggered a powerful immune response, suggesting that ImmunoVEX ${ }^{\mathrm{HSV} 2}$ may be more potent than other HSV-2 vaccines for which data has been published.

The company reported that the ImmunoVEX backbone could also be suitable for delivery of many other tumour or infectious disease antigens, including HIV, HPV and hepatitis $\mathrm{B}$ or $\mathrm{C}$.

\section{HSV-1 BASED VECTORS FOR CANCER GENE THERAPY}

HSV vectors have wide-range natural hosts and have been proven to efficiently infect numerous human tumour cell lines in vitro. A number of new therapies have been developed for treatment of cancer, and the knowledge of the basic defects that occur in malignant tumours has lead to the conclusion that the association of different therapeutic approaches is the method to eradicate these malignancies. The HSV oncolytic vectors used to date in preclinical and clinical trials are summarized in Table $\mathbf{3}$.

\section{Replication-Defective Vectors}

Multiple immediate early gene-deleted non-replicative HSV-1 vectors are characterized by high efficiency of transduction of several different host species and cell types, both dividing and non dividing, including various tumour as well as endothelial cells [29, 129-132]. The anticancer

Table 2. Summary HSV Based Vectors for Vaccination

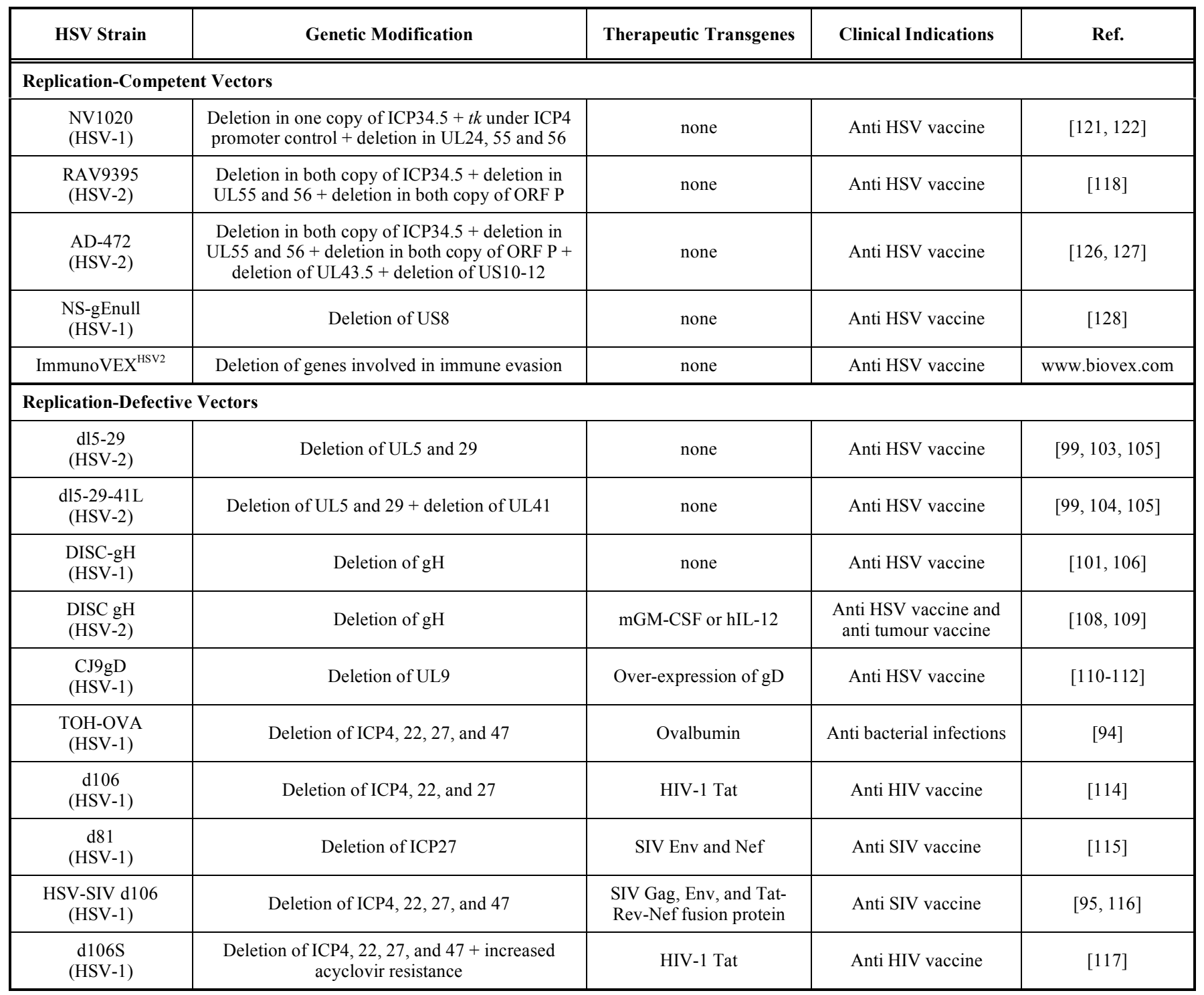


activities of replication-defective viruses depend on delivery and expression of an assortment of anticancer or immunomodulatory genes. These genes function alone or in combination with either radiotherapy and anticancer drugs or with anticancer vaccines.

Different replication-defective HSV vectors have been produced that deliver anticancer transgenes to tumour cells such as melanoma [30], gliosarcoma [130, 133, 134], or glioblastoma [135]. Two or more therapeutic molecules, acting additively or synergistically, can thus be expressed at comparable levels by cells transduced with a combination vector, which is clearly an advantage in comparison with coadministration of two or more vectors encoding a single transgene and also in comparison with co-expression of two molecules, separated by IRES sequences, by a unique vector.

These mutant vectors express, in association with the autologous HSV-1 tk gene acting as a suicide gene when accompanied by its pro-drug ganciclovir, further transgenes chosen for their potential to synergize in tumour cell killing and induction of antitumor immunity with genes encoding for soluble human cytokines (IL-2, GM-CSF and IFN- $\gamma$ ), the human B7.1 gene encoding a co-stimulatory surface antigen (CD80) [30], rat connexin 43 gene improving the HSV-1 TK/GCV killing of glioma cells by increasing the bystander effect [136] or rat connexin and human $\mathrm{TNF} \alpha[135,137]$. Recently, an HSV-1-derived replication-defective vector (T0-IFI16) was developed [135], which has been shown to efficiently transduce an interferon-inducible gene (IFI16), into primary human umbilical vein endothelial cells (HUVEC), which are usually poorly transfectable. It has also been possible to infect HUVEC cells with similar HSV-1based vectors expressing anti-angiogenic fusion proteins endostatin::angiostatin and endostatin::kringle 5. The expression of antiangiogenic proteins by directly infected HUVEC cells has been shown to induce cytostatic effects in proliferation assays in vitro. Also, by addition of gancyclovir to the cell culture media, a major cell killing effect was observed [129]. In vivo, the expression of autologous $t k$ gene in association with GCV was shown to be highly efficient in both reducing small tumour masses growth rates and also in inhibiting tumour cell engraftment. The expression by tumour cells of vector-encoded angiostatic proteins was also extremely efficient in inhibiting the tumour establishment, both in presence or in absence of GCV [129].

The wide spectrum of dividing or non-dividing cell types that can be easily infected by non-replicative HSV-1 vectors, and among them endothelial and dendritic cells, along with their large exogenous DNA accommodating capacity, makes these vectors very attractive delivery systems. These unique features might be of extreme importance for combined therapeutic strategies requiring the simultaneous expression of high levels of multiple foreign genes, like suicide genes, cytokines or other immunomodulatory molecules, antiangiogenic proteins, soluble growth factor receptors and so forth. As various types of tumours present different characteristics, the high manageability of large, well characterized HSV-1 genome might permit the combination, in a unique backbone, of the most appropriate exogenous genes for treatment of each particular tumour.

\section{Replication-Competent Vectors: Oncolytic Viruses}

A replicating vector for cancer therapy should be derived from viruses that are naturally endemic to the human population. The optimal strategy might be to derive a replicating vector from a highly prevalent but weakly pathogenic human virus [138]. Reversion to wt would then be of no serious risk to the patient or to the population.

Construction of oncolytic viruses that cannot only target cancer cells, but can also retain their ability to infect, usurp host replication machinery, then release newly made progeny to infect other transformed cells after lysing and killing the host cell, has become a major area of therapeutic cancer research, called "oncolytic virotherapy". There are some characteristics that an ideal replication-competent, oncolytic virus should possess above and beyond those viruses that function simply as delivery vectors: (i) be easy to engineer and to produce in large quantities; (ii) selectivity to neoplastic cell alone; (iii) minimal toxicity to normal tissue; (iv) show proliferation within and systematic killing of tumour tissue which itself may be rapidly propagating; (v) ability to disseminate throughout the tumour mass and possibly to sites of invasion distant from the initial inoculation site; (vi) carry low or bearable toxicity; (vii) genomically stable, thus avoiding the generation of toxic, undesirable mutants that could pose a danger; (viii) incorporate a "fail-safe" mechanism for inactivation; (ix) absence of potential spread to the general population; and (x) enduring efficacy despite prospect of encountering a mounting immune response to replicating viruses $[15,18$, 139-146].

So far, several oncolytic HSV vectors have been developed (Table 1) with particularly efforts for the treatment of malignant glioma [147].

\section{First-Generation Vectors}

The first generation of these vectors contains mutation in a single gene that restricted their replication to dividing cells. Three such HSV-1 mutants have been constructed: (1) dlsptk containing a deletion in the tk gene [148]; (2) hrR3 containing an insertion of the E. coli lac-Z gene in the early gene UL39, encoding the large subunit of the viral RR (ICP6) [149, 150]; (3) R3616 containing $1 \mathrm{~kb}$ deletions in both copies of the $\gamma-34.5$ gene, encoding the neurovirulence factor ICP34.5 [151-153].

TK mutants are highly neuroattenuated, and when used in different mouse models of various nervous system-derived tumour types, showed a slowed tumour growth and prolonged survival. However, clinical trials were not pursued because of (i) undesirable level of toxicity at high titers, and (ii) its TK-negative status made it resistant to traditional antiherpetic treatments, a major disadvantage should any viral toxicity to arise in treated patients [148, 154-156].

ICP6 mutants have been tested as replicative anticancer agents, alone or in combination with acyclovir/gancyclovir, as the mutants retain their sensitivity to such antivirals. Moreover, the $\mathrm{RR}^{-}$mutants have been shown to display an increased sensitivity to gancyclovir, compared to the wt virus. These recombinant viruses showed enhanced 
killing of tumour cells in vitro, and showed improved survival of animals. However, like TK mutants, they can cause fatal encephalitis when used at sufficient dose and were not thought to provide a sufficient margin of safety for testing in humans $[149,157]$.

It has been shown that deletion of ICP34.5, the neurovirulence factor essential for HSV pathogenicity, provides the greatest degree of attenuation of any individual mutation where the virus can still replicate in actively dividing cells. R3616, the prototype HSV-1 deleted in both copies of $\gamma-34.5$, had demonstrated attenuated neurovirulence but with maintained anti-glioma activity, and was found to produce no encephalitis in a nude mouse model [157-159]. The use of $\gamma-34.5$ mutated viruses demonstrated considerable antitumor efficacy, combined with a good safety profile, and different versions of HSV ICP34.5-deleted are currently in human clinical trials [160].

\section{Second-Generation Vectors}

Following preclinical testing with the above-mentioned oncolytic vectors, second generation vectors with multigenic mutations were created. G207 contains deletion in both $\gamma$ 34.5 loci and a lac-Z gene insertion in the ICP6 gene [161]. These multiple mutations made the reversion to wt highly unlikely and conferred several important safety advantages. Moreover, G207 retains its susceptibility to standard antiHSV therapies such as acyclovir, since the $t k$ gene is intact. After oncolytic activity and safety evaluation studies in the mouse model [161], G207 neurotoxicity was further evaluated in non-human primates [162]. These studies allowed to move into phase I clinical trials [163], and, presently, enrolment has begun for sequential phases Ib/II trials employing G207 as an anti-tumour agent for malignant gliomas $[164,165]$. MGH-1 is an oncolytic HSV-1 which shares the same characteristics of G207 and its oncolytic activity was evaluated in preclinical models $[155,166]$.

Almost simultaneously, HSV1716, derived from the parent wt strain HSV-1 17+ in which both the copies of $\gamma$ 34.5 have been deleted, also underwent clinical trials to evaluate its toxicity in patients with recurrent human glioma [167-169], after it was demonstrated to be avirulent in mice. HSV1716 has also been injected into subcutaneous nodules of metastatic melanoma in five patients and local evidence of anti-tumour effects was observed [170]. HSV1716 will move soon in phase I clinical trial for non-CNS solid tumours.

Oncolytic herpesvirus have been also studied as an oncolytic anti-tumour therapy against a variety of tumours different than GBM and anaplastic astrocytoma, such as human breast cancer in a brain metastatic model [171], colorectal cancer and liver metastases [172], prostate cancer [173], pancreatic cancer [174], and head and neck squamous carcinoma [175]. In many of these studies, the efficacy of G207 has been compared with that of the HSV-1 mutant NV1020 (formerly R7020) strain [121, 122], which was the first attenuated HSV virus to be constructed and analyzed as a viral vaccine in humans. This virus, based on HSV-1 strain $\mathrm{F}$, has a portion of the unique short region of the viral genome, encoding glycoproteins G, D, I and E, replaced by the homologous region from HSV-2, and possesses one copy of ICP4. NV1020, which was shown to be too attenuated to work as a live viral vaccine, is currently being investigated in phase I and II clinical trials for patients with colon cancer that has metastasized to the liver and has proven recalcitrant to chemotherapy $[176,177]$. This is also the first trial to investigate administration via intravascular delivery. In fact, oncolytic viruses can be administered locally, by direct intratumoral inoculation, or systemically, by intravascular administration. However, the route of administration of the virus did influence efficacy, as was observed in the animal model. The results demonstrated that NV1020 is a safe, novel therapeutic agent for treatment of refractory hepatic malignacy. An evolution of NV1020, namely NV1023, in which it has been inserted an HSV-2 fragment containing genes US2-2 and US2-5 into the UL/S junction and other minor mutations, is under evaluation, combined with ionizing radiation, in human cholangiocarcinoma cell lines and could also be useful for other malignancies such as pancreatic, rectal, prostate, and head/neck cancer [178]. Finally, it has been recently demonstrated that highly fusogenic derivatives of NV1020, named OncSyn and OncdSyn, carrying syncytial mutations in both $\mathrm{gB}$ (syn3) (OncSyn) and in gB and gK (syn1) (OncdSyn), can reduce primary and metastatic breast tumours in immunocompetent mice [179-181].

\section{Third-Generation Vectors}

G47 $\Delta$ is a third-generation vector that was constructed by deletion of US12 gene, encoding ICP47 protein, which normally blocks MHC class I-mediated antigen presentation in infected cells. Consequently, human melanoma cells infected with G47D expressed higher levels of MHC class I on their surface, compared to G207-infected cells, resulting in enhanced stimulation of tumour-infiltrating lymphocytes. The US12 deletion also removes the US11 promoter, so that US11 gene is expressed as an immediate-early gene under the control of the US12 promoter, thereby suppressing the diminished growth properties of ICP34.5 mutants [144]. This improved replication of G47 $\Delta$ translates into enhanced antitumor activity. Another HSV vector with the same characteristics of G47 $\Delta$ was isolated after serial passages, of an ICP34.5 deleted HSV, on a tumour cell lines. This viral isolate was shown to exhibit enhanced antitumor effect on prostate cancer [182].

\section{Last Generation Vectors: Transgene-Expressing Vectors}

Despite the promising results obtained with the engineered HSV-1-based oncolytic vectors described above, it is likely that a multimodal approach to eradicate cancer will be more effective with the final goal to improve safety and efficacy of the system. At this regard, oncolytic HSV vectors have been further modified to augment their antitumor efficacy, by incorporation of expression cassettes for the delivery of various transgenes. Moreover, if the therapeutic gene is chosen carefully, this may be synergistic with the antitumor effect of virus replication.

\subsection{Prodrug-Activating HSV-1 Vectors}

Oncolytic HSVs have been tested, which encode different prodrug-activating systems other than the endogenous TK activity of the virus. Both the 5fluorocytosine (5-FC) prodrug/yeast cytosine deaminase (CD) gene system [183], alone or in combination with the TK/gancyclovir system [184, 185], and the cytocrome P-450 (CYP2B1), which converts cyclophosphamide (CPA) to its 
active metabolites, are used to concentrate the toxic metabolites in virus-infected cells and were shown to induce beneficial effects [186-188]. Moreover, a new oncolytic HSV-1, MGH-2, was constructed, deleted for UL39 and ICP34.5 genes and with an insertion of the two prodrug activating genes, CYP2B1 and secreted human intestinal carboxylesterase $[189,190]$. Each of these can convert the inactive prodrugs, cyclophosphamide and irinotecan (CPT11), into their active metabolites, respectively. MGH-2 displays increased antitumor efficacy against human glioma cells both in vitro and in vivo when combined with cyclophosphamide and CPT-11. Importantly, cyclophosphamide, CPT-11, or the combination of cyclophosphamide and CPT-11 does not significantly affect oncolytic virus replication. Therefore, $\mathrm{MGH}-2$ provides effective multimodal therapy for gliomas in preclinical models when combined with these chemotherapy agents.

\subsection{Immunostimulatory HSV-1 Vectors}

Molecules including a number of interleukins and interferons have been tested with oncolytic HSVs. Among these, Interleukins (ILs) 4 [191], 12 [189, 192-195], 10 [191], granulocytes-macrophage colony stimulator factor (GM-CSF) [140, 160, 192], and B7.1 [196], which increase tumour immune recognition. This approach also reduces the possibility of toxicity derived from the systemic administration of the cytokine. Replication-competent vectors expressing IL-4 and IL-10 [191] were evaluated in an orthotopic model of murine GMP [191]. In this model, treatment of IL-4-expressing HSV increased survival over treatment with HSV alone, suggesting that cytokine gene therapy may mediate enhanced tumour-specific killing. Such effect is mediated by helper $\mathrm{T}$ cells of subset $2\left(\mathrm{~T}_{\mathrm{H}} 2\right)$ and has been attributed to $\mathrm{CD}^{+}$lymphocytes. Although IL-4 was effective in different animal models, generation of a $\mathrm{T}_{\mathrm{H}} 1$ response, including the induction of a memory response against tumour cells seems to have a more durable antitumor effect. At this regard the use of HSV vectors expressing IL12 or GM-CSF, two indispensable cytokines for activating DCs and boosting the strong immune responses against cancer, seems promising [197, 198]. GM-CSF engenders protective immunity by stimulating the recruitment, maturation, and function of DCs, while IL-12 released from DCs directly primes effector lymphocytes at local environments. In this regard, the gene transfer of GM-CSF into dying tumour cell may be more suitable form to elicit local antitumor responses by differentiating DC in situ and providing immunogenic tumour antigens for crosspresentation by paracrine fashion, whereas the expression of IL-12 may be an appropriate strategy to maximally boost antitumor effector functions. IL-12 also possesses antiangiogenic properties, which may represent a second potential mechanism of its antitumor activity [198]. M002 vector, derived from a replication-competent ICP34,5mutant which expresses mIL-12 was evaluated for its antitumor activity in a syngenic neuroblastoma murine model [189]. It was concluded that M002 can provide safe therapy with increased efficacy and survival in a model of nervous system tumours. Other vectors expressing IL-12, have been tested in different tumour models [192-195] showing efficacy in both treating the tumour and preventing recurrences after tumour-resection [199]. The antiangiogenetic property of IL-12 and its efficacy has been tested in animal model of squamous cell carcinoma [193]. A triple combination of oncolytic $\mathrm{HSV}-1$ vectors armed with IL-12, IL-18 and B7-1 have been studied in a murine model of neuro2a tumours and resulted in enhanced antitumor efficacy [200], suggesting that combined use of multiple oncoltic HSV-1 armed with different immunostimulatory genes may be a useful strategy for cancer therapy.

Several HSV-1 vector expressing GM-CSF have been used to treat experimental tumours [140, 160, 192, 201, 202] and some of them are in clinical trials [203-205]. Most of the oncolytic HSVs analyzed have been based on serially passaged laboratory strains of HSV. These strains have probably lost some of their aggressive properties. It has in fact been recently demonstrated that an oncolytic HSV, JS1/ICP34.5-/ICP47-/GM-CSF, named OncoVex, derived from a clinical isolate of HSV-1 and engineered to express GM-CSF, possesses a higher ability to kill tumour cells in vitro and in vivo. Moreover, in a model of mouse lymphoma, mice cured with this virus were protected against further tumour challenge [160]. OncoVex has demonstrated promising results both in phase I/II dose escalation study for head and neck squamous cell cancer [204] and in phase II clinical trial for unresectable malignant melanoma [203, 205]. In spite of the promising findings obtained in clinical trials, using OncoVex, the expression of GM-CSF gave contradictory results in different tumour models [206]. These contradictory activities of GM-CSF might depend upon additional factors operative in tumour microenvironment. Therefore, it is important to clarify the key regulatory circuits that attenuate the experimental activity of GM-CSFbased antitumor strategies. This might help in the definition of new strategies to enhance GM-CSF activity.

\subsection{Antiangiogenic Approaches Using HSV Vectors}

Angiogenesis has a critical role in tumour development and metastasis and novel antiangiogenic therapies are desirable [207-210]. Thus, strategies have been developed to inhibit tumour angiogenesis either by arming HSV vectors with antiangiogenic transgenes or with a combined treatment with antiangiogenic compounds and oncolytic HSV first [194, 208, 211-213]. In a study of Mullen and colleagues [211] the murine endostatin gene was incorporated into the HSV genome. The produced endostatin was found to inhibit angiogenesis in a human HT29 colon carcinoma model. In a second study of Liu TC and colleagues [213] a concurrent systemic Trichostatin A (TSA) and intratumoral oncolytic HSV, G47 , administration resulted in enhanced antiangiogenesis and enhanced antitumor efficacy in animal models. It was observed that in tumour and prolipherating endothelial cells, combination treatment enhanced cyclin D1 and VEGF inhibition. It has been recently demonstrated in an in vivo model that an oncolytic HSV-1, named RAMBO (Rapid Antiangiogenesis Mediated By Oncolytic virus), that can express vasculostatin (Vstat120), the cleaved and secreted extracellular fragment of brain-specific angiogenesis inhibitor 1 (BAI1), under the control of IE4/5 promoter, displays an anti-tumour effect upon delivery into established tumours. This supports the further development of RAMBO as a possible cancer therapy [214]. 


\section{Other Strategies in Developing HSV Oncolytic Vectors}

\subsection{Spontaneously Generated HSV-1 Vectors}

A Spontaneously generated HSV-1 vector, HF10, derived from strain $\mathrm{HF}$, which contains a $3.9 \mathrm{kbp}$ deletion at the right end of UL and UL/IRL junction, with resulting deletion in UL56, and rearrangements and deletion on the left end of the genome, was shown to possess oncolytic activity for disseminated peritoneal tumour in immunocompetent mice [215]. It has been recently shown that HF10 is effectively oncolytic in melanoma mouse models, and that intratumoral injection of HF10 induced systemic antitumor response [216].

\subsection{Fusogenic Vectors}

Another strategy is to clone therapeutic genes into the viral genome to arm the virus with additional cytotoxic mechanisms that augment the direct lytic functions of the virus. Particularly attractive in this context are cytotoxic mechanisms with potent bystander effect capable of eliminating tumour cells that the virus cannot reach. To this purpose, it has been recently demonstrated that incorporation of cell membrane fusion capability into an oncolytic HSV can significantly increase the antitumor potency of the virus [217-219]. These oncolytic HSVs were constructed by different methods: (i) screening for the syncytial phenotype after random mutation of a well-established oncolytic HSV (to obtain Fu-10); (ii) insertion of the gene encoding the hyperfusogenic membrane glycoprotein of gibbon ape leukemia virus (GALV.fus) into the genome of an oncolytic HSV (to generate Synco-2); (iii) incorporation of both of these two membrane fusion mechanisms into a single oncolytic HSV (to generate Synco-2D); and (iv) combined expression of GALV with a highly potent prodrug activation gene (yeast cytosine deaminase/uracil phosphoribosyltransferase fusion [Fcy::Fur]) [220]. These vectors have been tested for their antitumor activity against liver, breast, ovarian and metastatic prostate cancers showing a significant increase in viral oncolysis; this may lead to an enhanced clinical performance, especially in the late stage cancer patients.

\subsection{HSV-2 Based Vectors}

It has been recently proposed that the HSV-2 $\triangle \mathrm{PK}$ mutant, which is well tolerated in human patients, as resulted from studies against recurrent genital HSV-2 infections, has robust melanoma oncolytic activity in culture and in animal models (xenografts) [221]. The FusOn-H2 mutant, which contains the same PK deletion with insertion of GFP, has been proposed as a promising oncolytic agent for breast cancer, for renal cell carcinoma, and for neuroblastoma [222225].

\section{Chemotherapy or Radiotherapy to Enhance the Potency of Oncolytic HSV}

In early clinical trials, however, treatment with the current generation of oncolytic viruses did not significantly affect tumour growth [163, 167]. This suboptimal result may reflect viral gene deletions, which can reduce the replicative potential of viruses in tumour cells. For example, deletion of the $\gamma-34.5$ gene significantly reduced viral growth even in rapidly dividing cells $[144,149,191]$. A variety of strategies is being pursued to enhance the potency of oncolytic viruses by "arming" them with various transgenes. Overall, the results so far obtained demonstrate that this last generation HSV vectors can increase antitumor efficacy, especially if used in combination with pre-existing anticancer treatments, such as radiotherapy or chemotherapy [18, 186, 226, 227]. Combined oncolytic viral therapy and external beam radiotherapy (XRT) has shown significantly improved results over individual therapies in preclinical models [228]. Significant improvements in disease outcomes have been observed with combination HSV virotherapy and XRT in preclinical models. In two different studies, NV1066 (ICP0/ICP4/ $/ 34.5$ deletions) combined with irradiation was shown to significantly reduce tumour volume compared to either treatment alone for nonsmall cell lung cancer and malignant mesothelioma $[229,230]$. Moreover, the combination of NV1023 ( $\gamma 34.5 /$ UL24/UL56/US11/ICP47 deletions) with XRT was investigated in three models of cholangiocarcinoma generated using different cell lines [178]. This dual therapy showed a synergistic reduction in tumour volume in one model, whereas the effect was additive or not significantly better than individual therapies in the other models. Despite the promising results described above, the potential for combination therapy remains to be seen in a variety of other cancers. For example, in one study the combination of HSV oncolytic therapy and XRT, in prostate models, was not significantly better than virus therapy alone in both immunocompetent and immunocompromised models [227]. The underlying mechanism of increased HSV replication and oncolytic effect in the presence of XRT has been well characterized studying the synergy between ICP34.5-deleted viruses and conventional cancer therapy [231]. Interestingly, ICP34.5 shows significantly structural homology to a portion of human GADD34, a protein involved in the cell response to DNA damage [232]. ICP34.5 is responsible for dephosphorilation of eIF-2 $\alpha$, which is required for translation of both host and viral proteins. Radiation or chemotherapy-induced up regulation of GADD34 functionally replaces the ICP34.5 protein in infected tumour cells leading to increase viral protein synthesis and production of infectious virus particles.

Oncolytic HSVs have been also investigated in combination with various standard chemotherapeutics, such as cyclophosphamide (CPA) and cisplatin. Use of CPA as an immunosuppressant to enhance viral oncolysis has improved virotherapy efficacy in combination with HSV [233-235]. However, one of the potential pitfalls of CPA-mediated immune suppression is that in addition to promoting tumour oncolysis, it may also lead to increased virus dissemination through the body. In this regard, it has been observed that CPA can induce the spread of HSV into normal brain tissue following treatment of an orthotopic glioma tumour [236]. Cisplatin has also been investigated in combination with oncolytic HSV [237-239]. In a comprehensive study of the interaction between NV1066 HSV vector and cisplatin, moderate to strong synergy was observed. The mechanism of synergy may be similar to that with radiation. Cisplatin significantly increased viral titer and resulted in a marked increase in GADD34 mRNA and protein expression.

\section{TARGETING REPLICATION-COMPETENT VECTORS}

To prevent damage of healthy tissues, to decrease the risk of germ line transduction, and to design vectors that can be 
Table 3. Summary of Oncolytic Vectors and Clinical Trials

\begin{tabular}{|c|c|c|c|c|c|}
\hline HSV Strain & Genetic Modification & $\begin{array}{l}\text { Therapeutic } \\
\text { Transgenes }\end{array}$ & Stage & Clinical Indications & Ref. \\
\hline dlsptk & $t k$ deletion & none & Preclinical & & {$[148,240]$} \\
\hline hrR3 & UL39 disruption (large RR subunit) & none & Preclinical & & {$[155,241,242]$} \\
\hline HSV1716 & Deletion in both copies of ICP34.5 & none & $\begin{array}{l}\text { Human clinical trials } \\
\text { Phase I (recruitment not yet } \\
\text { open) }\end{array}$ & $\begin{array}{l}\text { Glioma, melanoma, head- } \\
\text { and-neck cancer. } \\
\text { Non-CNS solid tumours }\end{array}$ & $\begin{array}{c}{[167,169,170} \\
243,244]\end{array}$ \\
\hline R3616 & Deletion in both copies of ICP34.5 & none & Preclinical & & {$[151,157]$} \\
\hline R4009 & $\begin{array}{l}\text { Stop codon in both copies of } \\
\text { ICP34.5 }\end{array}$ & none & Preclinical & & {$[151,157]$} \\
\hline G207 & $\begin{array}{c}\text { Deletion in both copies of ICP34.5 } \\
+ \text { disruption of UL39 }\end{array}$ & none & $\begin{array}{l}\text { Human clinical trials phase } \\
\text { I, IB, and II }\end{array}$ & $\begin{array}{l}\text { Recurrent brain cancer } \\
\text { (glioma, astrocytoma, } \\
\text { glioblastoma }\end{array}$ & $\begin{array}{c}{[161-165,245,} \\
246]\end{array}$ \\
\hline MGH-1 & $\begin{array}{c}\text { Deletion in both copies of ICP34.5 } \\
+ \text { disruption of UL39 }\end{array}$ & none & Preclinical & & {$[149,166]$} \\
\hline MGH-2 & $\begin{array}{c}\text { Deletion in both copies of ICP34.5 } \\
+ \text { disruption of UL39 }\end{array}$ & $\begin{array}{l}\text { CYP2B1 and } \\
\text { shiCE }\end{array}$ & Preclinical & & [190] \\
\hline $\begin{array}{c}\text { R7020 } \\
(\mathrm{NV} 1020)\end{array}$ & $\begin{array}{c}\text { Deletion in one copy of ICP34.5+ } \\
t k \text { under ICP4 promoter control }+ \\
\text { deletion in UL24, } 55 \text { and } 56\end{array}$ & none & $\begin{array}{l}\text { Human clinical trials phase } \\
\text { I and II }\end{array}$ & $\begin{array}{l}\text { Liver, metastases derived } \\
\text { from colorectal cancer. }\end{array}$ & $\begin{array}{c}{[121,122,176,} \\
177]\end{array}$ \\
\hline G47 $\Delta$ & $\begin{array}{c}\text { Deletion in both copies of ICP34.5 } \\
+ \text { disruption of UL39 }\end{array}$ & none & Preclinical & & [144] \\
\hline Myb34.5 & $\begin{array}{l}\text { Deletion in both copies of ICP34.5 } \\
+ \text { disruption of UL39 + insertion of } \\
\text { an ICP34.5 gene under the control } \\
\text { of the B-myc promoter }\end{array}$ & none & Preclinical & & {$[247,248]$} \\
\hline DF3 334.5 & $\begin{array}{c}\text { Deletion in both copies of ICP34.5 } \\
+ \text { insertion of an ICP34.5 gene } \\
\text { under the control of the } \\
\text { DF3/MUC1 promoter }\end{array}$ & none & Preclinical & & {$[139,249]$} \\
\hline HF10 & $\begin{array}{l}\text { Spontaneous generation of HSC-1 } \\
\text { variant }\end{array}$ & none & Human clinical trials & & {$[215,216]$} \\
\hline NV1042 & $\begin{array}{l}\text { HSV-1/HSV-2 intertypic } \\
\text { recombinant }+ \text { contains only one } \\
\text { ICP34.5 copy }\end{array}$ & Murine IL-12 & Preclinical & & [192-195] \\
\hline$\underset{\mathrm{CSF}}{\mathrm{OncoVex}}{ }^{\mathrm{GM}-}$ & $\begin{array}{c}\text { Deletion in both copies of ICP34.5 } \\
+ \text { deletion of ICP47 }\end{array}$ & GM-CSF & Phase II/III & $\begin{array}{l}\text { Breast cancer, head-and- } \\
\text { neck cancer, melanoma }\end{array}$ & {$[160,250]$} \\
\hline RAMBO & $\begin{array}{c}\text { Deletion in both copies of ICP34.5 } \\
+ \text { UL39 disruption }\end{array}$ & $\begin{array}{l}\text { IE4/5 prom- } \\
\text { Vstat } 120\end{array}$ & Preclinical & & [214] \\
\hline $\begin{array}{l}\text { NP2 } \\
\text { enkephalin } \\
\text { expressing } \\
\text { vector }\end{array}$ & Deletions in ICP4, 27, 22 and 47 & $\begin{array}{l}\text { human prepro- } \\
\text { enkephalin }\end{array}$ & Phase I & $\begin{array}{l}\text { Chronic pain from } \\
\text { terminal cancer }\end{array}$ & {$[38,39]$} \\
\hline
\end{tabular}

administered intravenously, it is necessary to achieve targeted gene therapy. Genetic modifications to the genome of HSV-1 vectors have been generated to preferentially target viral infection and/or replication to tumour cells $v s$ normal cells [141].

Targeting viral infection to particular cells can be obtained by modifying the first steps of the virus life cycle, i.e. adsorption and penetration. Efforts for engineering the HSV-1 envelope to obtain targeted infection are currently in progress. Altering HSV-1 host range has proved a formidable task because HSV-1 infection is a complex process involving the action of several glycoproteins in cell attachment, entry, and cell-to-cell spread (Fig. 2).

As a first step, to eliminate the HSV tropism, a mutant virus deleted for $\mathrm{gC}$ and the $\mathrm{HS}$ binding domain of $\mathrm{gB}$, namely $\mathrm{KgBpK}^{-} \mathrm{gC}^{-}$, was generated [251]. This virus was further engineered to redirect infection to erythropoietin (EPO)-receptor positive cells using $\mathrm{gC}$-EPO fusion molecules. It was demonstrated that one of the $\mathrm{gC}$-EPO fusion molecules was incorporated into a recombinant HSV1 viral envelope and was able to stimulate proliferation of EPO growth dependent cell line FD-EPO. Otherwise, the lack of productive infection due to endocytosis of the virus 
resulted in an aborted infection [252]. It was recently demonstrated that the $\mathrm{KgBpK}^{-} \mathrm{gC}^{-}$virus, further modified to express and incorporate a fusion protein between $\mathrm{gC}$ and the preS1 active peptide (preS1ap) of HBV, was able to bind preferentially to hepatocytes, giving a productive infection [253]. However, this mutant still retains gD binding functions. Simultaneously, efforts are in progress to modify $\mathrm{gD}$, the other glycoprotein involved in HSV-1 binding and penetration into the host cell $[254,255]$. In a following report, R5111 mutant virus was described lacking the HS binding domains of $\mathrm{gB}$ and in which the HS and HVEM binding regions of $\mathrm{gC}$ and $\mathrm{gD}$, were substituted with IL-13 coding sequences. HSV-1 R5111 can infect J13R cells containing the IL-13R $\alpha 2$ receptor and lacking all other HSV1 receptors. However, this mutant still retains the other $\mathrm{gD}$ binding affinities, and is not yet established whether it can productively infect the target cells, in a similar way to that obtained with wt HSV [255]. An alternative approach reports a transiently vesicular stomatitis virus glycoprotein G (VSVG) pseudotyped $\mathrm{gD}$ minus HSV-1, but to date a stable mutant has not yet been reported [254]. A further stimulus to the search of new strategies to alter HSV cell tropism, derives from the observation, that selected mutations in $\mathrm{gD}$ can reduce or abolish entry/fusion activity with nectin-1 and nectin-2, the principal receptors for HSV-1 entry into neurons, without preventing activity of HVEM or 3-0-S HS, that alternatively can mediate entry into $\mathrm{T}$ cells and fibroblasts [256]. It has been recently reported the construction of an HSV-1 mutant that selectively targets the HER2 (epidermal growth factor 2)-expressing tumour cells by means of a point mutation and insertion of an anti-HER 2 single-chain antibody into $\mathrm{gD}$ that simultaneously allow the virus to be detargeted for nectin-1 and HVEM and retargeted to HER-2. The resulting recombinant, R-LM113, has been shown to enter the cells and spread to cell solely via HER2. Moreover, such HSV-1 recombinant strongly inhibited progressive tumour growth in nude mice bearing HER-2hyper-expressing human tumours $[257,258]$. At the same time, other groups have demonstrated the possibility of redirecting HSV-1 tropism by antibody-binding sites incorporated on the virion surface as a $\mathrm{gD}$ fusion protein, by incorporating either single-chain variable fragment $(\mathrm{scFv})$ anti-CD55, or anti-CD38, or anti-EGFR in place of residues 274-393 of gD, to specifically target tumour cells [259].

These data suggest that strains carrying gD mutations may establish transient infections in humans, but perhaps not latent infections of neurons, and are therefore candidates for development of safe virus vaccines and vaccines vectors.

Finally, the recently discovered the PILR $\alpha$ gB receptor represents another possible target to modify viral tropism.

One strategy to target replication of the attenuated virus is obtained by eliminating viral functions necessary for replication in normal cells. These mutations give the virus the attenuated phenotype that leads to replication only in permissive cells such as dividing tumour cells or cells with defects in specific cancer pathways [122, 148, 154, 161]. However, a limit of this strategy is that many normal tissues also have high mitotic indices, and such viruses may not discriminate between rapidly proliferating normal and cancer cells.
A second strategy to target viral replication to tumour cells, consists in placing the expression of essential viral genes under the control of tumour or tissue-specific promoters, that are preferentially active in tumour cells [139, $168,247,260,261]$. The use of tissue-specific promoters to direct viral replication to a specific tumour type have been explored more extensively in oncolytic adenoviruses and use of these promoters to regulate HSV replication could be further explored. A limitation in the use of these promoters is that viral replication is mainly targeted at a specific tumour type and often further restricted to only a subgroup. To this purpose, promoters active in most tumours [18, 247, 262] have been explored [263, 264], or radiation-responsive promoters, but there are instances where these promoters might be active in normal cells, leading to toxicity. A further obstacle is that, in the context of a tumour, it is likely that these promoters will not be active in all tumour cells and that not all cells will be infected. As a result, a subset of tumour cells will have a selective growth advantage and survive leading to tumour recurrence.

Different reports indicate the possibility to drive expression of ICP4 or ICP34.5 with tumour specific promoters. Viruses containing ICP4 driven by either human carcinoembryonic antigen (CEA) and MUC1/DF3 tumourassociated antigens promoters were demonstrated to replicate specifically in tumour cells but regulation of ICP4 expression by the CEA promoter during HSV-1 infection overly attenuated viral replication [139]. Conversely, regulation of ICP34.5 function by the DF3/MUC1 promoter/enhancer sequence, resulted in preferential replication into DF3/MUC1 expressing cancer cells, restricted biodistribution in vivo, and less toxicity [139, 249].

It has also been demonstrated that viruses, based on G207 backbone, containing ICP34.5 driven by either Musashi1 (KeM34.5 vector) [265, 266] or rQNestin [234] promoter can be used to drive HSV-1 virulence toward gliomas while maintaining the desirable neuro-attenuated phenotype.

The main HSV-1 targeting strategies reported to date are summarized in Table 4.

\section{IMAGING GENE THERAPY}

Molecular therapy using viruses would benefit greatly from a non-invasive modality for assessing dissemination of viruses. Non-invasive imaging, based on the use of positron emission tomography (PET) and bioluminescence (BLI) imaging markers, has been shown to be useful in assessing biological relevant distribution of virus in therapies using replication-competent HSV.

\section{Radionuclide Imaging}

Positron emission tomography (PET) and single photon emission computed tomography (SPECT) enable the assessment and quantification of the intensity and regional/spatial distribution of gene expression in vivo.

PET uses decaying nuclides such as ${ }^{11} \mathrm{C},{ }^{13} \mathrm{~N},{ }^{18} \mathrm{~F},{ }^{15} \mathrm{O}$, ${ }^{64} \mathrm{Cu}$, and ${ }^{124} \mathrm{I}$ and images the distribution of trace quantities of positron-emitting molecular probe administered. Molecular probes labeled with positron-emitting isotopes are used to detect biologically active molecules, as the result of 
Table 4. Summary of HSV-1 Replication-Competent Vectors Targeting Strategies

\begin{tabular}{|c|c|c|c|c|}
\hline HSV Strain & Genetic Modification & Targeting Molecule & Targeting Tissue/Organ & Ref. \\
\hline \multicolumn{5}{|l|}{ Targeting of Entry } \\
\hline $\mathrm{KgBpK}^{-} \mathrm{gC}-\mathrm{EPO}$ & $\begin{array}{l}\text { Deletion in } \mathrm{pK} \text { region of } \mathrm{gB}+ \\
\text { deletion of } \mathrm{gC}\end{array}$ & Insertion of gC-EPO fusion protein & EPO-receptor positive cells & {$[252]$} \\
\hline R5111 & $\begin{array}{c}\text { Deletion in } \mathrm{pK} \text { region of } \mathrm{gB}+ \\
\text { deletion of } \mathrm{HS} \text { binding regions of } \mathrm{gC} \\
\text { and } \mathrm{gD}\end{array}$ & $\begin{array}{l}\text { Insertion of gC-IL-13 and gD-IL-13 } \\
\text { fusion molecules }\end{array}$ & $\begin{array}{l}\text { IL-13R } \alpha 2 \text { receptor expressing } \\
\text { cells }\end{array}$ & {$[255]$} \\
\hline $\mathrm{KgBpK}^{-} \mathrm{gC}^{-} \mathrm{gD}^{-}$ & $\begin{array}{l}\text { Deletion in } \mathrm{pK} \text { region of } \mathrm{gB}+ \\
\text { deletion of } \mathrm{gC}+\text { deletion of } \mathrm{gD}\end{array}$ & Pseudotyping with VSV-G & VSV susceptible cells & [254] \\
\hline \multicolumn{5}{|c|}{ Targeting of Replication/Expression } \\
\hline CEAICP4; & Deletion of either ICP4 promoter & Substitution with CEA promoter & Tumour cells & [139] \\
\hline CEA $\gamma 34.5$ & Deletion of ICP34.5 promoter & Substitution with CEA promoter & Tumour cells & [139] \\
\hline $\mathrm{DF} 3 \gamma 34.5$ & Deletion of ICP 34.5 promoter & $\begin{array}{l}\text { Substitution with DF3/MUC1 } \\
\text { promoter/enhancer sequences } \\
\text { promoter }\end{array}$ & $\begin{array}{l}\mathrm{DF} 3 / \mathrm{MUC1} \text { expressing tumour } \\
\text { cells }\end{array}$ & {$[139,249]$} \\
\hline KeM34.5 & G207 backbone & $\begin{array}{l}\text { Insertion of Musashi1 promoter } \\
\text { driving ICP34.5 }\end{array}$ & Malignant glioma & {$[265,266]$} \\
\hline
\end{tabular}

the target-dependent sequestration of the systemically administered positron-emitting probe [267]. The ability of PET to image gene expression quantitatively, combined with the ease translation of techniques developed for small-animal PET imaging to the clinic, has been of clear benefit in HSV vector-based gene therapy trials.

Several genes have been proposed as potential marker genes for radiotracer-based molecular imaging. These marker genes can be broadly classified as genes whose gene product is an intracellular protein (e.g. enzymes) or associated to the cell membrane (membrane receptors or transporters). The most commonly used reporter gene is HSV-1 thymidine kinase $(t k)$ whose product can convert acycloguanosines (like ganciclovir, acyclovir, penciclovir and 9-[4-fluoro-3-(hydroxymethyl) butyl]guanine (FHBG)) as well as 2'-fluoro-nucleoside analogues of thymidine such as 1-(2-deoxy-2-fluoro- D-arabinofuranosyl)-5-iodouracil (FIAU) and its derivatives in the phosphorylated forms. The main advantage of the use of HSV-1-TK in gene therapy protocols is the fact that this gene can be used as an imaging gene and as a therapeutic gene. The phosphorylated acycloguanosines, following conversion to their di- and triphosphate forms by HSV-1-TK, can kill cells either by blocking DNA synthesis or by causing chain termination. Most commonly ganciclovir is used as prodrug in this suicide gene therapy paradigm. Molecular imaging with PET using $t k$ as a PET reporter gene offers the desired qualities of a noninvasive test which can be easily repeated to determine the location and magnitude of viral replication and tumour lysis and has been extensively used for both preclinical and clinical studies using HSV-1 oncolytic vectors [268]. Using replication-competent HSV-1 oncolytic virus with $t k$ under the control of different promoters, it has been demonstrated that viral infection proliferation and promoter characteristics all interact to influence FIAU accumulation and imaging [269]. Moreover, the combination of two marker/reporter genes, $t k$ and $l a c Z$, has been used to monitor the kinetics of hrR3 and MGH-1 vectors replication and spread in infected tumour cells. These vectors retained an intact viral $t k$ gene and contained a lac $Z$ insertional mutation within the gene encoding RR, while MGH-1 bore additional mutation at both $\gamma-34.5$ genes, reducing further the risk of recombination and neurovirulence [166]. Time-dependent and spatial relationships of HSV-1-tk and lacZ gene co-expression in culture and in vivo indicate the potential for indirect in vivo imaging of therapeutic gene expression in tumour tissue infected with any recombinant $\mathrm{HSV}-1$ vector where a therapeutic gene is substituted for the lacZ gene. Current imaging modalities have limited sensitivity for detection of micrometastases in lymph nodes and, therefore, there is a need for a better technique that can accurately identify occult sentinel limph nodes (SLNs) metastases. A new approach for imaging melanoma lymph node metastasis using an oncolytic HSV-1 and $\left[{ }^{18} \mathrm{~F}\right]$ FIAU-PET has been recently developed in a murine model melanoma [270]. It has been 
shown, for the first time, that the NV1023 HSV vector expressing the $t k$ gene can track to draining lymph nodes following direct intratumoral injection and infect metastatic melanoma cells in the SLNs. Nodal metastases can be then successfully identified by $\left[{ }^{18} \mathrm{~F}\right]$ FIAU-PET imaging. These findings are encouraging and translation to clinic is feasible. If successfully implemented, this imaging system has the potential for improving patient care by enabling: (1) a more sensitive non-invasive method for the detection of lymph nodes invaded by cancer, (2) delineation of the extent and anatomic location of regional metastases, (3) provide better pre-surgical assessment of disease extent in patients with suspected positive lymph nodes, and (4) provide guidance for adjuvant radiotherapy or chemotherapy to patients with lymph node metastases.

SPECT acquires information on the concentration of gamma emitting radionuclides, such as ${ }^{111} \mathrm{In},{ }^{123} \mathrm{I},{ }^{201} \mathrm{Ti}$, or ${ }_{99} \mathrm{mTc}$. In enveloped viruses such as HSV, the lipophilic ${ }^{111}$ In-oxine tracer can transverse the viral envelope and be stabilized, likely by rechelation to cystein-rich viral capsid protein such as glycoprotein D and/or ICP5/VP22 [271]. Using this technique, labelled HSV has been used to quantify viral mass distribution in a rodent brain tumour model [272].

Current research on imaging HSV-1-tk gene expression is focusing on: 1) methods for exact quantification of HSV-1TK expression, 2) improved HSV-1-TK probes for PET and SPECT, 3) translation of this imaging paradigm into other vector systems, 4) imaging follow-up in cancer therapy strategies, 5) imaging transcriptional activation, and 6) multimodal imaging by fusing the HSV-1-tk gene with further imaging genes.

\section{Bioluminescence Imaging (BLI)}

BLI exploits the emission of visible photons at specific wavelengths based on energy-dependent reactions catalyzed by luciferases. Luciferases comprise a family of photoproteins that emit detectable photons in the presence of oxygen and ATP during metabolism of substrates such as luciferin into oxyluciferin. BLI has been used to monitor tumour cell growth and regression, to visualize the kinetics of tumour cell clearance by chemotherapeutics, and to track gene expression (Fig. 3). The most used luciferase systems are based on firefly luciferase (Fluc) and Renilla luciferase (R-luc) genes [273-275].

In two recent studies luciferase imaging has been used to compare the transcriptional dynamics of IE and strict-late viral promoters in the context of oncolytic HSV vectors [276] and to develop a rapid method to generate multiple oncolytic HSV vectors [277], respectively. In the first study, it has been demonstrated that incorporation of a strict-late promoter-driven luciferase cassette into the vector would be useful for assessing tumour oncolysis in preclinical tumour treatment studies. In the second, an HSVQuik system, together with luciferase-labeled tumour models, has been shown to expedite the process of generating and evaluating oncolytic HSV vectors for cancer gene therapy application.

The ability to image two or more biological processes in a single animal can greatly increase the utility of luciferase imaging by offering the opportunity to distinguish the expression of two reporters biochemically. Combining genes encoding light-generating enzymes such as Fluc and R-luc with the new generation of supersensitive charged coupled device (CCD) cameras has opened the door to sensitive in vivo measurements/imaging of gene expression in living animals. The luciferases from Renilla and firely have different substrates, coelenterazine and D-luciferin, respectively, and can be imaged in tumours in the same living mouse with kinetics of light production being separable in time by separate injections of these two substrates. Recently, dual bioluminescent imaging has been used to monitor both gene delivery and efficacy of TRAILinduced apoptosis in tumours in vivo, following treatment with a replication-deficient HSV-1 vector [278].

\section{FACTORS THAT MAY AFFECT HSV VECTORS EFFICACY}

The two principal factors that affect the efficacy of HSVbased vectors in gene therapy are: (1) the immune response to viral vectors, and (2) the complexity of the tumour mass.

\section{Immune Response to HSV Infection}

Innate and adaptive immunity are both important in determining which HSV-based vector is more suitable for a certain strategy of gene therapy [279, 280].

Inferring immune consequences to HSV vectors via wt HSV infections is one approach to determining their utility. A second strategy is to employ animal models to establish the efficacy and type of immune responses that will ensue from using a particular HSV-based vector. However, we do not have a complete understanding of the components that modulate HSV wt infection or HSV vectors delivery and this may be due in part to the animal experimental models that do not resemble completely the natural host. In this regard, a recent substantial improvement may come from the development of humanized mice as a novel tool for the study of HSV infection and the derived immune response [281].

\section{Immune Response to Wild Type HSV}

HSV induce both innate and adaptive immunity in the infected host. The principal component of innate immunity that control HSV infection are: macrophages [282], polymorphonuclear leukocytes (PMNLs), natural killer (NK) cells and innate NK-like T cells (iNKT) [283, 284], and dendritic cells (DCs) [282]. Dendritic cells have a crucial role and function as a bridge between innate and adaptive immunity. Adaptive response to HSV infection include the cellular response mediated by $\mathrm{CD}^{+}$and $\mathrm{CD}^{+} \mathrm{T}$ cells and the humoral response by $\mathrm{B}$ cells and antibodies.

Chemokines [285, 286] and cytokines [279, 287] have an important role in the coordination and development of innate and adaptive immune response to HSV-1. Control of HSV-1 during primary infection requires recruitment of PMNLs macrophages and NK cells by specific chemokines, and culminates in the induction of antigen specific responses by $\mathrm{T}$ cells which control viral replication through lysis of infected cells and cytokine production. Effective innate control of viral replication may lower latent viral burden present in sensory ganglia, and reduce the frequency of subsequent reactivation. Cytokine production at the site of infection and in the sensory ganglion has been reported to affect the course of HSV infection. Several cytokines have been detected in these tissue during HSV infection both in 
human and in experimental animals. The cytokines detected include IFN- $\alpha,-\beta$ and $-\gamma$, IL-1, $-2,-4,-5,-6,-10,-12$ and -23 and also TNF- $\alpha$ [279, 287]. IFN- $\alpha$ and $-\beta$ limit the early acute replication of HSV [288]. IFN- $\gamma$ production and the presence of $\mathrm{CD}^{+}$and $\mathrm{CD} 8^{+} \mathrm{T}$ cells are key regulators of viral clearance during acute infection. Other proinflammatory cytokines are involved in regulation of viral replication and reactivation in sensory ganglia, such as IL-1, -6, -12 and TNF- $\alpha$. IL-12 has important roles in the development of Th1 response and in cell-mediated immunity. It has been reported that IL-23 is expressed in the brain during infection [289]. It is suggested a major role for IL-23 in the proinflammatory response [287, 289, 290]. The role of Th2 type cytokines in HSV infection has not been well established. IL-4 and IL-10 expression has been detected early during the infection in sensory ganglia of HSV-susceptible mouse strains [291].

\subsection{Innate Immunity}

The innate immune system serves as the first line of defence against HSV infection [292] by producing and releasing important cytokines [282] and chemokines [286] following recognition of viral signals via Toll-like receptors (TLRs) [293]. The principal effector mechanisms underlying viral innate defences are phagocytosis, components of the complement cascade [294], NK cells mediated cytotoxicity, interferon type 1 and type 2 [295, 296], apoptosis [297], and autophagy [298, 299].

The role of macrophages in the control HSV infection consists mainly in the phagocytosis of virion and infected cells apoptotic bodies that are recognized by receptors or through the presence of opsonines, such as specific fractions of complement or specific antibodies. Phagocytosis of infected cells apoptotic bodies is important for three main reasons: (1) to inhibit or restrict HSV infection, (2) to prevent undesirable inflammatory responses and (3) to initiate specific immune responses. In this regard, macrophages can function as APC. The complement system fulfils multiple functions, including the recognition of infected cells and communication with and activation of adaptive immunity [300]. All the complement cascades culminate in the central cleavage of $\mathrm{C} 3$ and in the generation of its active fragments $\mathrm{C} 3 \mathrm{a}$ and $\mathrm{C} 3 \mathrm{~b}$. Opsonization of virions or infected cells by covalently attached $\mathrm{C} 3 \mathrm{~b}$ favours their phagocytosis, amplification of complement activation and assembly of the C5 convertase. Cleavage of C5 induces the formation of multiprotein pore complex (the membraneattack complex (MAC), which leads to cell lysis. NK cells require activation by type I interferons or proinflammatories cytokines, such as IL-12, IL-15 and IL-18, before becoming fully functional effector cells. In many situations, DCs are the main source of the type I interferon and IL-12 that is necessary for NK-cells activation, and in turn IFN- $\gamma$ produced by NK cells can affect the maturation and effector functions of DCs, as well as other leukocytes that are responding to the infection [301]. NK cells contribute to host defence against HSV infection by their ability to rapidly secrete cytokines and chemokines, as well as to directly kill HSV-infected host cells. However, it remains unclear whether there is cognate recognition of the HSV-1 infected cells by NK cells or whether the effect of HSV-1 on NK cells are an indirect result of high-level production of type I
IFN and other cytokines that is induced by HSV infection. There are no reports of any viral proteins encoded by HSV that preferentially modulate or function as decoys or ligands of known NK-cell receptors. iNKT cells are restricted to the monomorpic MHC class-I-like molecule CD1d for foreign and self-glycolipid antigens [284]. NKT cells are involved in the innate response to HSV in mice [302]. Recent studies confirmed the predominant role of NKT cells in controlling early viral replication and in determining mortality, neuroinvasion, loss of sensory neurons, lesions and level of latency [303]. Type 1 interferons are produced in two distinct ways: (1) by infected cell detecting components of virus replication within them, and (2) by innate immune cells detecting the presence of viruses through TLRs. Plasmacytoid dendritic cells are the principal producers of type 1 interferons, in particular IFN- $\alpha$. Type 2 interferon which is produced early after infection by NK cells and later by $\mathrm{CD} 4^{+}$cells has been shown to be a crucial cytokine for the control of HSV infection. Apoptosis is initially triggered and subsequently blocked during a wt HSV-1 infection. Proapoptotic factors include the viral ICP0 gene transcript [304] and as yet unknown viral or cellular facilitator proteins. Seven viral gene products and two cellular proteins have been proposed to act in the prevention of apoptosis during infections [295, 297]. Together, these signals set up an apoptotic balance, which presumably delay cell death, until progeny virions are produced [297]. Autophagy is a process required for $\mathrm{HSV}-1$ virion degradation and protect against CNS viral disease [305]. Furthermore, autophagy has been shown to enhance the presentation of endogenous viral antigens on MHC class 1 molecules during HSV-1 infection [299]. HSV activates innate immunity through both TLRdependent and TLR-independent mechanisms [292, 306, 307].

The HSV TLR-dependent response entails TLR2, TLR3, TLR2/TLR6 heterodimer, TLR8 and TLR9. Viral or host glycoproteins/lipopeptides responsible for TLR2 agonist activity are currently unknown. In this regard, it has been reported that fragments of $\mathrm{gD}$ can induce an IFN- $\alpha$ response, implying that $\mathrm{gD}$ could interact with TLRs [308]. It has been found that glycoprotein-dependent and TLR2-indipendent innate immune recognition evokes a set of proinflammatory cytokines such as: TNF- $\alpha$, IL-1 $\beta$ [309]. TLR2 recognition may be particularly important during HSV-1 encephalitis, as microglia strongly express TLR2 [309, 310]. Recently, it has been shown that the complex of the four glycoproteins $\mathrm{gB}$, $\mathrm{gD}, \mathrm{gH}$ and $\mathrm{gL}$, which are essential for viral attachment/entry (Fig. 2), expressed on the surface of Cos7 cells mediates monocyte-derived DC recognition via a nucleic acid-independent and TLR-independent pathway, leading to the up-regulation of CD40, CD83, CD86 and HLA-DR and to the production of IFN- $\alpha$ and IL-10, but not IL-12p70 [311]. TLR3, TLR8 and TLR9 are recognized by virus-derived double stranded RNA (poly-I:C), virus-derived single stranded RNA (ssRNA) and unmethylated CpG motifs, respectively. TLR3 seems to be the dominant TLR involved in recognition of $\mathrm{HSV}-1$, and patients with dominant-negative TLR3 mutations were recently found to be highly susceptible to herpes simplex encephalitis (HSE) [312]. This result does suggest that dsRNA detection is a critical step in innate recognition of HSV-1 infection implicating TLR3 which is expressed in human neurons, 
microglia, and astrocytes [313]. It has also been found that TLR2 and TLR9 can act in synergy to induce an early cytokine response, thereby restricting viral load in the brain [265]. An accumulating body of evidence has demonstrated that in addition to the membrane-bound type DNA-sensing receptor TLR9, there are cytosolic DNA receptors that can also evoke these response [314]. In this regard, it has been observed that HSV-1 induces IFN- $\alpha$ production via TLR9dependent and-independent pathways [306].

The multiplicity of TLRs detecting HSV infection necessitates a robust ability of the virus to effectively block multiple innate signalling pathways to survive and, in the case of viral vectors, to be effective. Therapeutically delivered HSV-based vectors may contain elements that stimulate these responses; depending on the application, this may or may not be desirable.

\subsection{Adaptive Immunity}

In contrast to an innate response, adaptive responses are mediated by immune cells specific for an antigen. The clonal selection of lymphocytes gives the immune system the capacity to recognize and have memory for specific pathogens and to mount a rapid and potent response against subsequent attacks from that pathogen. Antigen-presenting cells (APCs), such as DCs, take up pathogens, become activated and migrate to lymphnodes where they interact with $\mathrm{T}$ cells and differentiate into $\mathrm{T}$ cells helper type 1 (Th1) or $\mathrm{T}$ cells helper type 2 (Th2). Th1 responses rely on the presence of the cytokines IFN- $\gamma$ and IL-1, whereas Th2 responses occur in presence of IL-4 and IL-10. Typically, the Th2 pathway will elicit a humoral response characteristically producing antibodies of IgG1 isotype and are not inflammatory in nature. Alternatively, responses that proceed down to Th1 pathway typically produce antibodies of $\operatorname{IgG} 2 \mathrm{~b}$ isotype, and activate cytotoxic T cell lymphocytes (CTLs) and a host of proinflammatory cytokines.

\subsection{HSV Immune-Evasion Strategies}

Different studies identified several HSV-encoded mechanisms which interfere with antiviral host innate and adaptive immunity including: (1) nonspecific degradation of host mRNA by the RNAse vhs [315]; (2) block of DC activation. It has been demonstrated, for the first time, that vhs can block the induction of DC activation by TLRindependent pathways [316]; (3) inhibition of PKR by US11 [317] and $\gamma-34.5$ [226]; (4) defective CD1d recycling from the endosome to the cell surface. HSV has developed an immune-evasion strategy that impair CD1d-mediated antigen presentation, suggesting a role for NKT cells in antiviral response [318]; (5) inhibition of MHC-I peptide loading by ICP47, thus disabling CTLs from recognizing cell infected with HSV [319]; (6) suppression of interferon response and TLR-dependent inflammatory response by ICP0 [320, 321]; (7) inhibition of apoptosis and interferon. In HSV-1, antiapoptotic activity has been assigned to immediate-early proteins ICP4, ICP27, US3, ICP22, gD, and others [295, 297], whereas ICP0 was found to be necessary (and sufficient) to induce the initial apoptosis induction event associated with HSV-1 infection [304]. Granzyme B or Fas caspase-activation and apoptosis have been shown to be inhibited by gJ [322]. The latency-associated transcript (LAT) has been also shown to inhibit apoptosis and promote neuronal survival [323, 324]; (8) inhibition of autophagy by ICP34.5 [21, 325]. It has been recently reported that $\gamma-34.5$ is involved in the inhibition of autophagy through the inhibition of Beclin 1, a critical factor involved in this pathway [21]; (9) evasion of immunity mediated by antibody and complement. Glycoprotein $\mathrm{C}$ binds complement component $\mathrm{C} 3 \mathrm{~b}$, preventing the activation of the complement cascade [326]; while glycoproteins E and I form a highaffinity receptor that binds the $\mathrm{Fc}$ region of immunoglobulin $\mathrm{G}$ (IgG) inhibiting complement activation and antibodydependent cellular cytotoxicity [327]. Recently, it has been shown that $\mathrm{gC}$ and $\mathrm{gE}$ can block antibody access to neutralizing domains on glycoproteins involved in entry as a novel mechanism of immune evasion by HSV-1 [328].

Taken together these data suggest that HSV evasion of innate and adaptive immunity is multifactorial and complex, and relies on the partially redundant activities of various HSV proteins. Reviewing these viral strategies of HSV immune evasion is important to understand whether their inclusion within an HSV vector system would be beneficial or detrimental to a particular application.

\section{Effect of Innate and Adaptive Immunity on Vector Efficacy}

HSV1-based vector are particularly amenable to gene therapy applications within the CNS. Because aspects of the innate immune response to $\mathrm{HSV}-1$ vectors in CNS are largely unknown, it is important to develop new tools for such studies. In this regards, Zeier and colleagues [329] have recently compared the host response of a replicationdefective HSV-1 vector to that of a replication-competent HSV-1 using microarray analysis. Pathway analysis revealed that both the replicating and nonreplicating vectors induced robust antigen presentation but only mild interferon, chemokine, and cytokine signalling responses. The ICP4 deleted replication-defective vector was restricted in several of the TLR receptor-signalling pathways, indicating reduced stimulation of innate immune response. These array analyses suggest that although the replication-defective vector induces detectable activation of immune response pathway, the number and magnitude of the induced response is dramatically restricted compared to the replicating vector and with the exception of antigen presentation, host gene expression induced by nonreplicating vector resembles mock infection.

Innate immunity is critically important in limiting wt viral infections and in the context of HSV oncolytic therapy, this branch of the immune system appears to be a potent obstacle for achieving oncolytic vector replication and tumour destruction [330]. In this regard, drugs that inhibit innate immune response have been shown to enhance glioma virotherapy [235]. Moreover, both the antitumor efficacies as well as the intratumoral viral titers were found to be significantly increased with the concurrent depletion of mononuclear cells and the elimination of antiviral cytokines [235].

Following activation of innate immunity, the adaptive component of the immune system is recruited to the site of infection and participates in both the killing of virally infected cells and the production of antibodies against foreign antigens. The induction of an immune response 
against antiviral products can represent the major problem and may reduce the effectiveness of HSV-1-derived vectors. In fact, immune responses arising from the delivery of recombinant HSV vectors can be due to several factors, such as: viral particles components copurified packaging cell debris, different routes of delivery, multiple injections of the vectors, low-level de novo viral gene product expression. As a consequence of this last aspect, replication-defective vectors may contains ORFs that are expressed at low levels even in the absence of immediate-early gene products, augmenting the potential for antigen processing and subsequent MHC class I presentation.

HSV-based vectors have been used in a variety of diverse applications including gene transfer for gene therapy, as oncolytic viruses, or as a vaccination platform. In the case of gene transfer, an immune response against the vector or the transgene would be detrimental to sustained transgene expression, weakening the efficiency of the therapy. Targeted oncolytic viruses must replicate in and destroy cancer cells selectively enhancing, at the same time, tumourspecific immunity. Alternatively, when using HSV as a vaccination platform the preferred outcome is a directed immune response to the transgene. The desired results of different applications in gene therapy might be opposites and would require different strategies in constructing HSV-based vectors.

To prolong the effect of transgenes expressed from viral vectors in gene transfer therapy, it has been shown that treatment with cyclosporine A can reduce the inflammatory response to a HSV vector leading to improved transgene expression [331], while immunomodulative treatment with Linomide seems to facilitates the spread and expression of ICP34.5-negative vector in CNS [332].

In oncolytic virotherapy, CTLs have been implicated as the critical responders to viral antigens presented on the surface of tumour cells. CTLs are subsequently redirected to tumour cell antigens, thereby enhancing the efficacy of oncolytic HSV-1 by inducing antitumor immunity [144, 333]. In this regard, the inclusion of genes encoding for various cytokines into viral vectors to enhance antitumor immune responses has been also tested and found to be beneficial in several preclinical models of cancer [204, 206]. As a further improvement in oncolytic virotherapy, it has been observed that apoptotic bodies produced upon viral infection and their subsequent engulfment by APCs can potentiate cytotoxic $\mathrm{T}$ lymphocyte activity and the antitumour response. The potential to exploit this in conjunction with OV therapy to enhance anti-tumour immunity is only beginning to be realized and needs to be further investigated [330].

ICP34.5-deleted HSV vectors have been extensively used both in gene transfer therapy and in oncolytic virotherapy. However, immune response to these vectors has not been thoroughly elucidated. It has shown that infection with ICP34.5-deleted HSV vectors results in alterations in splenocyte subsets and cytokine expression [334]. The viruses carrying IL-4 or IL-10 transgenes or even the ICP34.5-deleted HSV vectors without transgenes have been shown to induce Th2 type cytokine response, whereas the wt HSV-1 induces Th1 type cytokine response in immunological cell populations. However, in the CNS the cytokine expression was more variable [334]. Moreover, it has been reported that virus R8306, expressing IL-4 transgene suppressed IFN- $\gamma$ and induced IL-23 expression during the acute infection but decreased its expression during the later time points. Furthermore, R8308 virus without transgenes or R8308 with IL-10 transgene induced IFN- $\gamma$ as well as IL-23 responses in the brain. The virus R3616 with the deletion of both ICP34.5 genes causes differences in the splenocyte subsets in comparison to the wild-type infection, inducing a stronger proliferation of CD4+ and CD8+T cells, as well as of the CD11c+ antigen presenting cells [334]. This indicate an additional role of ICP34.5 as to those already observed, such as immune evasion and inhibition of the host interferon response [335, 336]. The immune responses evoked by the ICP34.5-deleted vectors used in the clinical cancer therapies (G207, 1716, NV1020 and OncoVex) have not been reported and can therefore not yet be compared with the reported results. The immunological reactions due to the HSV vector are needed to be studied in more detail. The specific Th1 or Th2 type cytokine responses can be used to benefit the therapy. The ICP34.5-deleted HSV vectors are excellent basis and platform for the development of even more attenuated and safe vectors, such as to avoid some of the risk factors described above.

Concerning the use of viral vector as vaccines, numerous strategies have attempted to influence or direct the immune response toward either a Th1 type or Th2 type; the presence of particular cytokines is one way to accomplish this goal. The presence of IFN- $\gamma$ and IL-1 will push the development of a Th1-type response. This type of response is useful when cellular immunity and inflammation are desired. The presence of IL-4 and IL-10 will skew a response toward the Th2 type. These cytokines bring about a strong humoral response, avoiding the often unnecessary, and dangerous, inflammation and presence of CTLs. The preferred cytokine gene can be inserted into the HSV-based vector, allowing for its coexpression with the antigen of interest, increasing the likelihood that a particular response is established. Another consideration when attempting to direct an adaptive response is the choice of transgene within the vector, since whole gene products may contain several different epitopes, which can be $\mathrm{T}$ or $\mathrm{B}$ cell epitopes. Expressing only a portion of an antigen of interest, including a specific epitope, or coexpressing an epitope that is a strong inducer of a known response type, can push the response toward one that is more humoral or cellular in nature.

\subsection{Effect of Pre-Existing Adaptive Anti HSV Immunity on Vector Efficacy}

The main aspect of adaptive immunity that should be taken into consideration when using HSV vectors in different gene therapy strategies is due to the presence of anti HSV antibodies in a high percentage of the population. It is conceivable that these antibodies may interfere with HSVbased vectors either by directly neutralizing the infectivity of viral vector particles or else by triggering the rapid clearance of vector-transduced cells.

The effect of pre-existing immunity on HSV-1 vectors delivery has been extensively studied using oncolytic virus recombinants. It has been shown that pre-existing immunity to HSV-1 does not seem to affect oncolytic HSV-1 therapy when the virus is administered intraneoplastically [337]. 
Further, the presence of neutralizing antibodies and cell mediated immunity to HSV-1 did not alter the efficacy of an oncolytic HSV-1 after intraportal administration to mice with diffuse liver metastases [242]. Moreover, multiple injections can be applied without being affected by immune resistance to the viral vector [279]. Even though these results are encouraging, the impact of pre-existing immunity on HSV-1 cancer gene therapy and virotherapy still needs to be carefully evaluated by further studies. More research in laboratory and in clinics would be required to address all these issues.

Concerning the effect of pre-existing immunity on HSV vectors used as vaccine tools, Brockman and colleagues [98] have shown that cellular and humoral immune responses to a model antigen ( $E$. coli $\beta$-galactosidase), encoded by a replication-defective HSV-1 vector (deleted in the gene encoding ICP8), were unaffected by pre-existing immunity in mice, when the vaccine was delivered via the subcutaneous route [98]. On the contrary, in a more recent study it was shown that humoral as well as cellular immune responses against a different model antigen (ovalbumin) encoded by the vaccine were strongly diminished in HSV-1seropositive mice. This inhibition could be observed in mice infected with wild-type HSV-1 or with a replicationdefective vector. Although these data clearly indicate that pre-existing antiviral host immunity impairs the efficacy of HSV-1-derived vaccine vectors, they also show that vaccination under these constraints might still be feasible [338].

\subsection{Strategies to Protect HSV Vector from Host Immunity:} The Trojan Horse

Oncolytic viruses can be efficiently neutralized by antiviral antibodies in the blood stream or sequestered by phagocytic cells in the liver and spleen, and they often fail to extravasate and migrate in tumour deposits or in the tissue to which tumour metastasize. As an alternative to the administration of naked viruses, virus-infected carrier cells are currently under investigation as vehicles ("Trojan horse") to deliver oncolytic viruses more reliably, uniformly and efficiently to sites of tumour growth in the body even in virus-immune individuals [339]. The enhanced delivery of viruses by carrier cells is a current development that has been addressed in only a small number of studies, according to the cell type utilized for virus delivery: tumour cells, mesenchymal progenitor cells, neuronal stem cells, T-cells, monocyte/dendritic cells or endothelial progenitor cells. Coukos and colleagues [340] conducted the first study on cell carrier-mediated oncolytic virus delivery in which a human teratocarcinoma cell line was infected with an oncolytic HSV, for the intraperitoneal therapy of epithelial ovarian cancer (EOC). In this study, it was reported that the oncolytic effect of HSV1716 was enhanced by the utilization of the carrier cell line.

\section{The Complexity of the Tumour Mass}

Targeted virotherapy has emerged as an effective and potent strategy for the fight against cancer. However, clinical trials have demonstrated that therapeutic benefit in response to oncolytic virotherapy has been limited [146, 341]. These trials suggest that the virus failed to distribute throughout the tumour mass. Long-term viral persistence in the tumour tissue without tumour eradication suggests that viral spread is the limiting factor and that a barrier mechanism exists within the tumour tissue to hinder spread. Tumour tissue extracellular matrix (ECM) is a major barrier for transport of macromolecules. Tumour ECM is characterized by a complex network composed of elastic fibers and collagen interdispersed with glycosaminoglycans and proteoglicans, which form a fluid-saturated gel-like medium. Because of the presence of the tumour ECM, a number of highmolecular-weight agents, including viral vectors, fail to penetrate the tumour tissue and exhibit limited therapeutic effectiveness [342].

Several strategies have been developed to enhance oncolytic HSV spread through ECM, among them the use/expression of enzymes that can degrade tumour ECM, or viral induced apoptosis inside tumour ECM.

\section{Enzyme Treatment or Expression}

It has been recently demonstrated that degradation of the fibrillar collagen network by collagenase, in a human melanoma xenograft, favours the regression of tumour vasculature and improves the distribution and the efficacy of oncolytic HSV in tumour tissue [343]. Successively, it has been shown that human matrix metalloproteinases- 1 and -8 (MMP-1 or MMP-8), which degrade fibrillar collagens, proteoglycans, and other structural matrix components, enhance efficacy of oncolytic HSV therapy [344]. Therefore, intratumoral expression of MMPs seems to be a promising strategy for improving viral spread and therapeutic potential of oncolytic viruses by modulation of tumour ECM.

However, some concerns about strategies that cause degradation of ECM exist. While degradation of ECM with enzymes, such as collagenase and MMPs, may improve viral penetration and distribution, on the other hand may also increase tumour spread. In fact, MMPs and collagenase have been shown to play an important role in tumour invasion and metastasis [345]. Even if, there is also some emerging evidence that MMP-8 does not promote tumorigenesis or metastasis and may be antimetastatic [346]. Therefore, further thorough and detailed studies are required to gain an improved understanding of the potential risk associated with combined replicating oncolytic virus and ECM-degrading enzyme.

\section{Viral-Induced Apoptosis}

Induction of apoptosis in the tumour mass can facilitate the release and distribution of viruses. Interestingly, apoptosis induced during viral DNA replication seems to compromise viral production, whereas apoptosis induced after virion assembly enhances viral release and dissemination from infected cells [297, 347]. Apoptosis is significantly elevated in tumour tissue treated with oncolytic viruses and chemotherapeutics, as chemotherapy-induced cell death occurs mainly by the apoptotic pathway. Therefore, tumour cell apoptosis could be at the basis of the strong synergy observed between oncolytic HSV with various chemotherapeutics [348]. As it has been described above, interstitial collagen fibers and the narrow spacing ( $20 \mathrm{~nm}$ ) between cancer cells are major barriers hindering the movement of large viral particles and limit the success of oncolytic virotherapy. The void space produced by cancer 
cell apoptosis might enhance the initial spread and efficacy of oncolytic HSV. At this regard, it has been reported that Paclitaxel plus TRAIL pretreatment, two inducing agents of apoptosis, enhances oncolytic HSV intratumoral delivery/ penetration and antitumor efficacy [349]. These observations emphasize the important relationship between induction of the apoptotic pathway and viral spread in solid-tumour tissue. The formation of apoptotic bodies, a morphological characteristic of apoptosis, can also facilitate the dispersal of viral particles throughout the tumour mass. Apoptotic bodies can also be rapidly phagocytosed by neighbouring cells, such as macrophages and tumour cells, and disperse the virus throughout the intercellular spaces. Viral dissemination through apoptotic bodies may be one of the major contributors for the synergistic therapeutic effect of oncolytic virotherapy and chemotherapy.

\section{How to Investigate Viral Spread Inside Tumour ECM}

Viral spread within the tumour mass cannot be investigated using conventional monolayer cell cultures, because these models poorly mimic the solid tumour microenvironment. An alternative is multicellular tumour spheroids (MTSs), which have gained in importance as an in vitro model of solid tumours [350]. The 3-dimensional (D) MTSs are intermediate in complexity between standard 2-D monolayer cultures in vitro and tumour tissues in vivo. They consist entirely of tumour cells and therefore fall to represent the native 3-D architecture and heterogeneity of solid tumours in vivo. As an example, glioblastoma (GBM) biopsy material obtained at surgery, has been cultured in the form of multicellular spheroids, where the essential phenotypic characteristics of the tumour tissue are retained [351]. Direct transplantation of such "organotypic" spheroids into rodent brains forms lesions that eventually recapitulate all the histopathological infiltration, angiogenesis, endothelial proliferations and dilated, thrombotic vessels [352]. The effect of oncolytic G207 virus, currently used in clinical therapy, has been assessed on a set of xenograft phenotypes that follow these biological features described above [347]. The study highlights the favourable cellular responses to G207 treatment seen from a clinical viewpoint, such as reduced tumour cell proliferation, more frequent events of tumour cell death, and a strongly attenuated tumour vascular compartment. However, these beneficial changes were only observed in areas of active viral replication, leaving nontransduced tumour tissues unaffected.

\section{NEW PERSPECTIVES IN TUMOUR ONCOLYTIC VIROTHERAPY}

\section{Oncolytic Virotherapy for the Cancer Stem Cells}

From a variety of malignancies, investigators have identified a subpopulation of cells, which are capable of initiating and sustaining tumour growth in vivo [347, 353]. These cells, which have been called "tumour initiating", "cancer stem cells (CSCs)" or "cancer stem-like cells", were found to possess characteristics of adult organ stem cells such as self-renewal and multilineage differentiation, implicating a transformed stem cell as the cell of tumour origin. The indication that there are distinctive subpopulations of cells within tumours with stem-like properties has led the investigators to identify a variety of cell-surface markers that can be used to isolate and study these cells. Recent discoveries indicate that CSCs embody chemo- and radioresistance and have been correlated with advanced disease and resistance to current therapies, and thus help explain the treatment resistance of many cancers. There also seems to be a direct link between epithelialmesenchimal transition phenomena and CSCs. Cancer cure is predicated upon effectively targeting and eradicating the CSC population. Oncolytic viruses have undergone many developments and through multiple generations offer an effective way to specifically target and eradicate CSCs, while still maintaining the ability to affect the general tumour cell population [354]. Recent studies have explored the activity of oncolytic adenovirus against CSCs derived from breast cancer [355] and brain tumours [356]. Recently, Wakimoto and colleagues [357] have reported a novel therapeutic strategy for glioblastoma-derived cancer stemlike cells (GBM-SCs) using oncolytic HSV-1. The authors have shown, for the first time, the efficacy of oncolytic HSV against GBM-SCs and correlate this cytotoxic property with specific oncolytic HSV mutations. Moreover, the new glioma models, derived from neurospheres enriched for GBM-CD133 positive SCs that very efficiently formed highly invasive and/or vascular tumours upon intracerebral implantation into immunodeficient mice, provide powerful tools for testing experimental therapeutics and studying invasion and angiogenesis

\section{MicroRNA in Oncolytic Virotherapy}

A key issue in developing a safe and effective oncolytic virotherapy is the achievement of maximal killing of tumour cells while maintaining tumour specificity of viral targeting. In this regard, HSV oncolytic vectors have been developed where different cancer-specific promoters were incorporated in front of an essential viral gene to achieve selective viral replication (in) and specific killing of cancer cells [139, 234, $249,266]$. However, nonspecific toxicity to normal tissue due to leaky promoters has remained a problems [358, 359] and suggests that improved stringency of oncolytic viral targeting needs to be developed. One approach to achieve this is to take advantage of unique tissue-associated patterns of expression of microRNAs (miRNA). Differential miRNA expression profile between normal and cancer cells have been shown by microarray analysis of clinical samples and several miRNA signatures within the genome have been proven to be promising biomarkers for prognosis and diagnosis of cancers [360, 361]. Recent studies have also shown that some miRNA are overexpressed and some are down-regulated in several cancer cells compared with their normal tissue of origin, suggesting that these miRNA may play a role as oncogenes or tumour suppressor in the tumourigenesis of various human cancer [362, 363]. These observations represent an important step toward the potential application of miRNA-based virotherapy for the treatment of cancer [364]. There are possibly two different strategies that can be used to target cancer by miRNA. The first, is to take advantage of the differential miRNA expression between cancer and non-neoplastic tissue. In this regard, Lee CY and co workers [365], have demonstrated that inclusion of specific miRNA target sequence into the 3'-UTR of an essential HSV-1 gene is a viable strategy for restricting viral replication and oncolysis to cancer cells while sparing normal tissue. Using this strategy, it is possible to further 
A

\section{Days}
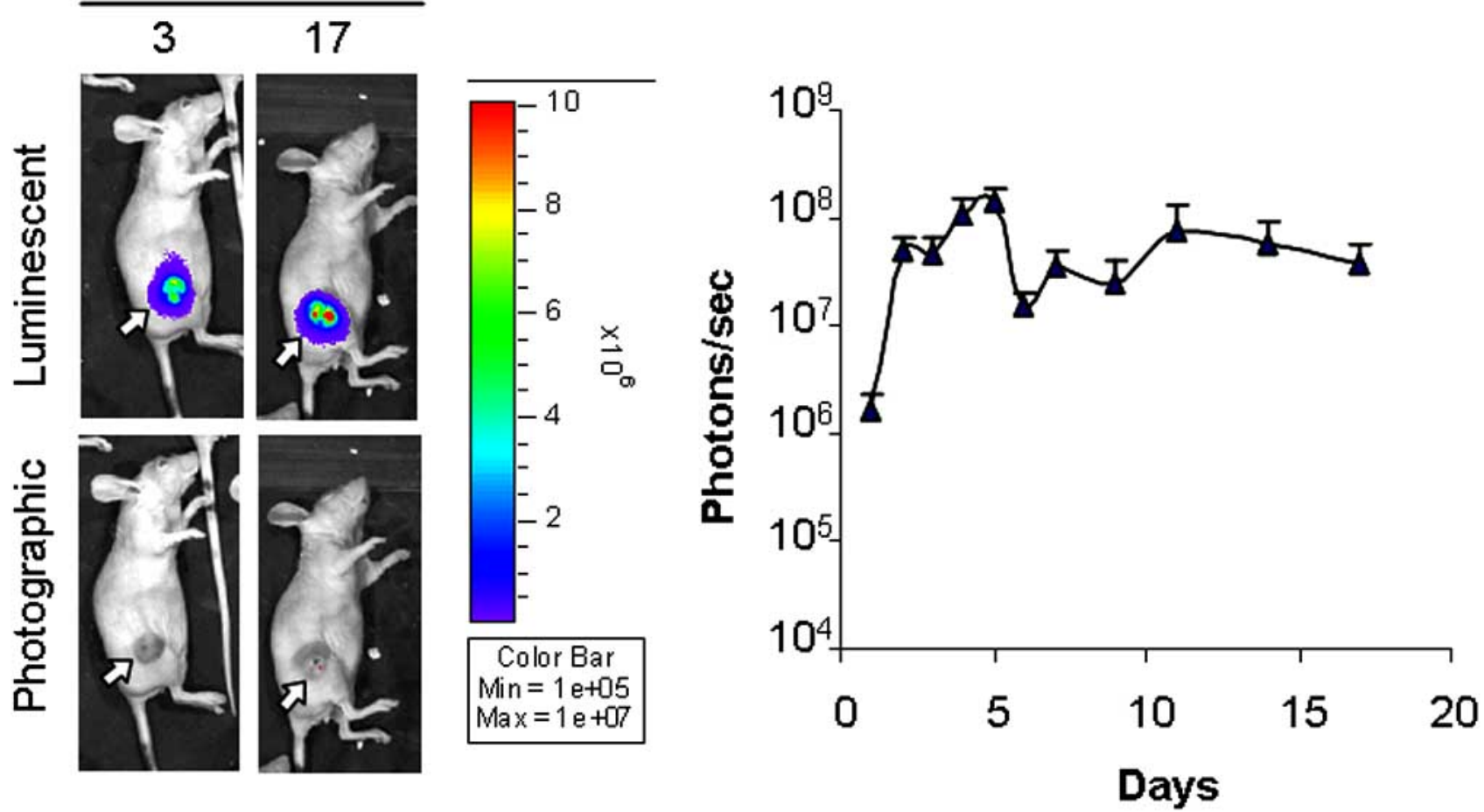

Fig. (3). Monitoring of virus transduction in a model of subcutaneous hepatocellular carcinoma (HCC) [367]. To follow HSV-1 C-gal-Luc strain replication in the tumour mass the virus was inoculated into the experimental tumour, developed on the right flank of athymic mice, and localization and intensity of luciferase expression was monitored by in vivo bioluminescence imaging. (A) Overlay luminescent/photographic and photographic images of a representative animal at 3 and 17 days post-infection. The arrows indicate the location of tumours. Intensity of light emission is represented by an artificial colour code normalized to allow comparison of different acquisitions. The maximum (red) and minimum (blue) correspond to $10^{7}$ and $10^{5}$ photons/s, respectively. (B) Quantification of luciferase activity over time. The average light emission in photons $/ \mathrm{s}(\mathrm{n}=7)$ is reported.

enhance tumour specificity and to improve regulation of oncolytic viral replication by increasing the copy number of miRNA target sequences. In addition, target sequences of more than one miRNa species can be incorporated into $3^{\prime}$ UTR because miRNA expression patterns differ across normal tissue of different origins. Through synergistic effects of various regulatory elements in the promoter 5'UTR or 3'UTR stringent regulation of viral gene expression and viral replication will be possible to develop a highly effective and tumour-specific virotherapy for cancer treatment.

The second strategy to target cancer by miRNA is to modify the expression of few deregulated miRNA in tumours using non-lytic viral vectors for miRNA replacement or inhibition. Most therapeutically useful miRNAs seem to be expressed at low levels in tumours but are highly expressed, and therefore tolerated, in normal tissue. In an elegant study, Kota and colleagues [366] have demonstrated that hepatocellular carcinomas (HCC) exhibit reduced expression of miR-26a, a miRNA that is normally expressed at high level in diverse tissue. Systemic administration of this miRNA in a mouse model of HCC using adeno-associated virus (AAV) results in inhibition of cancer cell proliferation, induction of tumour-specific apoptosis, and dramatic protection from disease progression without toxicity. These findings suggest that delivery of miRNA that are highly expressed and therefore tolerated in normal tissue but lost in disease cells may provide a general strategy for miRNA replacement therapy. HSV vectors, such as amplicon, could be used in these last described experimental studies.

\section{CONCLUSION}

Herpes simplex virus-based vectors for gene therapy exist in three forms: amplicons, replication-defective vectors and replication-competent vectors. This review focuses on the progress using replication-defective and replicationcompetent HSVs. Replication-defective vectors have reached a developmental stage that has completely eliminated toxicity, and these vectors are therefore safe for the target cells, even when infected at high multiplicities. Furthermore, these vectors have proven suitable and powerful tools for different types of experimental gene therapy settings in small animals, as well as for studies of neural functions, as it is shown in Table 1. However some difficulties that still remain to be resolved in many cases, account for the fact that these vectors are only now reaching the clinics for neurological 
disorders. For the first time, a defective recombinant vector (NP2) expressing preproenkephalin is now moving into a clinical trial to treat pain due to malignancy.

Replication-defective and replication-competent HSV vectors for vaccination have been extensively studies in preclinical models but none of them have reached the clinical phase due to the possibility of adverse effects. Both vector types have been used for vaccination against HSV or for other viral infections, following accommodation of heterologous genes into the HSV genome backbone (Table 2). While replication-competent HSV vectors are advantageous in many applications for their persistence, replication-defective vectors may also induce a durable immune response. The efficacy of either vector might potentially be affected by the pre-existing immunity to HSV viral antigens in the host. Live attenuated HSV vaccines compared to replication-defective vectors have many clear advantages for two reasons: (1) they provide a vehicle for complete presentation of all viral antigens to the host's immune system, stimulating both humoral and cell-mediated immune responses and (2) can be efficiently propagated with ease in cell cultures and are therefore extremely costeffective vaccines. However, it is important that in the construction of HSV vectors for vaccination should be taken into account the presence of those viral genes whose expression favours the immune evasion of the virus. The ideal vector has to be rationally designed by removing the genes that allow HSV to avoid the immune system. Whether these vectors will prove to be more effective in combination with cytokine adjuvants, to redirect the immune response to the desired phenotype, or booster immunizations with other vectors or the appropriate subunit antigen will await future studies.

While antitumor strategies using replication-defective HSV-1 vectors to deliver therapeutic transgenes have yielded encouraging results, the fasting growing area in HSV-1 vector-mediated cancer treatment lays with replicationcompetent HSV-1 oncolytic viruses. HSV vector delivery to tumour cells is a challenge because of three major obstacles: inadequate penetration in tumour interstitial space; significant uptake of HSV vectors in normal organ; and host immune response to HSV vector. These problems common to all HSV vectors, have not been solved completely although they can be reduced using the strategies discussed above. These strategies can be used alone or in different combinations, depending on the method of administration and the type of tumours. In the future the challenge is to refine what has been developed since now or to acquire new strategies for overcoming the difficulties encountered in defeating cancer. Improving HSV vectors can follow several directions in order to: (1) enhance the distribution of viral vectors in tumour tissue; (2) develop novel devices that can reduce the dissemination of viral vectors in healthy tissues; (3) search and design new viral vectors that can target unique markers either on tumour cell membranes, on extracellular matrix, or in the microenvironment; (4) search and design new HSV vectors that can be activated selectively in tumours; (5) engineer the genome of HSV so the vectors will have the balanced (appropriate) immunogenic potential and plasma half-life for the different therapeutic strategies; (6) combine the HSV oncolytic potential with administration of cutting-edge molecular targeted medicines; (7) develop novel devices, such as virus-infected cells as a Trojan horse vehicle, to evade antiviral mechanism encountered in the bloodstream, prevent uptake by off-target tissues, and act as microscale factories to produce oncolytic HSV upon arrival in tumour beds; (8) develop new animal models that closely mimic that peculiar disease; (9) get advantage from the recent studies on microRNAs; (10) attack tumour stem cells by engineering oncolytic HSV due to the fact that cancer stem cells possess enhanced tumour-forming capability and are resistant to current anticancer therapies.

It is believed that research in these directions will lead to the development of new technologies and vectors that can improve efficacy and reduce toxicity in HSV-based tumour therapy, yielding oncolytic vectors to be used in clinical trials.

The findings reported in this review demonstrate the importance of understanding basic virology in the design of vector system and the powerful approach of exploiting favourable properties of the parent virus in generation of HSV vectors for gene therapy. Most of the studies have revealed a complex set of interaction between HSV and host, which underlie the mechanism responsible for the journey of the virus from initial epithelium attachment, entry and lytic infection, to latent infection in sensory ganglia, and subsequent reactivation. Each of these properties has to be exploited in different way for the generation of HSV vectors with therapeutic application as diverse as neurological diseases, cancer and vaccine. A great understanding of the mechanism of the host immune responses by HSV vectors is essential for the development of next generation safe gene therapy HSV vectors. The different layers of protection that are targeted by HSV immune evasive strategies necessitate to be extensively studied to find ways in which HSV vectors, for the different branches of gene therapy, can be designed and administered. On the other side, there is the need to continue to gain information concerning genetic structure, function and mechanisms underlying human diseases. Our ability to use these information for clinical applications will determine if the technology described here eventually becomes established in clinical practice.

\section{ACKNOWLEDGEMENTS}

The assistance of Dott. Marco Manservigi for Fig. 2 drawing, and Mrs. Annalisa Peverati for technical issues are acknowledged. This work was supported by: UE contract HEVAR "INCO-CT-2006-032209" R. MANSERVIGI; UE contract THOVLEN "LSHB-CT-2005-018649" R. MANSERVIGI; PRIN 2007 R. MANSERVIGI; PRIN 2007 P. MARCONI.

\section{REFERENCES}

[1] Roizman B, Knipe DM, Whitley RJ. In: Knipe DM, Howley PM, Eds. Fields Virology. 5th ed. Philadelphia, PA, Lippincot, Williams and Wilkins, a Wolters Kluwer Business 2007; 2501-601.

[2] Nicola AV, Straus SE. Cellular and viral requirements for rapid endocytic entry of herpes simplex virus. J Virol 2004; 78: 7508-17.

[3] Satoh T, Arii J, Suenaga T, et al. PILRalpha is a herpes simplex virus-1 entry coreceptor that associates with glycoprotein B. Cell 2008; 132: 935-44.

[4] Subramanian RP, Geraghty RJ. Herpes simplex virus type 1 mediates fusion through a hemifusion intermediate by sequential activity of glycoproteins D, H, L, and B. Proc Natl Acad Sci USA 2007; 104: 2903-8. 
[5] Jardetzky TS, Lamb RA. Virology: a class act. Nature 2004; 427: 307-8.

[6] Chernomordik LV, Kozlov MM. Membrane hemifusion: crossing a chasm in two leaps. Cell 2005; 123: 375-82.

[7] Bender FC, Whitbeck JC, Ponce de Leon M, et al. Specific association of glycoprotein B with lipid rafts during herpes simplex virus entry. J Virol 2003; 77: 9542-52.

[8] Hannah BP, Cairns TM, Bender FC, et al. Herpes simplex virus glycoprotein B associates with target membranes via its fusion loops. J Virol 2009; 83: 6825-36.

[9] Diefenbach RJ, Miranda-Saksena M, Douglas MW, Cunningham AL. Transport and egress of herpes simplex virus in neurons. Rev Med Virol 2008; 18: 35-51.

[10] Itzhaki RF, Wozniak MA. Herpes simplex virus type 1 in Alzheimer's disease: the enemy within. J Alzheimers Dis 2008; 13: 393-405.

[11] Wang J, Fan Q, Satoh T, et al. Binding of herpes simplex virus glycoprotein $\mathrm{B}(\mathrm{gB})$ to PILR \{alpha\} depends on specific sialylated O-linked glycans on gB. J Virol 2009; 83(24): 13042-5.

[12] Fan Q, Lin E, Satoh T, Arase H, Spear PG. Differential effects on cell fusion activity of mutations in herpes simplex virus 1 glycoprotein $\mathrm{B}(\mathrm{gB})$ dependent on whether a $\mathrm{gD}$ receptor or a $\mathrm{gB}$ receptor is overexpressed. J Virol 2009; 83: 7384-90.

[13] Arii J, Uema M, Morimoto T, et al. Entry of herpes simplex virus 1 and other alphaherpesviruses via the paired immunoglobulin-like type 2 receptor alpha. J Virol 2009; 83: 4520-7.

[14] Hu JC, Coffin RS. Oncolytic herpes simplex virus for tumor therapy. Int Rev Neurobiol 2003; 55: 165-84.

[15] Todo T. Oncolytic virus therapy using genetically engineered herpes simplex viruses. Hum Cell 2002; 15: 151-9.

[16] Norgren RB, Jr., Lehman MN. Herpes simplex virus as a transneuronal tracer. Neurosci Biobehav Rev 1998; 22: 695-708.

[17] Epstein AL. HSV-1-derived amplicon vectors: recent technological improvements and remaining difficulties--a review. Mem Inst Oswaldo Cruz 2009; 104: 399-410.

[18] Post DE, Fulci G, Chiocca EA, Van Meir EG. Replicative oncolytic herpes simplex viruses in combination cancer therapies. Curr Gene Ther 2004; 4: 41-51.

[19] Cheng G, Feng Z, He B. Herpes simplex virus 1 infection activates the endoplasmic reticulum resident kinase PERK and mediates eIF2alpha dephosphorylation by the gamma(1)34.5 protein. J Virol 2005; 79: 1379-88.

[20] Jing X, Cerveny M, Yang K, He B. Replication of herpes simplex virus 1 depends on the gamma 134.5 functions that facilitate virus response to interferon and egress in the different stages of productive infection. J Virol 2004; 78: 7653-66.

[21] Leib DA, Alexander DE, Cox D, Yin J, Ferguson TA. Interaction of ICP34.5 with Beclin 1 modulates herpes simplex virus type 1 pathogenesis through control of CD4+ T-cell responses. J Virol 2009; 83: 12164-71.

[22] Frampton AR, Jr., Goins WF, Nakano K, Burton EA, Glorioso JC. HSV trafficking and development of gene therapy vectors with applications in the nervous system. Gene Ther 2005; 12: 891-901.

[23] Palmer JA, Branston RH, Lilley CE, et al. Development and optimization of herpes simplex virus vectors for multiple long-term gene delivery to the peripheral nervous system. J Virol 2000; 74: 5604-18.

[24] McGraw HM, Friedman HM. Herpes simplex virus type 1 glycoprotein E mediates retrograde spread from epithelial cells to neurites. J Virol 2009; 83: 4791-9.

[25] Uchida H, Shah WA, Ozuer A, et al. Generation of herpesvirus entry mediator (HVEM)-restricted herpes simplex virus type 1 mutant viruses: resistance of HVEM-expressing cells and identification of mutations that rescue nectin-1 recognition. J Virol 2009; 83: 2951-61.

[26] Lu X, Triezenberg SJ. Chromatin assembly on herpes simplex virus genomes during lytic infection. Biochim Biophys Acta 2009.

[27] Knipe DM, Cliffe A. Chromatin control of herpes simplex virus lytic and latent infection. Nat Rev Microbiol 2008; 6: 211-21.

[28] Burton EA, Bai Q, Goins WF, Glorioso JC. Replication-defective genomic herpes simplex vectors: design and production. Curr Opin Biotechnol 2002; 13: 424-8.

[29] Berto E, Bozac A, Marconi P. Development and application of replication-incompetent HSV-1-based vectors. Gene Ther 2005; 12 Suppl 1: S98-102.
[30] Krisky DM, Marconi PC, Oligino TJ, et al. Development of herpes simplex virus replication-defective multigene vectors for combination gene therapy applications. Gene Ther 1998; 5: 151730 .

[31] Chattopadhyay M, Mata M, Goss J, et al. Prolonged preservation of nerve function in diabetic neuropathy in mice by herpes simplex virus-mediated gene transfer. Diabetologia 2007; 50: 1550-8.

[32] Chattopadhyay M, Mata M, Fink DJ. Continuous delta-opioid receptor activation reduces neuronal voltage-gated sodium channel (NaV1.7) levels through activation of protein kinase $\mathrm{C}$ in painful diabetic neuropathy. J Neurosci 2008; 28: 6652-8.

[33] Chattopadhyay M, Walter C, Mata M, Fink DJ. Neuroprotective effect of herpes simplex virus-mediated gene transfer of erythropoietin in hyperglycemic dorsal root ganglion neurons. Brain 2009; 132: 879-88.

[34] Furlan R, Bergami A, Brambilla E, et al. HSV-1-mediated IL-1 receptor antagonist gene therapy ameliorates MOG(35-55)-induced experimental autoimmune encephalomyelitis in C57BL/6 mice. Gene Ther 2007; 14: 93-8.

[35] Paradiso B, Marconi P, Zucchini S, et al. Localized delivery of fibroblast growth factor-2 and brain-derived neurotrophic factor reduces spontaneous seizures in an epilepsy model. Proc Natl Acad Sci USA 2009; 106: 7191-6.

[36] Hong CS, Goins WF, Goss JR, Burton EA, Glorioso JC. Herpes simplex virus RNAi and neprilysin gene transfer vectors reduce accumulation of Alzheimer's disease-related amyloid-beta peptide in vivo. Gene Ther 2006; 13: 1068-79.

[37] Puskovic V, Wolfe D, Wechuck J, et al. HSV-mediated delivery of erythropoietin restores dopaminergic function in MPTP-treated mice. Mol Ther 2006; 14: 710-5.

[38] Wolfe D, Wechuck J, Krisky D, Mata M, Fink DJ. A clinical trial of gene therapy for chronic pain. Pain Med 2009; 10: 1325-30.

[39] Wolfe D, Mata M, Fink DJ. A human trial of HSV-mediated gene transfer for the treatment of chronic pain. Gene Ther 2009; 16: 45560 .

[40] Glorioso JC, Fink DJ. Herpes vector-mediated gene transfer in the treatment of chronic pain. Mol Ther 2009; 17: 13-8.

[41] Berges BK, Yellayi S, Karolewski BA, et al. Widespread correction of lysosomal storage in the mucopolysaccharidosis type VII mouse brain with a herpes simplex virus type 1 vector expressing beta-glucuronidase. Mol Ther 2006; 13: 859-69.

[42] Martino S, Marconi P, Tancini B, et al. A direct gene transfer strategy via brain internal capsule reverses the biochemical defect in Tay-Sachs disease. Hum Mol Genet 2005; 14: 2113-23.

[43] Kann O, Kovacs R, Njunting M, et al. Metabolic dysfunction during neuronal activation in the ex vivo hippocampus from chronic epileptic rats and humans. Brain 2005; 128: 2396-407.

[44] Lehmann TN, Gabriel S, Kovacs R, et al. Alterations of neuronal connectivity in area CA1 of hippocampal slices from temporal lobe epilepsy patients and from pilocarpine-treated epileptic rats. Epilepsia 2000; 41 Suppl 6: S190-4.

[45] Tetz LM, Rezk PE, Ratcliffe RH, et al. Development of a rat pilocarpine model of seizure/status epilepticus that mimics chemical warfare nerve agent exposure. Toxicol Ind Health 2006; 22: $255-66$.

[46] Fernandez O. Combination therapy in multiple sclerosis. J Neurol Sci 2007; 259: 95-103.

[47] Compston A. The basis for treatment in multiple sclerosis. Acta Neurol Scand Suppl 2006; 183: 41-7.

[48] Furlan R, Brambilla E, Ruffini F, et al. Intrathecal delivery of IFNgamma protects $\mathrm{C} 57 \mathrm{BL} / 6$ mice from chronic-progressive experimental autoimmune encephalomyelitis by increasing apoptosis of central nervous system-infiltrating lymphocytes. J Immunol 2001; 167: 1821-9.

[49] Martino G, Poliani PL, Marconi PC, Comi G, Furlan R. Cytokine gene therapy of autoimmune demyelination revisited using herpes simplex virus type-1-derived vectors. Gene Ther 2000; 7: 1087-93.

[50] Yamada M, Oligino T, Mata M, et al. Herpes simplex virus vectormediated expression of $\mathrm{Bcl}-2$ prevents 6-hydroxydopamineinduced degeneration of neurons in the substantia nigra in vivo. Proc Natl Acad Sci USA 1999; 96: 4078-83.

[51] Natsume A, Mata M, Goss J, et al. Bcl-2 and GDNF delivered by HSV-mediated gene transfer act additively to protect dopaminergic neurons from 6-OHDA-induced degeneration. Exp Neurol 2001; 169: $231-8$. 
[52] Puskovic V, Wolfe D, Goss J, et al. Prolonged biologically active transgene expression driven by HSV LAP2 in brain in vivo. Mol Ther 2004; 10: 67-75.

[53] Calcutt NA, Jolivalt CG, Fernyhough P. Growth factors as therapeutics for diabetic neuropathy. Curr Drug Targets 2008; 9: 47-59.

[54] Apfel SC, Schwartz S, Adornato BT, et al. Efficacy and safety of recombinant human nerve growth factor in patients with diabetic polyneuropathy: A randomized controlled trial. rhNGF Clinical Investigator Group. JAMA 2000; 284: 2215-21.

[55] Mata M, Hao S, Fink DJ. Applications of gene therapy to the treatment of chronic pain. Curr Gene Ther 2008; 8: 42-8.

[56] Chattopadhyay M, Goss J, Lacomis D, et al. Protective effect of HSV-mediated gene transfer of nerve growth factor in pyridoxine neuropathy demonstrates functional activity of trkA receptors in large sensory neurons of adult animals. Eur J Neurosci 2003; 17: $732-40$.

[57] Chattopadhyay M, Goss J, Wolfe D, et al. Protective effect of herpes simplex virus-mediated neurotrophin gene transfer in cisplatin neuropathy. Brain 2004; 127: 929-39.

[58] Chattopadhyay M, Krisky D, Wolfe D, et al. HSV-mediated gene transfer of vascular endothelial growth factor to dorsal root ganglia prevents diabetic neuropathy. Gene Ther 2005; 12: 1377-84.

[59] Goss JR, Goins WF, Lacomis D, et al. Herpes simplex-mediated gene transfer of nerve growth factor protects against peripheral neuropathy in streptozotocin-induced diabetes in the mouse. Diabetes 2002; 51: 2227-32.

[60] Bennett NE, Kim JH, Wolfe DP, et al. Improvement in erectile dysfunction after neurotrophic factor gene therapy in diabetic rats. $\mathrm{J}$ Urol 2005; 173: 1820-4.

[61] Mata M, Chattopadhyay M, Fink DJ. Gene therapy for the treatment of diabetic neuropathy. Curr Diab Rep 2008; 8: 431-6.

[62] Sasaki K, Chancellor MB, Goins WF, et al. Gene therapy using replication-defective herpes simplex virus vectors expressing nerve growth factor in a rat model of diabetic cystopathy. Diabetes 2004; 53: $2723-30$

[63] Goins WF, Goss JR, Chancellor MB, et al. Herpes simplex virus vector-mediated gene delivery for the treatment of lower urinary tract pain. Gene Ther 2009; 16: 558-69.

[64] Anesti AM, Peeters PJ, Royaux I, Coffin RS. Efficient delivery of RNA Interference to peripheral neurons in vivo using herpes simplex virus. Nucleic Acids Res 2008; 36: e86.

[65] Yang H, McNearney TA, Chu R, et al. Enkephalin-encoding herpes simplex virus-1 decreases inflammation and hotplate sensitivity in a chronic pancreatitis model. Mol Pain 2008; 4: 8 .

[66] Westlund KN. Gene therapy for pancreatitis pain. Gene Ther 2009; 16: 483-92.

[67] Liu J, Wolfe D, Hao S, et al. Peripherally delivered glutamic acid decarboxylase gene therapy for spinal cord injury pain. Mol Ther 2004; 10: 57-66.

[68] Lee JY, Fink DJ, Mata M. Vector-mediated gene transfer to express inhibitory neurotransmitters in dorsal root ganglion reduces pain in a rodent model of lumbar radiculopathy. Spine 2006; 31 : 1555-8.

[69] Wilson SP, Yeomans DC, Bender MA, et al. Antihyperalgesic effects of infection with a preproenkephalin-encoding herpes virus. Proc Natl Acad Sci USA 1999; 96: 3211-6.

[70] Antunes Bras JM, Epstein AL, Bourgoin S, et al. Herpes simplex virus 1-mediated transfer of preproenkephalin $\mathrm{A}$ in rat dorsal root ganglia. J Neurochem 1998; 70: 1299-303.

[71] Goss JR, Mata M, Goins WF, et al. Antinociceptive effect of a genomic herpes simplex virus-based vector expressing human proenkephalin in rat dorsal root ganglion. Gene Ther 2001; 8: 5516.

[72] Yeomans DC, Lu Y, Laurito CE, et al. Recombinant herpes vectormediated analgesia in a primate model of hyperalgesia. Mol Ther 2006; 13: 589-97.

[73] Zhou Z, Peng X, Hao S, Fink DJ, Mata M. HSV-mediated transfer of interleukin-10 reduces inflammatory pain through modulation of membrane tumor necrosis factor alpha in spinal cord microglia. Gene Ther 2008; 15: 183-90.

[74] Hao S, Mata M, Glorioso JC, Fink DJ. Gene transfer to interfere with TNFalpha signaling in neuropathic pain. Gene Ther 2007; 14: 1010-6.

[75] Meikle PJ, Hopwood JJ, Clague AE, Carey WF. Prevalence of lysosomal storage disorders. JAMA 1999; 281: 249-54.
[76] Broberg E, Setala N, Roytta M, et al. Expression of interleukin-4 but not of interleukin-10 from a replicative herpes simplex virus type 1 viral vector precludes experimental allergic encephalomyelitis. Gene Ther 2001; 8: 769-77.

[77] Laing JM, Smith CC, Aurelian L. Multi-targeted neuroprotection by the HSV-2 gene ICP10PK includes robust bystander activity through PI3-K/Akt and/or MEK/ERK-dependent neuronal release of vascular endothelial growth factor and fractalkine. J Neurochem 2010; 112: 662-76.

[78] Wolfe D, Niranjan A, Trichel A, et al. Safety and biodistribution studies of an HSV multigene vector following intracranial delivery to non-human primates. Gene Ther 2004; 11: 1675-84.

[79] Poliani PL, Brok H, Furlan R, et al. Delivery to the central nervous system of a nonreplicative herpes simplex type 1 vector engineered with the interleukin 4 gene protects rhesus monkeys from hyperacute autoimmune encephalomyelitis. Hum Gene Ther 2001; 12: $905-20$

[80] Goins WF, Krisky DM, Wechuck JB, Huang S, Glorioso JC. Construction and production of recombinant herpes simplex virus vectors. Methods Mol Biol 2008; 433: 97-113.

[81] Rasmussen M, Kong L, Zhang GR, et al. Glutamatergic or GABAergic neuron-specific, long-term expression in neocortical neurons from helper virus-free HSV-1 vectors containing the phosphate-activated glutaminase, vesicular glutamate transporter-1, or glutamic acid decarboxylase promoter. Brain Res 2007; 1144: 19-32.

[82] Glorioso JC, Mata M, Fink DJ. Exploiting the neurotherapeutic potential of peptides: targeted delivery using HSV vectors. Exp Opin Biol Ther 2003; 3: 1233-9.

[83] Martins I, Pinto M, Wilson SP, Lima D, Tavares I. Dynamic of migration of HSV-1 from a medullary pronociceptive centre: antinociception by overexpression of the preproenkephalin transgene. Eur J Neurosci 2008; 28: 2075-83.

[84] Miki Y, Nonoguchi N, Ikeda N, et al. Vascular endothelial growth factor gene-transferred bone marrow stromal cells engineered with a herpes simplex virus type 1 vector can improve neurological deficits and reduce infarction volume in rat brain ischemia. Neurosurgery 2007; 61: 586-94; discussion 94-5.

[85] Hsu YC, Lee DC, Chiu IM. Neural stem cells, neural progenitors, and neurotrophic factors. Cell Transplant 2007; 16: 133-50.

[86] Cao H, Zhang GR, Wang X, Kong L, Geller AI. Enhanced nigrostriatal neuron-specific, long-term expression by using neuralspecific promoters in combination with targeted gene transfer by modified helper virus-free HSV-1 vector particles. BMC Neurosci 2008; 9: 37.

[87] Marconi P, Zucchini S, Berto E, et al. Effects of defective herpes simplex vectors expressing neurotrophic factors on the proliferation and differentiation of nervous cells in vivo. Gene Ther 2005; 12 : 559-69.

[88] Goss JR, Gold MS, Glorioso JC. HSV vector-mediated modification of primary nociceptor afferents: an approach to inhibit chronic pain. Gene Ther 2009; 16: 493-501.

[89] Roizman B. Introduction: objectives of herpes simplex virus vaccines seen from a historical perspective. Rev Infect Dis 1991; 13(Suppl 11): S892-4.

[90] Stanberry LR. Clinical trials of prophylactic and therapeutic herpes simplex virus vaccines. Herpes 2004; (11 Suppl 3): 161A-9A.

[91] Koelle DM, Corey L. Recent progress in herpes simplex virus immunobiology and vaccine research. Clin Microbiol Rev 2003; 16: $96-113$

[92] Krause PR, Straus SE. Herpesvirus vaccines. Development, controversies, and applications. Infect Dis Clin North Am 1999; 13: 61-81, vi.

[93] Suter M, Lew AM, Grob P, et al. BAC-VAC, a novel generation of (DNA) vaccines: A bacterial artificial chromosome (BAC) containing a replication-competent, packaging-defective virus genome induces protective immunity against herpes simplex virus 1. Proc Natl Acad Sci USA 1999; 96: 12697-702.

[94] Lauterbach H, Kerksiek KM, Busch DH, et al. Protection from bacterial infection by a single vaccination with replication-deficient mutant herpes simplex virus type 1. J Virol 2004; 78: 4020-8.

[95] Watanabe D, Brockman MA, Ndung'u T, et al. Properties of a herpes simplex virus multiple immediate-early gene-deleted recombinant as a vaccine vector. Virology 2007; 357: 186-98

[96] Brehm M, Samaniego LA, Bonneau RH, DeLuca NA, Tevethia SS Immunogenicity of herpes simplex virus type 1 mutants containing 
deletions in one or more alpha-genes: ICP4, ICP27, ICP22, and ICP0. Virology 1999; 256: 258-69.

[97] Hocknell PK, Wiley RD, Wang X, et al. Expression of human immunodeficiency virus type 1 gp120 from herpes simplex virus type 1-derived amplicons results in potent, specific, and durable cellular and humoral immune responses. J Virol 2002; 76: 5565-80.

[98] Brockman MA, Knipe DM. Herpes simplex virus vectors elicit durable immune responses in the presence of preexisting host immunity. J Virol 2002; 76: 3678-87.

[99] Hoshino Y, Pesnicak L, Dowdell KC, et al. Comparison of immunogenicity and protective efficacy of genital herpes vaccine candidates herpes simplex virus $2 \mathrm{~d} 15-29$ and d15-29-41L in mice and guinea pigs. Vaccine 2008; 26: 4034-40.

[100] Us D. Herpes simplex virus vaccine studies: from past to present. Mikrobiyol Bul 2006; 40: 413-33.

[101] McLean CS, Erturk M, Jennings R, et al. Protective vaccination against primary and recurrent disease caused by herpes simplex virus (HSV) type 2 using a genetically disabled HSV-1. J Infect Dis 1994; 170: 1100-9.

[102] Da Costa XJ, Morrison LA, Knipe DM. Comparison of different forms of herpes simplex replication-defective mutant viruses as vaccines in a mouse model of HSV-2 genital infection. Virology 2001; 288: 256-63.

[103] Da Costa X, Kramer MF, Zhu J, Brockman MA, Knipe DM. Construction, phenotypic analysis, and immunogenicity of a UL5/UL29 double deletion mutant of herpes simplex virus 2. J Virol 2000; 74: 7963-71.

[104] Dudek T, Mathews LC, Knipe DM. Disruption of the U(L)41 gene in the herpes simplex virus 2 dl5-29 mutant increases its immunogenicity and protective capacity in a murine model of genital herpes. Virology 2008; 372: 165-75.

[105] Hoshino Y, Pesnicak L, Dowdell KC, et al. Protection from herpes simplex virus (HSV)-2 infection with replication-defective HSV-2 or glycoprotein D2 vaccines in HSV-1-seropositive and HSV-1seronegative guinea pigs. J Infect Dis 2009; 200: 1088-95.

[106] McLean CS, NiChallanain D, Duncan I, et al. Induction of a protective immune response by mucosal vaccination with a DISC HSV-1 vaccine. Vaccine 1996; 14: 987-92.

[107] Boursnell ME, Entwisle C, Blakeley D, et al. A genetically inactivated herpes simplex virus type $2(\mathrm{HSV}-2)$ vaccine provides effective protection against primary and recurrent HSV-2 disease. $\mathrm{J}$ Infect Dis 1997; 175: 16-25.

[108] Boursnell ME, Entwisle C, Ali SA, et al. Disabled infectious single cycle (DISC) herpes simplex virus as a vector for immunotherapy of cancer. Adv Exp Med Biol 1998; 451: 379-84.

[109] Ali SA, McLean CS, Boursnell ME, et al. Preclinical evaluation of "whole" cell vaccines for prophylaxis and therapy using a disabled infectious single cycle-herpes simplex virus vector to transduce cytokine genes. Cancer Res 2000; 60: 1663-70.

[110] Brans R, Eriksson E, Yao F. Immunization with a dominantnegative recombinant HSV type 1 protects against HSV-1 skin disease in guinea pigs. J Invest Dermatol 2008; 128: 2825-32.

[111] Brans R, Akhrameyeva NV, Yao F. Prevention of genital herpes simplex virus type 1 and 2 disease in mice immunized with a gDexpressing dominant-negative recombinant HSV-1. J Invest Dermatol 2009; 129: 2470-9.

[112] Lu Z, Brans R, Akhrameyeva NV, et al. High-level expression of glycoprotein D by a dominant-negative HSV-1 virus augments its efficacy as a vaccine against HSV-1 infection. J Invest Dermatol 2009; 129: 1174-84

[113] Fiorentini S, Becker PD, Marini E, et al. HIV-1 matrix protein $\mathrm{p} 17$ modulates in vivo preactivated murine $\mathrm{T}$-cell response and enhances the induction of systemic and mucosal immunity against intranasally co-administered antigens. Viral Immunol 2006; 19: 177-88.

[114] Bozac A, Berto E, Vasquez F, et al. Expression of human immunodeficiency virus type 1 tat from a replication-deficient herpes simplex type 1 vector induces antigen-specific $\mathrm{T}$ cell responses. Vaccine 2006; 24: 7148-58.

[115] Murphy CG, Lucas WT, Means RE, et al. Vaccine protection against simian immunodeficiency virus by recombinant strains of herpes simplex virus. J Virol 2000; 74: 7745-54.

[116] Kaur A, Sanford HB, Garry D, et al. Ability of herpes simplex virus vectors to boost immune responses to DNA vectors and to protect against challenge by simian immunodeficiency virus. Virology 2007; 357: 199-214.
[117] Liu X, Broberg E, Watanabe D, et al. Genetic engineering of a modified herpes simplex virus 1 vaccine vector. Vaccine 2009; 27: 2760-7.

[118] Spector FC, Kern ER, Palmer J, et al. Evaluation of a live attenuated recombinant virus RAV 9395 as a herpes simplex virus type 2 vaccine in guinea pigs. J Infect Dis 1998; 177: 1143-54.

[119] Morrison LA. Vaccines against genital herpes: progress and limitations. Drugs 2002; 62: 1119-29.

[120] De Giuli Morghen C, Radaelli A, Zanotto C, Marconi P, Manservigi R. Virus vectors for immunoprophylaxis. AIDS Rev 2000; $2: 127-35$.

[121] Meignier B, Longnecker R, Roizman B. In vivo behavior of genetically engineered herpes simplex viruses R7017 and R7020: construction and evaluation in rodents. J Infect Dis 1988; 158: 60214.

[122] Meignier B, Martin B, Whitley RJ, Roizman B. In vivo behavior of genetically engineered herpes simplex viruses R7017 and R7020. II. Studies in immunocompetent and immunosuppressed owl monkeys (Aotus trivirgatus). J Infect Dis 1990; 162: 313-21.

[123] Bernstein DI, Ireland J, Bourne N. Pathogenesis of acyclovirresistant herpes simplex type 2 isolates in animal models of genital herpes: models for antiviral evaluations. Antiviral Res 2000; 47: 159-69.

[124] Aurelian L, Kokuba H, Smith CC. Vaccine potential of a herpes simplex virus type 2 mutant deleted in the PK domain of the large subunit of ribonucleotide reductase (ICP10). Vaccine 1999; 17: 1951-63.

[125] Walker J, Leib DA. Protection from primary infection and establishment of latency by vaccination with a herpes simplex virus type 1 recombinant deficient in the virion host shutoff (vhs) function. Vaccine 1998; 16: 1-5.

[126] Quenelle DC, Collins DJ, Rice TL, et al. Effect of an immune enhancer, GPI-0100, on vaccination with live attenuated herpes simplex virus (HSV) type 2 or glycoprotein D on genital HSV-2 infections of guinea pigs. Antiviral Res 2008; 80: 223-4.

[127] Prichard MN, Kaiwar R, Jackman WT, et al. Evaluation of AD472, a live attenuated recombinant herpes simplex virus type 2 vaccine in guinea pigs. Vaccine 2005; 23: 5424-31.

[128] Brittle EE, Wang F, Lubinski JM, Bunte RM, Friedman HM. A replication-competent, neuronal spread-defective, live attenuated herpes simplex virus type 1 vaccine. J Virol 2008; 82: 8431-41.

[129] Berto E, Bozac A, Volpi I, et al. Antitumor effects of nonreplicative herpes simplex vectors expressing antiangiogenic proteins and thymidine kinase on Lewis lung carcinoma establishment and growth. Cancer Gene Ther 2007; 14: 791-801.

[130] Niranjan A, Wolfe D, Tamura M, et al. Treatment of rat gliosarcoma brain tumors by HSV-based multigene therapy combined with radiosurgery. Mol Ther 2003; 8: 530-42.

[131] Niranjan A, Wolfe D, Fellows W, et al. Gene transfer to glial tumors using herpes simplex virus. Methods Mol Biol 2004; 246: 323-37.

[132] Raffaella R, Gioia D, De Andrea M, et al. The interferon-inducible IFI16 gene inhibits tube morphogenesis and proliferation of primary, but not HPV16 E6/E7-immortalized human endothelial cells. Exp Cell Res 2004; 293: 331-45.

[133] Moriuchi S, Krisky DM, Marconi PC, et al. HSV vector cytotoxicity is inversely correlated with effective TK/GCV suicide gene therapy of rat gliosarcoma. Gene Ther 2000; 7: 1483-90.

[134] Moriuchi S, Wolfe D, Tamura M, et al. Double suicide gene therapy using a replication defective herpes simplex virus vector reveals reciprocal interference in a malignant glioma model. Gene Ther 2002; 9: 584-91.

[135] Niranjan A, Moriuchi S, Lunsford LD, et al. Effective treatment of experimental glioblastoma by HSV vector-mediated TNF alpha and HSV-tk gene transfer in combination with radiosurgery and ganciclovir administration. Mol Ther 2000; $2: 114-20$

[136] Marconi P, Tamura M, Moriuchi S, et al. Connexin 43-enhanced suicide gene therapy using herpesviral vectors. Mol Ther 2000; 1 : 71-81.

[137] Moriuchi S, Oligino T, Krisky D, et al. Enhanced tumor cell killing in the presence of ganciclovir by herpes simplex virus type 1 vector-directed coexpression of human tumor necrosis factor-alpha and herpes simplex virus thymidine kinase. Cancer Res 1998; 58: 5731-7.

[138] Advani SJ, Chung SM, Yan SY, et al. Replication-competent, nonneuroinvasive genetically engineered herpes virus is highly 
effective in the treatment of therapy-resistant experimental human tumors. Cancer Res 1999; 59: 2055-8.

[139] Mullen JT, Kasuya H, Yoon SS, et al. Regulation of herpes simplex virus 1 replication using tumor-associated promoters. Ann Surg 2002; 236: 502-12; discussion 12-3.

[140] Toda M, Martuza RL, Rabkin SD. Tumor growth inhibition by intratumoral inoculation of defective herpes simplex virus vectors expressing granulocyte-macrophage colony-stimulating factor. Mol Ther 2000; 2 : 324-9.

[141] Galanis E, Vile R, Russell SJ. Delivery systems intended for in vivo gene therapy of cancer: targeting and replication competent viral vectors. Crit Rev Oncol Hematol 2001; 38: 177-92.

[142] Markert JM, Parker JN, Gillespie GY, Whitley RJ. Genetically engineered human herpes simplex virus in the treatment of brain tumours. Herpes 2001; 8: 17-22.

[143] Toda M, Rabkin SD, Kojima H, Martuza RL. Herpes simplex virus as an in situ cancer vaccine for the induction of specific anti-tumor immunity. Hum Gene Ther 1999; 10: 385-93.

[144] Todo T, Martuza RL, Rabkin SD, Johnson PA. Oncolytic herpes simplex virus vector with enhanced MHC class I presentation and tumor cell killing. Proc Natl Acad Sci USA 2001; 98: 6396-401.

[145] Mullen JT, Tanabe KK. Viral oncolysis. Oncologist 2002; 7: 10619.

[146] Markert JM, Parker JN, Buchsbaum DJ, et al. Oncolytic HSV-1 for the treatment of brain tumours. Herpes 2006; 13: 66-71.

[147] Grandi P, Peruzzi P, Reinhart B, et al. Design and application of oncolytic HSV vectors for glioblastoma therapy. Exp Rev Neurother 2009; 9: 505-17.

[148] Martuza RL, Malick A, Markert JM, Ruffner KL, Coen DM. Experimental therapy of human glioma by means of a genetically engineered virus mutant. Science 1991; 252: 854-6.

[149] Kramm CM, Rainov NG, Sena-Esteves M, et al. Long-term survival in a rodent model of disseminated brain tumors by combined intrathecal delivery of herpes vectors and ganciclovir treatment. Hum Gene Ther 1996; 7: 1989-94.

[150] Jeyaretna DS, Rabkin SD, Martuza RL. Oncolytic herpes simplex virus therapy for peripheral nerve tumors. Neurosurg Focus 2007; 22: E4.

[151] Andreansky S, Soroceanu L, Flotte ER, et al. Evaluation of genetically engineered herpes simplex viruses as oncolytic agents for human malignant brain tumors. Cancer Res 1997; 57: 1502-9.

[152] Cassady KA, Gross M, Roizman B. The second-site mutation in the herpes simplex virus recombinants lacking the gamma134.5 genes precludes shutoff of protein synthesis by blocking the phosphorylation of eIF-2alpha. J Virol 1998; 72: 7005-11.

[153] Dambach MJ, Trecki J, Martin N, Markovitz NS. Oncolytic viruses derived from the gamma34.5-deleted herpes simplex virus recombinant R3616 encode a truncated UL3 protein. Mol Ther 2006; 13: 891-8.

[154] Boviatsis EJ, Scharf JM, Chase M, et al. Antitumor activity and reporter gene transfer into rat brain neoplasms inoculated with herpes simplex virus vectors defective in thymidine kinase or ribonucleotide reductase. Gene Ther 1994; 1: 323-31.

[155] Kramm CM, Chase M, Herrlinger U, et al. Therapeutic efficiency and safety of a second-generation replication-conditional HSV1 vector for brain tumor gene therapy. Hum Gene Ther 1997; 8: 2057-68.

[156] Carroll NM, Chase M, Chiocca EA, Tanabe KK. The effect of ganciclovir on herpes simplex virus-mediated oncolysis. J Surg Res 1997; 69: 413-7.

[157] Chambers R, Gillespie GY, Soroceanu L, et al. Comparison of genetically engineered herpes simplex viruses for the treatment of brain tumors in a scid mouse model of human malignant glioma. Proc Natl Acad Sci USA 1995; 92: 1411-5.

[158] Chou J, Kern ER, Whitley RJ, Roizman B. Mapping of herpes simplex virus-1 neurovirulence to gamma 134.5, a gene nonessential for growth in culture. Science 1990; 250: 1262-6.

[159] Markert JM, Malick A, Coen DM, Martuza RL. Reduction and elimination of encephalitis in an experimental glioma therapy model with attenuated herpes simplex mutants that retain susceptibility to acyclovir. Neurosurgery 1993; 32: 597-603.

[160] Liu BL, Robinson M, Han ZQ, et al. ICP34.5 deleted herpes simplex virus with enhanced oncolytic, immune stimulating, and anti-tumour properties. Gene Ther 2003; 10: 292-303.
[161] Mineta T, Rabkin SD, Yazaki T, Hunter WD, Martuza RL. Attenuated multi-mutated herpes simplex virus-1 for the treatment of malignant gliomas. Nat Med 1995; 1: 938-43.

[162] Hunter WD, Martuza RL, Feigenbaum F, et al. Attenuated, replication-competent herpes simplex virus type 1 mutant G207: safety evaluation of intracerebral injection in nonhuman primates. $\mathrm{J}$ Virol 1999; 73: 6319-26.

[163] Markert JM, Medlock MD, Rabkin SD, et al. Conditionally replicating herpes simplex virus mutant, G207 for the treatment of malignant glioma: results of a phase I trial. Gene Ther 2000; 7: 867-74.

[164] Markert JM, Liechty PG, Wang W, et al. Phase Ib trial of mutant herpes simplex virus G207 inoculated pre-and post-tumor resection for recurrent GBM. Mol Ther 2009; 17: 199-207.

[165] Aghi MK, Chiocca EA. Phase ib trial of oncolytic herpes virus G207 shows safety of multiple injections and documents viral replication. Mol Ther 2009; 17: 8-9.

[166] Jacobs A, Tjuvajev JG, Dubrovin M, et al. Positron Emission tomography-based imaging of transgene expression mediated by replication-conditional, oncolytic herpes simplex virus type 1 mutant vectors in vivo. Cancer Res 2001; 61: 2983-95.

[167] Rampling R, Cruickshank G, Papanastassiou V, et al. Toxicity evaluation of replication-competent herpes simplex virus (ICP 34.5 null mutant 1716) in patients with recurrent malignant glioma. Gene Ther 2000; 7: 859-66.

[168] MacLean AR, ul-Fareed M, Robertson L, Harland J, Brown SM. Herpes simplex virus type 1 deletion variants 1714 and 1716 pinpoint neurovirulence-related sequences in Glasgow strain 17+ between immediate early gene 1 and the 'a' sequence. J Gen Virol 1991; 72 (Pt 3): 631-9.

[169] Harrow S, Papanastassiou V, Harland J, et al. HSV1716 injection into the brain adjacent to tumour following surgical resection of high-grade glioma: safety data and long-term survival. Gene Ther 2004; 11: 1648-58.

[170] Randazzo BP, Kesari S, Gesser RM, et al. Treatment of experimental intracranial murine melanoma with a neuroattenuated herpes simplex virus 1 mutant. Virology 1995; 211: 94-101.

[171] Toda M, Rabkin SD, Martuza RL. Treatment of human breast cancer in a brain metastatic model by G207, a replicationcompetent multimutated herpes simplex virus 1 . Hum Gene Ther 1998; 9: 2177-85.

[172] Kooby DA, Carew JF, Halterman MW, et al. Oncolytic viral therapy for human colorectal cancer and liver metastases using a multi-mutated herpes simplex virus type-1 (G207). FASEB J 1999; 13: $1325-34$.

[173] Cozzi PJ, Burke PB, Bhargav A, et al. Oncolytic viral gene therapy for prostate cancer using two attenuated, replication-competent, genetically engineered herpes simplex viruses. Prostate 2002; 53: 95-100.

[174] McAuliffe PF, Jarnagin WR, Johnson P, et al. Effective treatment of pancreatic tumors with two multimutated herpes simplex oncolytic viruses. J Gastrointest Surg 2000; 4: 580-8.

[175] Carew JF, Kooby DA, Halterman MW, Federoff HJ, Fong Y. Selective infection and cytolysis of human head and neck squamous cell carcinoma with sparing of normal mucosa by a cytotoxic herpes simplex virus type 1 (G207). Hum Gene Ther 1999; 10: 1599-606.

[176] Kelly KJ, Wong J, Fong Y. Herpes simplex virus NV1020 as a novel and promising therapy for hepatic malignancy. Exp Opin Investig Drugs 2008; 17: 1105-13.

[177] Fong Y, Kim T, Bhargava A, et al. A herpes oncolytic virus can be delivered via the vasculature to produce biologic changes in human colorectal cancer. Mol Ther 2009; 17: 389-94.

[178] Jarnagin WR, Zager JS, Hezel M, et al. Treatment of cholangiocarcinoma with oncolytic herpes simplex virus combined with external beam radiation therapy. Cancer Gene Ther 2006; 13: 326-34.

[179] Israyelyan AH, Melancon JM, Lomax LG, et al. Effective treatment of human breast tumor in a mouse xenograft model with herpes simplex virus type 1 specifying the NV1020 genomic deletion and the gBsyn3 syncytial mutation enabling high viral replication and spread in breast cancer cells. Hum Gene Ther 2007; 18: 457-73.

[180] Israyelyan A, Shannon EJ, Baghian A, Kearney MT, Kousoulas KG. Thalidomide suppressed the growth of 4T1 cells into solid tumors in Balb/c mice in a combination therapy with the oncolytic 
fusogenic HSV-1 OncdSyn. Cancer Chemother Pharmacol 2009; 64: 1201-10.

[181] Israyelyan A, Chouljenko VN, Baghian A, et al. Herpes simplex virus type-1(HSV-1) oncolytic and highly fusogenic mutants carrying the NV1020 genomic deletion effectively inhibit primary and metastatic tumors in mice. Virol $\mathrm{J} 2008 ; 5: 68$.

[182] Taneja S, MacGregor J, Markus S, Ha S, Mohr I. Enhanced antitumor efficacy of a herpes simplex virus mutant isolated by genetic selection in cancer cells. Proc Natl Acad Sci USA 2001; 98 : 8804-8.

[183] Nakamura H, Mullen JT, Chandrasekhar S, et al. Multimodality therapy with a replication-conditional herpes simplex virus 1 mutant that expresses yeast cytosine deaminase for intratumoral conversion of 5-fluorocytosine to 5-fluorouracil. Cancer Res 2001; 61: 5447-52.

[184] Toda M, Martuza RL, Rabkin SD. Combination suicide/cytokine gene therapy as adjuvants to a defective herpes simplex virus-based cancer vaccine. Gene Ther 2001; 8: 332-9.

[185] Aghi M, Kramm CM, Chou TC, Breakefield XO, Chiocca EA. Synergistic anticancer effects of ganciclovir/thymidine kinase and 5-fluorocytosine/cytosine deaminase gene therapies. J Natl Cancer Inst 1998; 90: 370-80.

[186] Aghi M, Chou TC, Suling K, Breakefield XO, Chiocca EA. Multimodal cancer treatment mediated by a replicating oncolytic virus that delivers the oxazaphosphorine/rat cytochrome P450 2B1 and ganciclovir/herpes simplex virus thymidine kinase gene therapies. Cancer Res 1999; 59: 3861-5.

[187] Pawlik TM, Nakamura H, Mullen JT, et al. Prodrug bioactivation and oncolysis of diffuse liver metastases by a herpes simplex virus 1 mutant that expresses the CYP2B1 transgene. Cancer 2002; 95: 1171-81.

[188] Currier MA, Gillespie RA, Sawtell NM, et al. Efficacy and safety of the oncolytic herpes simplex virus rRp450 alone and combined with cyclophosphamide. Mol Ther 2008; 16: 879-85.

[189] Parker JN, Gillespie GY, Love CE, et al. Engineered herpes simplex virus expressing IL-12 in the treatment of experimental murine brain tumors. Proc Natl Acad Sci USA 2000; 97: 2208-13.

[190] Tyminski E, Leroy S, Terada K, et al. Brain tumor oncolysis with replication-conditional herpes simplex virus type 1 expressing the prodrug-activating genes, CYP2B1 and secreted human intestinal carboxylesterase, in combination with cyclophosphamide and irinotecan. Cancer Res 2005; 65: 6850-7.

[191] Andreansky S, He B, van Cott J, et al. Treatment of intracranial gliomas in immunocompetent mice using herpes simplex viruses that express murine interleukins. Gene Ther 1998; 5: 121-30.

[192] Wong RJ, Patel SG, Kim S, et al. Cytokine gene transfer enhances herpes oncolytic therapy in murine squamous cell carcinoma. Hum Gene Ther 2001; 12: 253-65.

[193] Wong RJ, Chan MK, Yu Z, et al. Angiogenesis inhibition by an oncolytic herpes virus expressing interleukin 12. Clin Cancer Res 2004; 10: 4509-16.

[194] Wong RJ, Chan MK, Yu Z, et al. Effective intravenous therapy of murine pulmonary metastases with an oncolytic herpes virus expressing interleukin 12. Clin Cancer Res 2004; 10: 251-9.

[195] Bennett JJ, Malhotra S, Wong RJ, et al. Interleukin 12 secretion enhances antitumor efficacy of oncolytic herpes simplex viral therapy for colorectal cancer. Ann Surg 2001; 233: 819-26.

[196] Todo T, Martuza RL, Dallman MJ, Rabkin SD. In situ expression of soluble B7-1 in the context of oncolytic herpes simplex virus induces potent antitumor immunity. Cancer Res 2001; 61: 153-61.

[197] Jinushi M, Tahara H. Cytokine gene-mediated immunotherapy: current status and future perspectives. Cancer Sci 2009; 100: 138996.

[198] Del Vecchio M, Bajetta E, Canova S, et al. Interleukin-12: biological properties and clinical application. Clin Cancer Res 2007; 13: 4677-85.

[199] Jarnagin WR, Zager JS, Klimstra D, et al. Neoadjuvant treatment of hepatic malignancy: an oncolytic herpes simplex virus expressing IL-12 effectively treats the parent tumor and protects against recurrence-after resection. Cancer Gene Ther 2003; 10: 215-23.

[200] Ino Y, Saeki Y, Fukuhara H, Todo T. Triple combination of oncolytic herpes simplex virus-1 vectors armed with interleukin-12, interleukin-18, or soluble B7-1 results in enhanced antitumor efficacy. Clin Cancer Res 2006; 12: 643-52.
[201] Malhotra S, Kim T, Zager J, et al. Use of an oncolytic virus secreting GM-CSF as combined oncolytic and immunotherapy for treatment of colorectal and hepatic adenocarcinomas. Surgery 2007; 141: 520-9.

[202] Derubertis BG, Stiles BM, Bhargava A, et al. Cytokine-secreting herpes viral mutants effectively treat tumor in a murine metastatic colorectal liver model by oncolytic and T-cell-dependent mechanisms. Cancer Gene Ther 2007; 14: 590-7.

[203] Kaufman HL, Kim DW, DeRaffele G, et al. Local and distant immunity induced by intralesional vaccination with an oncolytic herpes virus encoding GM-CSF in patients with stage IIIc and IV melanoma. Ann Surg Oncol 2010; 17: 718-30.

[204] Hu JC, Coffin RS, Davis CJ, et al. A phase I study of OncoVEXGM-CSF, a second-generation oncolytic herpes simplex virus expressing granulocyte macrophage colony-stimulating factor. Clin Cancer Res 2006; 12: 6737-47.

[205] Senzer NN, Kaufman HL, Amatruda T, et al. Phase II clinical trial of a granulocyte-macrophage colony-stimulating factor-encoding, second-generation oncolytic herpesvirus in patients with unresectable metastatic melanoma. J Clin Oncol 2009; 27: 5763-71.

[206] Varghese S, Rabkin SD, Liu R, et al. Enhanced therapeutic efficacy of IL-12, but not GM-CSF, expressing oncolytic herpes simplex virus for transgenic mouse derived prostate cancers. Cancer Gene Ther 2006; 13: 253-65.

[207] Brandwijk RJ, Griffioen AW, Thijssen VL. Targeted gene-delivery strategies for angiostatic cancer treatment. Trends Mol Med 2007; 13: $200-9$

[208] Liu TC, Zhang T, Fukuhara H, et al. Oncolytic HSV armed with platelet factor 4 , an antiangiogenic agent, shows enhanced efficacy. Mol Ther 2006; 14: 789-97.

[209] Tysome JR, Lemoine NR, Wang Y. Combination of antiangiogenic therapy and virotherapy: arming oncolytic viruses with anti-angiogenic genes. Curr Opin Mol Ther 2009; 11: 664-9.

[210] Norden AD, Drappatz J, Wen PY. Novel anti-angiogenic therapies for malignant gliomas. Lancet Neurol 2008; 7: 1152-60.

[211] Mullen JT, Donahue JM, Chandrasekhar S, et al. Oncolysis by viral replication and inhibition of angiogenesis by a replicationconditional herpes simplex virus that expresses mouse endostatin. Cancer 2004; 101: 869-77.

[212] Benencia F, Courreges MC, Conejo-Garcia JR, et al. Oncolytic HSV exerts direct antiangiogenic activity in ovarian carcinoma. Hum Gene Ther 2005; 16: 765-78.

[213] Liu TC, Castelo-Branco P, Rabkin SD, Martuza RL. Trichostatin A and oncolytic HSV combination therapy shows enhanced antitumoral and antiangiogenic effects Mol Ther 2008; 16: 1041-7.

[214] Hardcastle J, Kurozumi K, Dmitrieva N, et al. Enhanced antitumor efficacy of vasculostatin (Vstat120) expressing oncolytic HSV-1. Mol Ther 2010; 18: 285-94.

[215] Takakuwa H, Goshima F, Nozawa N, et al. Oncolytic viral therapy using a spontaneously generated herpes simplex virus type 1 variant for disseminated peritoneal tumor in immunocompetent mice. Arch Virol 2003; 148: 813-25.

[216] Watanabe D, Goshima F, Mori I, et al. Oncolytic virotherapy for malignant melanoma with herpes simplex virus type 1 mutant HF10. J Dermatol Sci 2008; 50: 185-96.

[217] Nakamori M, Fu X, Pettaway CA, Zhang X. Potent antitumor activity after systemic delivery of a doubly fusogenic oncolytic herpes simplex virus against metastatic prostate cancer. Prostate 2004; 60: 53-60.

[218] Fu X, Zhang X. Potent systemic antitumor activity from an oncolytic herpes simplex virus of syncytial phenotype. Cancer Res 2002; 62: 2306-12

[219] Fu X, Tao L, Jin A, et al. Expression of a fusogenic membrane glycoprotein by an oncolytic herpes simplex virus potentiates the viral antitumor effect. Mol Ther 2003; 7: 748-54.

[220] Simpson GR, Coffin RS. Construction and characterization of an oncolytic HSV vector containing a fusogenic glycoprotein and prodrug activation for enhanced local tumor control. Methods Mol Biol 2009; 542: 551-64.

[221] Colunga AG, Laing JM, Aurelian L. The HSV-2 mutant DeltaPK induces melanoma oncolysis through nonredundant death programs and associated with autophagy and pyroptosis proteins. Gene Ther 2009.

[222] Fu X, Nakamori M, Tao L, Amato R, Zhang X. Antitumor effects of two newly constructed oncolytic herpes simplex viruses against renal cell carcinoma. Int J Oncol 2007; 30: 1561-7. 
[223] Fu X, Tao L, Cai R, Prigge J, Zhang X. A mutant type 2 herpes simplex virus deleted for the protein kinase domain of the ICP10 gene is a potent oncolytic virus. Mol Ther 2006; 13: 882-90.

[224] Li H, Dutuor A, Fu X, Zhang X. Induction of strong antitumor immunity by an HSV-2-based oncolytic virus in a murine mammary tumor model. J Gene Med 2007; 9: 161-9.

[225] Li H, Dutuor A, Tao L, Fu X, Zhang X. Virotherapy with a type 2 herpes simplex virus-derived oncolytic virus induces potent antitumor immunity against neuroblastoma. Clin Cancer Res 2007; 13: 316-22.

[226] He B, Chou J, Brandimarti R, et al. Suppression of the phenotype of gamma(1)34.5- herpes simplex virus 1: failure of activated RNA-dependent protein kinase to shut off protein synthesis is associated with a deletion in the domain of the alpha47 gene. J Virol 1997; 71: 6049-54.

[227] Jorgensen TJ, Katz S, Wittmack EK, et al. Ionizing radiation does not alter the antitumor activity of herpes simplex virus vector G207 in subcutaneous tumor models of human and murine prostate cancer. Neoplasia 2001; 3: 451-6.

[228] Ottolino-Perry K, Diallo JS, Lichty BD, Bell JC, Andrea McCart J. Intelligent design: combination therapy with oncolytic viruses. Mol Ther 2010; 18: 251-63.

[229] Blank SV, Rubin SC, Coukos G, et al. Replication-selective herpes simplex virus type 1 mutant therapy of cervical cancer is enhanced by low-dose radiation. Hum Gene Ther 2002; 13: 627-39.

[230] Adusumilli PS, Chan MK, Hezel M, et al. Radiation-induced cellular DNA damage repair response enhances viral gene therapy efficacy in the treatment of malignant pleural mesothelioma. Ann Surg Oncol 2007; 14: 258-69.

[231] Advani SJ, Mezhir JJ, Roizman B, Weichselbaum RR. ReVOLT: radiation-enhanced viral oncolytic therapy. Int J Radiat Oncol Biol Phys 2006; 66: 637-46.

[232] Chou J, Roizman B. Herpes simplex virus 1 gamma(1)34.5 gene function, which blocks the host response to infection, maps in the homologous domain of the genes expressed during growth arrest and DNA damage. Proc Natl Acad Sci USA 1994; 91: 5247-51.

[233] Ikeda K, Wakimoto H, Ichikawa T, et al. Complement depletion facilitates the infection of multiple brain tumors by an intravascular, replication-conditional herpes simplex virus mutant. J Virol 2000; 74: 4765-75.

[234] Kambara H, Okano H, Chiocca EA, Saeki Y. An oncolytic HSV-1 mutant expressing ICP34.5 under control of a nestin promoter increases survival of animals even when symptomatic from a brain tumor. Cancer Res 2005; 65: 2832-9.

[235] Fulci G, Breymann L, Gianni D, et al. Cyclophosphamide enhances glioma virotherapy by inhibiting innate immune responses. Proc Natl Acad Sci USA 2006; 103: 12873-8.

[236] Wakimoto H, Fulci G, Tyminski E, Chiocca EA. Altered expression of antiviral cytokine mRNAs associated with cyclophosphamide's enhancement of viral oncolysis. Gene Ther 2004; 11:214-23.

[237] Adusumilli PS, Chan MK, Chun YS, et al. Cisplatin-induced GADD34 upregulation potentiates oncolytic viral therapy in the treatment of malignant pleural mesothelioma. Cancer Biol Ther 2006; 5: 48-53.

[238] Kasuya H, Nishiyama Y, Nomoto S, et al. Suitability of a US3inactivated HSV mutant (L1BR1) as an oncolytic virus for pancreatic cancer therapy. Cancer Gene Ther 2007; 14: 533-42.

[239] Mace AT, Harrow SJ, Ganly I, Brown SM. Cytotoxic effects of the oncolytic herpes simplex virus HSV1716 alone and in combination with cisplatin in head and neck squamous cell carcinoma. Acta Otolaryngol 2007; 127: 880-7.

[240] Valyi-Nagy T, Fareed MU, O'Keefe JS, et al. The herpes simplex virus type 1 strain $17+$ gamma 34.5 deletion mutant 1716 is avirulent in SCID mice. J Gen Virol 1994; 75 (Pt 8): 2059-63.

[241] Pawlik TM, Nakamura H, Yoon SS, et al. Oncolysis of diffuse hepatocellular carcinoma by intravascular administration of a replication-competent, genetically engineered herpesvirus. Cancer Res 2000; 60: 2790-5.

[242] Yoon SS, Nakamura H, Carroll NM, et al. An oncolytic herpes simplex virus type 1 selectively destroys diffuse liver metastases from colon carcinoma. FASEB J 2000; 14: 301-11.

[243] Kesari S, Randazzo BP, Valyi-Nagy T, et al. Therapy of experimental human brain tumors using a neuroattenuated herpes simplex virus mutant. Lab Invest 1995; 73: 636-48.
[244] Papanastassiou V, Rampling R, Fraser M, et al. The potential for efficacy of the modified (ICP 34.5(-)) herpes simplex virus HSV1716 following intratumoural injection into human malignant glioma: a proof of principle study. Gene Ther 2002; 9: 398-406.

[245] Todo T, Feigenbaum F, Rabkin SD, et al. Viral shedding and biodistribution of G207, a multimutated, conditionally replicating herpes simplex virus type 1 , after intracerebral inoculation in aotus. Mol Ther 2000; 2: 588-95.

[246] Varghese S, Newsome JT, Rabkin SD, et al. Preclinical safety evaluation of G207, a replication-competent herpes simplex virus type 1, inoculated intraprostatically in mice and nonhuman primates. Hum Gene Ther 2001; 12: 999-1010.

[247] Chung RY, Saeki Y, Chiocca EA. B-myb promoter retargeting of herpes simplex virus gamma34.5 gene-mediated virulence toward tumor and cycling cells. J Virol 1999; 73: 7556-64.

[248] Nakamura H, Kasuya H, Mullen JT, et al. Regulation of herpes simplex virus gamma(1)34.5 expression and oncolysis of diffuse liver metastases by Myb34.5. J Clin Invest 2002; 109: 871-82.

[249] Kasuya H, Pawlik TM, Mullen JT, et al. Selectivity of an oncolytic herpes simplex virus for cells expressing the DF3/MUC1 antigen. Cancer Res 2004; 64: 2561-7.

[250] Shen Y, Nemunaitis J. Herpes simplex virus 1 (HSV-1) for cancer treatment. Cancer Gene Ther 2006; 13: 975-92.

[251] Laquerre S, Argnani R, Anderson DB, et al. Heparan sulfate proteoglycan binding by herpes simplex virus type 1 glycoproteins $\mathrm{B}$ and $\mathrm{C}$, which differ in their contributions to virus attachment, penetration, and cell-to-cell spread. J Virol 1998; 72: 6119-30.

[252] Laquerre S, Anderson DB, Stolz DB, Glorioso JC. Recombinant herpes simplex virus type 1 engineered for targeted binding to erythropoietin receptor-bearing cells. J Virol 1998; 72: 9683-97.

[253] Argnani R, Boccafogli L, Marconi PC, Manservigi R. Specific targeted binding of herpes simplex virus type 1 to hepatocytes via the human hepatitis B virus preS1 peptide. Gene Ther 2004; 11 : 1087-98.

[254] Anderson DB, Laquerre S, Ghosh K, et al. Pseudotyping of glycoprotein D-deficient herpes simplex virus type 1 with vesicular stomatitis virus glycoprotein $\mathrm{G}$ enables mutant virus attachment and entry. J Virol 2000; 74: 2481-7.

[255] Zhou G, Ye GJ, Debinski W, Roizman B. Engineered herpes simplex virus 1 is dependent on IL13Ralpha 2 receptor for cell entry and independent of glycoprotein D receptor interaction. Proc Natl Acad Sci USA 2002; 99: 15124-9.

[256] Manoj S, Jogger CR, Myscofski D, Yoon M, Spear PG. Mutations in herpes simplex virus glycoprotein $\mathrm{D}$ that prevent cell entry via nectins and alter cell tropism. Proc Natl Acad Sci USA 2004; 101: 12414-21.

[257] Menotti L, Cerretani A, Hengel H, Campadelli-Fiume G. Construction of a fully retargeted herpes simplex virus 1 recombinant capable of entering cells solely via human epidermal growth factor receptor 2. J Virol 2008; 82: 10153-61.

[258] Menotti L, Nicoletti G, Gatta V, et al. Inhibition of human tumor growth in mice by an oncolytic herpes simplex virus designed to target solely HER-2-positive cells. Proc Natl Acad Sci USA 2009; 106: 9039-44.

[259] Conner J, Braidwood L, Brown SM. A strategy for systemic delivery of the oncolytic herpes virus HSV1716: redirected tropism by antibody-binding sites incorporated on the virion surface as a glycoprotein D fusion protein. Gene Ther 2008; 15: 1579-92.

[260] Miyatake S, Iyer A, Martuza RL, Rabkin SD. Transcriptional targeting of herpes simplex virus for cell-specific replication. J Virol 1997; 71: 5124-32.

[261] Yamamura H, Hashio M, Noguchi M, et al. Identification of the transcriptional regulatory sequences of human calponin promoter and their use in targeting a conditionally replicating herpes vector to malignant human soft tissue and bone tumors. Cancer Res 2001; 61: 3969-77.

[262] Hernandez-Alcoceba R, Pihalja M, Qian D, Clarke MF. New oncolytic adenoviruses with hypoxia- and estrogen receptorregulated replication. Hum Gene Ther 2002; 13: 1737-50.

[263] Marples B, Scott SD, Hendry JH, et al. Development of synthetic promoters for radiation-mediated gene therapy. Gene Ther 2000; 7 : 511-7.

[264] Scott SD, Marples B. Radiation-activated antitumor vectors. Methods Mol Med 2004; 90: 389-402.

[265] Kanai R, Eguchi K, Takahashi M, et al. Enhanced therapeutic efficacy of oncolytic herpes vector G207 against human non-small 
cell lung cancer--expression of an RNA-binding protein, Musashil, as a marker for the tailored gene therapy. J Gene Med 2006; 8: 1329-40.

[266] Kanai R, Tomita H, Hirose $\mathrm{Y}$, et al. Augmented therapeutic efficacy of an oncolytic herpes simplex virus type 1 mutant expressing ICP34.5 under the transcriptional control of musashi1 promoter in the treatment of malignant glioma. Hum Gene Ther 2007; 18: 63-73

[267] Waerzeggers $\mathrm{Y}$, Monfared $\mathrm{P}$, Viel T, et al. Methods to monitor gene therapy with molecular imaging. Methods 2009; 48: 146-60.

[268] Kuruppu D, Dorfman JD, Tanabe KK. HSV-1 viral oncolysis and molecular imaging with PET. Curr Cancer Drug Targets 2007; 7: 175-80.

[269] Bennett JJ, Tjuvajev J, Johnson P, et al. Positron emission tomography imaging for herpes virus infection: Implications for oncolytic viral treatments of cancer. Nat Med 2001; 7: 859-63.

[270] Brader P, Kelly K, Gang S, et al. Imaging of lymph node micrometastases using an oncolytic herpes virus and [F]FEAU PET. PLoS One 2009; 4: e4789.

[271] Schellingerhout D, Bogdanov A, Jr., Marecos E, et al. Mapping the in vivo distribution of herpes simplex virions. Hum Gene Ther 1998; 9: 1543-9.

[272] Schellingerhout D, Rainov NG, Breakefield XO, Weissleder R. Quantitation of HSV mass distribution in a rodent brain tumor model. Gene Ther 2000; 7: 1648-55.

[273] Bhaumik S, Gambhir SS. Optical imaging of Renilla luciferase reporter gene expression in living mice. Proc Natl Acad Sci USA 2002; 99: 377-82

[274] Greer LF, 3rd, Szalay AA. Imaging of light emission from the expression of luciferases in living cells and organisms: a review. Luminescence 2002; 17: 43-74.

[275] Shah K, Jacobs A, Breakefield XO, Weissleder R. Molecular imaging of gene therapy for cancer. Gene Ther 2004; 11: 1175-87.

[276] Yamamoto S, Deckter LA, Kasai K, Chiocca EA, Saeki Y. Imaging immediate-early and strict-late promoter activity during oncolytic herpes simplex virus type 1 infection and replication in tumors. Gene Ther 2006; 13: 1731-6.

[277] Terada K, Wakimoto H, Tyminski E, Chiocca EA, Saeki Y. Development of a rapid method to generate multiple oncolytic HSV vectors and their in vivo evaluation using syngeneic mouse tumor models. Gene Ther 2006; 13: 705-14.

[278] Shah K, Tang Y, Breakefield X, Weissleder R. Real-time imaging of TRAIL-induced apoptosis of glioma tumors in vivo. Oncogene 2003; 22: 6865-72.

[279] Broberg EK, Hukkanen V. Immune response to herpes simplex virus and gamma134.5 deleted HSV vectors. Curr Gene Ther 2005; 5: 523-30.

[280] Ryan DA, Federoff HJ. Immune responses to herpesviral vectors. Hum Gene Ther 2009; 20: 434-41.

[281] Kwant-Mitchell A, Ashkar AA, Rosenthal KL. Mucosal innate and adaptive immune responses against herpes simplex virus type 2 in a humanized mouse model. J Virol 2009; 83: 10664-76.

[282] Ellermann-Eriksen S. Macrophages and cytokines in the early defence against herpes simplex virus. Virol J 2005; 2: 59.

[283] Nandakumar S, Woolard SN, Yuan D, Rouse BT, Kumaraguru U. Natural killer cells as novel helpers in anti-herpes simplex virus immune response. J Virol 2008; 82: 10820-31.

[284] Diana J, Lehuen A. NKT cells: Friend or foe during viral infections? Eur J Immunol 2009; 39: 3283-91.

[285] Carr DJ, Tomanek L. Herpes simplex virus and the chemokines that mediate the inflammation. Curr Top Microbiol Immunol 2006; 303: 47-65.

[286] Wuest TR, Carr DJ. The role of chemokines during herpes simplex virus-1 infection. Front Biosci 2008; 13: 4862-72.

[287] Hukkanen V, Broberg E, Salmi A, Eralinna JP. Cytokines in experimental herpes simplex virus infection. Int Rev Immunol 2002; $21: 355-71$.

[288] Leib DA, Harrison TE, Laslo KM, et al. Interferons regulate the phenotype of wild-type and mutant herpes simplex viruses in vivo. J Exp Med 1999; 189: 663-72.

[289] Broberg EK, Setala N, Eralinna JP, et al. Herpes simplex virus type 1 infection induces upregulation of interleukin-23 (p19) mRNA expression in trigeminal ganglia of $\mathrm{BALB} / \mathrm{c}$ mice. $\mathrm{J}$ Interferon Cytokine Res 2002; 22: 641-51.

[290] Wiekowski MT, Leach MW, Evans EW, et al. Ubiquitous transgenic expression of the IL-23 subunit 19 induces multiorgan inflammation, runting, infertility, and premature death. J Immunol 2001; 166: 7563-70.

[291] Shimeld C, Easty DL, Hill TJ. Reactivation of herpes simplex virus type 1 in the mouse trigeminal ganglion: an in vivo study of virus antigen and cytokines. J Virol 1999; 73: 1767-73.

[292] Mossman KL, Ashkar AA. Herpesviruses and the innate immune response. Viral Immunol 2005; 18: 267-81.

[293] Herbst-Kralovetz M, Pyles R. Toll-like receptors, innate immunity and HSV pathogenesis. Herpes 2006; 13: 37-41.

[294] Lubinski J, Nagashunmugam T, Friedman HM. Viral interference with antibody and complement. Semin Cell Dev Biol 1998; 9: 32937.

[295] Paladino P, Mossman KL. Mechanisms employed by herpes simplex virus 1 to inhibit the interferon response. J Interferon Cytokine Res 2009; 29: 599-607.

[296] Randall RE, Goodbourn S. Interferons and viruses: an interplay between induction, signalling, antiviral responses and virus countermeasures. J Gen Virol 2008; 89: 1-47.

[297] Nguyen ML, Blaho JA. Apoptosis during herpes simplex virus infection. Adv Virus Res 2007; 69: 67-97.

[298] Lee DY, Lee J, Sugden B. The unfolded protein response and autophagy: herpesviruses rule! J Virol 2009; 83: 1168-72.

[299] English L, Chemali M, Duron J, et al. Autophagy enhances the presentation of endogenous viral antigens on MHC class I molecules during HSV-1 infection. Nat Immunol 2009; 10: 480-7.

[300] Lambris JD, Ricklin D, Geisbrecht BV. Complement evasion by human pathogens. Nat Rev Microbiol 2008; 6: 132-42.

[301] Lanier LL. Evolutionary struggles between NK cells and viruses. Nat Rev Immunol 2008; 8: 259-68.

[302] Grubor-Bauk B, Simmons A, Mayrhofer G, Speck PG. Impaired clearance of herpes simplex virus type 1 from mice lacking CD1d or NKT cells expressing the semivariant V alpha 14-J alpha 281 TCR. J Immunol 2003; 170: 1430-4.

[303] Grubor-Bauk B, Arthur JL, Mayrhofer G. Importance of NKT cells in resistance to herpes simplex virus, fate of virus-infected neurons, and level of latency in mice. J Virol 2008; 82: 11073-83.

[304] Samaniego LA, Neiderhiser L, DeLuca NA. Persistence and expression of the herpes simplex virus genome in the absence of immediate-early proteins. J Virol 1998; 72: 3307-20.

[305] Orvedahl A, Alexander D, Talloczy Z, et al. HSV-1 ICP34.5 confers neurovirulence by targeting the Beclin 1 autophagy protein Cell Host Microbe 2007; 1: 23-35.

[306] Hochrein H, Schlatter B, O'Keeffe M, et al. Herpes simplex virus type-1 induces IFN-alpha production via Toll-like receptor 9dependent and -independent pathways. Proc Natl Acad Sci USA 2004; 101: 11416-21.

[307] Malmgaard L, Melchjorsen J, Bowie AG, Mogensen SC, Paludan SR. Viral activation of macrophages through TLR-dependent and independent pathways. J Immunol 2004; 173: 6890-8.

[308] Ankel H, Westra DF, Welling-Wester S, Lebon P. Induction of interferon-alpha by glycoprotein D of herpes simplex virus: a possible role of chemokine receptors. Virology 1998; 251: 317-26.

[309] Aravalli RN, Hu S, Rowen TN, Palmquist JM, Lokensgard JR Cutting edge: TLR2-mediated proinflammatory cytokine and chemokine production by microglial cells in response to herpes simplex virus. J Immunol 2005; 175: 4189-93.

[310] Lokensgard JR, Cheeran MC, Hu S, Gekker G, Peterson PK. Glial cell responses to herpesvirus infections: role in defense and immunopathogenesis. J Infect Dis 2002; 186 Suppl 2: S171-9.

[311] Reske A, Pollara G, Krummenacher C, Katz DR, Chain BM. Glycoprotein-dependent and TLR2-independent innate immune recognition of herpes simplex virus-1 by dendritic cells. J Immunol 2008; 180: 7525-36.

[312] Zhang SY, Jouanguy E, Ugolini S, et al. TLR3 deficiency in patients with herpes simplex encephalitis. Science 2007; 317: $1522-7$.

[313] Zhou Y, Ye L, Wan Q, et al. Activation of Toll-like receptors inhibits herpes simplex virus-1 infection of human neuronal cells. J Neurosci Res 2009; 87: 2916-25.

[314] Yanai H, Savitsky D, Tamura T, Taniguchi T. Regulation of the cytosolic DNA-sensing system in innate immunity: a current view. Curr Opin Immunol 2009; 21: 17-22.

[315] Murphy JA, Duerst RJ, Smith TJ, Morrison LA. Herpes simplex virus type 2 virion host shutoff protein regulates alpha/beta interferon but not adaptive immune responses during primary infection in vivo. J Virol 2003; 77: 9337-45. 
[316] Cotter CR, Nguyen ML, Yount JS, et al. The virion host shut-off (vhs) protein blocks a TLR-independent pathway of herpes simplex virus type 1 recognition in human and mouse dendritic cells. PLoS One 2010; 5 : e8684.

[317] Poppers J, Mulvey M, Khoo D, Mohr I. Inhibition of PKR activation by the proline-rich RNA binding domain of the herpes simplex virus type 1 Us11 protein. J Virol 2000; 74: 11215-21.

[318] Yuan W, Dasgupta A, Cresswell P. Herpes simplex virus evades natural killer $\mathrm{T}$ cell recognition by suppressing CD1d recycling. Nat Immunol 2006; 7: 835-42.

[319] Hill A, Jugovic P, York I, et al. Herpes simplex virus turns off the TAP to evade host immunity. Nature 1995; 375: 411-5.

[320] Eidson KM, Hobbs WE, Manning BJ, Carlson P, DeLuca NA. Expression of herpes simplex virus ICP0 inhibits the induction of interferon-stimulated genes by viral infection. J Virol 2002; 76: 2180-91.

[321] Daubeuf S, Singh D, Tan Y, et al. HSV ICP0 recruits USP7 to modulate TLR-mediated innate response. Blood 2009; 113: 326475 .

[322] Jerome KR, Chen Z, Lang R, et al. HSV and glycoprotein J inhibit caspase activation and apoptosis induced by granzyme B or Fas. J Immunol 2001; 167: 3928-35

[323] Shen W, Sa e Silva M, Jaber T, et al. Two small RNAs encoded within the first 1.5 kilobases of the herpes simplex virus type 1 latency-associated transcript can inhibit productive infection and cooperate to inhibit apoptosis. J Virol 2009; 83: 9131-9.

[324] Perng GC, Jones C, Ciacci-Zanella J, et al. Virus-induced neuronal apoptosis blocked by the herpes simplex virus latency-associated transcript. Science 2000; 287: 1500-3.

[325] Orvedahl A, Levine B. Autophagy and viral neurovirulence. Cell Microbiol 2008; 10: 1747-56.

[326] Friedman HM, Cohen GH, Eisenberg RJ, Seidel CA, Cines DB. Glycoprotein $\mathrm{C}$ of herpes simplex virus 1 acts as a receptor for the C3b complement component on infected cells. Nature 1984; 309: 633-5.

[327] Frank I, Friedman HM. A novel function of the herpes simplex virus type 1 Fc receptor: participation in bipolar bridging of antiviral immunoglobulin Gen J Virol 1989; 63: 4479-88.

[328] Hook LM, Huang J, Jiang M, Hodinka R, Friedman HM. Blocking antibody access to neutralizing domains on glycoproteins involved in entry as a novel mechanism of immune evasion by herpes simplex virus type 1 glycoproteins C and E. J Virol 2008; 82: 6935-41.

[329] Zeier Z, Aguilar JS, Lopez CM, et al. A limited innate immune response is induced by a replication-defective herpes simplex virus vector following delivery to the murine central nervous system. $\mathrm{J}$ Neurovirol 2009; 15: 411-24.

[330] Haseley A, Alvarez-Breckenridge C, Chaudhury AR, Kaur B. Advances in oncolytic virus therapy for glioma. Recent Pat CNS Drug Discov 2009; 4: 1-13.

[331] Mabon PJ, Weaver LC, Dekaban GA. Cyclosporin A reduces the inflammatory response to a multi-mutant herpes simplex virus type-1 leading to improved transgene expression in sympathetic preganglionic neurons in hamsters. J Neurovirol 1999; 5: 268-79.

[332] Peltoniemi J, Broberg EK, Nygardas M, et al. Enhancement of Th2 responses to replicative herpes simplex virus type 1 vectors by immunomodulative chemotherapy. Int Immunopharmacol 2006; 6: 817-29.

[333] Thomas DL, Fraser NW. HSV-1 therapy of primary tumors reduces the number of metastases in an immune-competent model of metastatic breast cancer. Mol Ther 2003; 8: 543-51.

[334] Broberg EK, Salmi AA, Hukkanen V. IL-4 is the key regulator in herpes simplex virus-based gene therapy of BALB/c experimental autoimmune encephalomyelitis. Neurosci Lett 2004; 364: 173-8.

[335] Cheng G, Yang K, He B. Dephosphorylation of eIF-2alpha mediated by the gamma(1)34.5 protein of herpes simplex virus type 1 is required for viral response to interferon but is not sufficient for efficient viral replication. J Virol 2003; 77: 10154-61.

[336] Cheng G, Brett ME, He B. Val193 and Phe195 of the gamma 1 34.5 protein of herpes simplex virus 1 are required for viral resistance to interferon-alpha/beta. Virology 2001; 290: 115-20.

[337] Chahlavi A, Rabkin S, Todo T, Sundaresan P, Martuza R. Effect of prior exposure to herpes simplex virus 1 on viral vector-mediated tumor therapy in immunocompetent mice. Gene Ther 1999; 6: 1751-8.
[338] Lauterbach H, Ried C, Epstein AL, Marconi P, Brocker T. Reduced immune responses after vaccination with a recombinant herpes simplex virus type 1 vector in the presence of antiviral immunity. $\mathrm{J}$ Gen Virol 2005; 86: 2401-10.

[339] Russell SJ, Peng KW. The utility of cells as vehicles for oncolytic virus therapies. Curr Opin Mol Ther 2008; 10: 380-6.

[340] Coukos G, Makrigiannakis A, Kang EH, et al. Use of carrier cells to deliver a replication-selective herpes simplex virus-1 mutant for the intraperitoneal therapy of epithelial ovarian cancer. Clin Cancer Res 1999; 5: 1523-37.

[341] Todo T. Oncolytic virus therapy using genetically engineered herpes simplex viruses. Front Biosci 2008; 13: 2060-4.

[342] Yun CO. Overcoming the extracellular matrix barrier to improve intratumoral spread and therapeutic potential of oncolytic virotherapy. Curr Opin Mol Ther 2008; 10: 356-61.

[343] McKee TD, Grandi P, Mok W, et al. Degradation of fibrillar collagen in a human melanoma xenograft improves the efficacy of an oncolytic herpes simplex virus vector 10.1158/0008-5472.CAN05-2242. Cancer Res 2006; 66: 2509-13.

[344] Mok W, Boucher Y, Jain RK. Matrix metalloproteinases-1 and -8 improve the distribution and efficacy of an oncolytic virus. Cancer Res 2007; 67: 10664-8.

[345] Deryugina EI, Quigley JP. Matrix metalloproteinases and tumor metastasis. Cancer Metastasis Rev 2006; 25: 9-34

[346] Montel V, Kleeman J, Agarwal D, et al. Altered metastatic behavior of human breast cancer cells after experimental manipulation of matrix metalloproteinase 8 gene expression. Cancer Res 2004; 64: 1687-94.

[347] Huszthy PC, Immervoll H, Wang J, et al. Cellular effects of oncolytic viral therapy on the glioblastoma microenvironment. Gene Ther 2010; 17: 202-16.

[348] Watanabe I, Kasuya H, Nomura N, et al. Effects of tumor selective replication-competent herpes viruses in combination with gemcitabine on pancreatic cancer. Cancer Chemother Pharmacol 2008; 61: 875-82.

[349] Nagano S, Perentes JY, Jain RK, Boucher Y. Cancer cell death enhances the penetration and efficacy of oncolytic herpes simplex virus in tumors. Cancer Res 2008; 68: 3795-802.

[350] Lin RZ, Chang HY. Recent advances in three-dimensional multicellular spheroid culture for biomedical research. Biotechnol J 2008; 3: 1172-84.

[351] Bjerkvig R, Tonnesen A, Laerum OD, Backlund EO. Multicellular tumor spheroids from human gliomas maintained in organ culture. J Neurosurg 1990; 72: 463-75.

[352] Engebraaten O, Hjortland GO, Hirschberg H, Fodstad O. Growth of precultured human glioma specimens in nude rat brain. J Neurosurg 1999; 90: 125-32

[353] Rosen JM, Jordan CT. The increasing complexity of the cancer stem cell paradigm. Science 2009; 324: 1670-3.

[354] Liu TC, Kirn D. Targeting the untargetable: oncolytic virotherapy for the cancer stem cell. Mol Ther 2007; 15: 2060-1.

[355] Eriksson M, Guse K, Bauerschmitz G, et al. Oncolytic adenoviruses kill breast cancer initiating CD44+CD24-/low cells. Mol Ther 2007; 15: 2088-93.

[356] Jiang H, Gomez-Manzano C, Aoki H, et al. Examination of the therapeutic potential of Delta-24-RGD in brain tumor stem cells: role of autophagic cell death. J Natl Cancer Inst 2007; 99: 1410-4.

[357] Wakimoto H, Kesari S, Farrell CJ, et al. Human glioblastomaderived cancer stem cells: establishment of invasive glioma models and treatment with oncolytic herpes simplex virus vectors. Cancer Res 2009; 69: 3472-81.

[358] Yang CT, Song $\mathrm{J}, \mathrm{Bu} \mathrm{X}$, et al. Herpes simplex virus type-1 infection upregulates cellular promoters and telomerase activity in both tumor and nontumor human cells. Gene Ther 2003; 10: 1494502 .

[359] Lee CY, Bu LX, Rennie PS, Jia WW. An HSV-1 amplicon system for prostate-specific expression of ICP4 to complement oncolytic viral replication for in vitro and in vivo treatment of prostate cancer cells. Cancer Gene Ther 2007; 14: 652-60.

[360] Rosenfeld N, Aharonov R, Meiri E, et al. MicroRNAs accurately identify cancer tissue origin. Nat Biotechnol 2008; 26: 462-9.

[361] Silber J, Lim DA, Petritsch C, et al. miR-124 and miR-137 inhibit proliferation of glioblastoma multiforme cells and induce differentiation of brain tumor stem cells. BMC Med 2008; 6: 14. 
[362] Volinia S, Calin GA, Liu CG, et al. A microRNA expression signature of human solid tumors defines cancer gene targets. Proc Natl Acad Sci USA 2006; 103: 2257-61.

[363] Gramantieri L, Fornari F, Callegari E, et al. MicroRNA involvement in hepatocellular carcinoma. J Cell Mol Med. 2008; 12: 2189-204.

[364] Tenoever B. MicroManipulating viral-based therapeutics. Discov Med 2009; 8: 51-4.
[365] Lee CY, Rennie PS, Jia WW. MicroRNA regulation of oncolytic herpes simplex virus-1 for selective killing of prostate cancer cells. Clin Cancer Res 2009; 15: 5126-35.

[366] Kota J, Chivukula RR, O'Donnell KA, et al. Therapeutic microRNA delivery suppresses tumorigenesis in a murine liver cancer model. Cell 2009; 137: 1005-17.

[367] Santamaria E, Mora MI, Carro-Roldan E, et al. Identification of replication-competent $\mathrm{HSV}-1 \mathrm{Cgal}+$ strain targets in a mouse model of human hepatocarcinoma xenograft. J Proteomics 2009; 73: $153-60$.

(C) Manservigi et al.; Licensee Bentham Open.

This is an open access article licensed under the terms of the Creative Commons Attribution Non-Commercial License (http: //creativecommons.org/licenses/by-nc/ $3.0 /$ ) which permits unrestricted, non-commercial use, distribution and reproduction in any medium, provided the work is properly cited. 